University of Rhode Island

DigitalCommons@URI

Open Access Dissertations

1992

\title{
Models of Shame, Family Functioning, and Psychosocial Outcomes in a College Population
}

Sherri Nelson Fitts

University of Rhode Island

Follow this and additional works at: https://digitalcommons.uri.edu/oa_diss

\section{Recommended Citation}

Fitts, Sherri Nelson, "Models of Shame, Family Functioning, and Psychosocial Outcomes in a College Population" (1992). Open Access Dissertations. Paper 1060.

https://digitalcommons.uri.edu/oa_diss/1060

This Dissertation is brought to you for free and open access by DigitalCommons@URI. It has been accepted for inclusion in Open Access Dissertations by an authorized administrator of DigitalCommons@URI. For more information, please contact digitalcommons-group@uri.edu. 


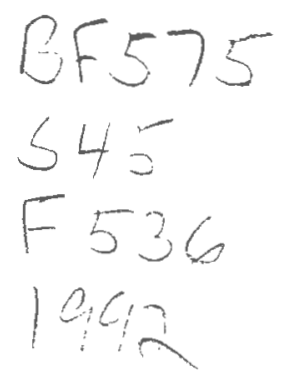

MODELS OF SHAME, FAMILY FUNCTIONING, AND PSYCHOSOCIAL OUTCOMES IN A COLLEGE POPULATION

BY

SHERRI NELSON FITTS

A DISSERTATION SUBMITTED IN PARTIAL FULFILLMENT OF THE REQUIREMENTS FOR THE DEGREE OF

DOCTOR OF PHILOSOPHY

IN

PSYCHOLOGY

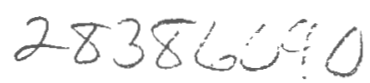

UNIVERSITY OF RHODE ISLAND

1992 


\section{Abstract}

An empirical investigation of shame was conducted, using a structural equation modeling approach with a sample of 750 undergraduates. The general model being tested involved three sets of latent constructs: family functioning as the independent variable, shame as the mediating variable, and five psychosocial outcomes as the dependent variables. Five models were generated, one per outcome variable. Three of the outcomes were maladaptive ones: substance use, depression, and suicide ideation. The remaining two, risk-taking propensity and achievement orientation, were more neutrally toned. It was hypothesized that family dysfunctioning would be directly related to shame; and in turn, shame would be directly related to maladaptive outcomes. No significant relationship between shame and the two neutral outcomes was expected.

The findings obtained supported the basic hypotheses, and produced variations according to outcome and across genders. Higher levels of family dysfunctioning were correlated with higher levels of shame for both genders. For women, shame was significantly related to substance use, depression, and suicide ideation. This was true for men with depression and suicide ideation, but not for substance use, suggesting that affective state is Iinked to 
substance use more for women than for men. In addition to the mediating effects of shame, there were direct links between level of family functioning and suicide ideation for women, and both depression and suicide ideation for men. Perceived level of family functioning was not significantly related to substance use for either gender.

For men, greater shame was correlated with decreased risk-taking propensity, suggesting that shame may be associated with behavioral constriction for men. Neither shame nor family functioning appears to play a role in risk-taking propensity for women. The achievement orientation model yielded poor results for the measurement model, rendering suspect any conclusions based on the structural model. A more precise conceptualization of this construct is needed in order to examine the structural relationships between family functioning, shame, and achievement orientation.

These findings support the notion that shame is a significant concomitant of maladaptive outcomes, providing empirical support for theoretical and clinical viewpoints. They point to the importance of integrating shame more fully into models of psychopathology. 


\section{Acknowledgements}

No project the size of a dissertation or getting a $\mathrm{PhD}$ is done alone. Many accomplices are necessary. Some participate knowingly, others unwittingly. To the latter group, I apologize. To all, I am grateful.

Starting at the beginning, I would like to acknowledge my parents, Beverly and Roy Nelson, for many things too numerous to mention here, but especially for their support and love. And then there was that one Thanksgiving week-end when I carted my data to their house and they good-naturedly "volunteered" to help prepare the data sheets for scanning, a distinctly onerous task which my mother spent many extra hours to complete after the week-end was over. All this, without any mention of my tackiness in bringing this uninvited guest along with me.

One of the most rewarding aspects of my time at URI has been the wonderful relationships I have made throughout this intensely personal and professional journey. The creation of a history through the sharing of experiences, both profound and mundane, has been exhirilating and buoying. The intellectual stimulation, the laughter and tears, have been shared with many who are special to me. In particular, I would like to acknowledge Tony Giuliano, to whom I am indebted for a new and deepened meaning of friendship. And also Judith Lubiner, supervisor and 
friend, who has been a source of inspiration and a wonderful role model.

I have benefited from the wisdom and guidance of many supervisors and professors, and have truly felt blessed for the experience I have had at URI. I appreciate the input and guidance from my committee members: Lynn Pasquerella in Philosophy; John Stevenson's scholarly approach and thought-provoking questions. Larry Grebstein has served as adviser in so many ways and has been unfailingly generous of his time and support. His belief in me has provided me with a base of confidence that is lasting and strong.

Lisa Harlow has been my major professor for five years. In addition to her seemingly limitless tolerance for my working style, she has provided a model of enthusiasm and dedication to research that is always inspiring. I have been spoiled by her attentiveness and level of availability. She has been mentor as well as teacher.

I would be remiss if I did not acknowledge the hundreds of students who were willing to share a piece of themselves with me. And I am grateful to the many professors who made it possible for me to gather such a large sample size.

Finally, there is my husband, Ted, who has known only graduate school for our entire six-year marriage (he may consider himself to be in the unwitting category). Among countless hardships, he has endured late-night printing 
right outside the bedroom door and participated in all-hours xeroxing. I'm not sure that this is what he nad in mind when he said "for better or worse." This process and his part in it has made me think that honorary degrees should be conferred on all significant others. Short of that however, I will start with a promise to cook more dinners from now on. I am glad that we are partners in life. 


\section{Table of Contents}

Abstract ii

Acknowledgements iv

Table of Contents vii

List of Tables viii

List of Figures ix

Chapter 1: Introduction 1

$\begin{array}{ll}\text { Chapter 2: Methods } & 26\end{array}$

Chapter 3: Results 52

$\begin{array}{ll}\text { Chapter 4: Discussion } & 87\end{array}$

$\begin{array}{ll}\text { References } & 114\end{array}$

$\begin{array}{ll}\text { Appendices } & 123\end{array}$

$\begin{array}{ll}\text { Tables } & 164\end{array}$

$\begin{array}{ll}\text { Figures } & 177\end{array}$

Bibliography 185 


\section{List of Tables}

Table 1: Description of Sample

Table 2: ISS Internal Consistency and Factorial structure

Table 3: Convergent/Divergent Validity of the ISS and SCAAIR Using Pearson

Correlation Coefficients

Table 4: SCAAIR Internal Consistency and Factorial Structure

Table 5: Summary Statistics and Mean Sex Differences for all Observed Variables

Table 6: Prinicipal Components Analyse

Table 7: Third-Level Principal Components Analyses 173

Table 8: Summary of Model Fit Indices (Maximum

Likelihood Estimation) for Models 1-5 174

Table 9: Summary of Model Fit Indices (Maximum Likelihood Estimation) for Overall Models ( 5 DVis and 3 DVs)

Table 10: Chi-squared Pairwise Comparisons 


\section{List of Figures}

Figure 1: General Format of the Five Structural Models

Figure 2: Model 1 (Substance Use) 178

Figure 3: Model 2 (Depression) 179

Figure 4: Model 3 (Suicide Ideation) 180

Figure 5: Model 4 (Risk-Taking Propensity) 181

Figure 6: Model 5 (Achievement Orientation) 182

Figure 7: Combination Model (Substance Use, Depression, Suicide Ideation, Risk-Taking Propensity, Achievement Orientation) 183

Figure 8: Combination Model (Substance Use, Depression, Suicide Ideation) 
Models of Shame, Family Functioning, and Psychosocial Outcomes in a College Population

\section{Introduction}

The construct of shame has received increasing attention in the theoretical and clinical literature in recent years. At least three reasons may account for this heightened emphasis (Goldberg, 1991). First, shame is a phenomenon that has been relatively neglected. Second, because it is not fully understood, there is a push towards explication. Third, despite its historical neglect, it has long been considered an important affect; Charles Darwin, for example, (1872/1965) labelled it a "master emotion."

While a strong belief exists that pathological amounts of shame may contribute to the genesis of psychopathology (e.g., Lewis, 1971; Kaufman, 1985, 1989), little empirical research in this area has been conducted. A related assumption apparent in the clinical literature is that family dysfunctioning may induce shame in the individual (e.g., Stierlin 1974; Fossum \& Mason, 1986; Kaufman, 1985). Taken together, these two hypotheses suggest that family dysfunctioning can lead to high levels of shame which in turn can lead to various maladaptive outcomes (Kaufman, 1985, 1989). This general idea has been given a great deal of credence in the clinical literature and the popular press (witness the Adult Children of Alcoholics (ACOA) 
movement). But empirical examinations cf shame which make explicit connections both to family dysfunctioning and individual psychopathology are not available. This investigation represents such an attempt.

Using shame as the conceptual focus, the research summarized here involves a comparative analysis of five specific models of psychosocial outcomes in a college population. The overall theoretical context is a general model which postulates relationships among the constructs of family functioning, shame, and psychosocial outcomes. Specifically, the underlying hypothesis being tested is that family dysfunctioning is correlated with higher levels of shame, which in turn, is correlated with higher levels of maladaptive behavior, but not with more neutrally toned behavior. The models differ by dependent variable. Each of the models was evaluated using structural equation modeling techniques, a method particularly useful for exploring relationships at the level of latent constructs. The general format of the five models is shown in Figure 1. The five specific structural equation models are represented in Figures 2-6 (see Results section). The theoretical framework is described below in greater detail.

Insert Figure 1 about here 


\section{Definitional Issues}

A working definition of shame will be considered first since this construct is an elusive and complex one. Theories regarding the nature of shame and its role in psychological functioning have changed over time, and several viewpoints currently exist. "Shame" can be defined in both absolute and relative terms. In this study, shame is defined in absolute terms as a primarily affective construct, though it is recognized that there are cognitive, physiological, and behavioral concomitants to shame as well. Shame represents a feeling of being defective in some way. It is often accompanied by feelings of being diminished in the eyes of another person (whether imagined or real) and an experience of sudden, unexpected exposure (Lewis, 1971; Tangney, 1988). It has been dubbed the most "social" of emotions, in that its experience involves judgment by some real or imagined other. Nuttin (1950) stated that shame captures both the "privacy and penetrability" of human consciousness.

A close relative of shame is guilt. Shame is distinguished from guilt in that shame involves the whole self. Whereas guilt arises out of the perception of having done something wrong, shame arises out of the perception of being something wrong. So guilt is related more to perceived specific behaviors, while shame has more to do 
with the overall perceived sense of self. Similarly, Kohut: (1977) maintains that "guilty man" is the master of his destiny, whereas "tragic (shame) man" is a victim of circumstance. Goldberg (1991) distinguishes shame from guilt along the dimension of activity versus passivity, with guilt being linked to activity and shame to passivity. Piers and Singer (1953) viewed the threat in shame as abandonment and the threat in guilt as punishment.

The philosopher Gabrielle Taylor (1987) suggests that shame and guilt are similar emotions, in that they are both emotions of self-assessment and both moral emotions, but otherwise, they are quite different. Guilt is localized and pertains to wrongdoing, while shame is a generalized feeling that involves the basic integrity of the self. (This helps to explain why it is so devastating.) In this sense, she views shame as linked with self-respect rather than self-esteem. Shame involves self-assessment of "the kind of person one thinks one is" (p. 89).

In his exposition of a comprehensive affect theory, Tomkins (e.g., 1963, 1987) contends that affect is innate, rather than learned. He views affect as the most important component of motivation. On this point he differs from Freud, who saw the drives, particularly sexual and aggressive ones, as the primary innate biological motivating mechanism. Tomkins takes a broad view of the 
construct of shame, one that encompasses both inferiority and immorality. He contends that there are nine innate affects, three positive and six negative. Shame is an auxillary affect rather than a primary one in that it operates only after one or more of the positive affects (excitement, interest, joy) have been activated. It serves as a damper to the essentially exuberant expression inherent in the positive affects. Without shame, there would be no limits placed on these emotions. Thus the innate motivator of shame is the incomplete reduction of excitement, interest, or joy.

While very much focused on the physiological underpinnings of affect, Tomkins (1987) also points to the interpersonal nature of shame. He maintains that in contrast to some other negative affects (e.g., disgust), the experience of shame includes the wish to reconnect with the other. The inference here is that shame must at least initially be experienced in the context of a positive relationship. This view supports the contention of Kaufman (1985) and others that shame is an ambivalent affect because it serves to keep others away while simultaneously producing a longing for reparation through the reunion with the other.

While definitional issues regarding shame are very important in conducting empirical research, this study 
employs a macro-level approach to shame rather than a micro-level analysis. Several researchers have scrutinized the nature of shame very closely in an effort to capture the affective, cognitive, and behavioral components, for example, by coding sections of therapeutic or interpersonal interactions (Retzinger, 1987, 1989a, 1989b; Geppert, 1986; Geppert \& Heckhausen, 1988). This work is very important in deciphering the nature of shame and in elucidating its distinguishing aspects. In contrast, the current study takes a broader approach. It examines how the overall construct of shame is related to two other categories of constructs, namely family functioning and maladaptive outcomes .

\section{Historical Perspectives on Shame}

Shame has been an undercurrent in the psychological literature for some time. Freud, as the representative of classical psychoanalytic conceptualizations, was heavily influenced by Darwin. From this perspective, Freud incorporated into his own work the concepts of biology being equal to destiny, psychic determinism, and a drive-oriented psychological apparatus. Freud linked shame with sexuality, locating its biological roots in the evolution to the upright position taken by man and the resultant exposure of his genitals $(1930 / 1961)$. He also viewed shame as a "feminine characteristic par excellence" 
(Freud, 1933/1964, p. 132). He saw it as a reaction formation (a defensive maneuver involving the experiencing on a conscious level of the exact opposite of the true, unconscious feeling) against the exhibitionistic, voyeuristic drives. However, Freud ultimately concentrated more on guilt and paid little heed to the study of shame. Many modern writers have suggested that this initial bifurcation that began with Freud led to the relative neglect of the psychological importance of shame.

Erikson (1950) linked shame with developmental issues of autonomy and control. Piers and Singer (1953) viewed shame as a tension between the ego and the ego-ideal. From this perspective, shame results when a person does not live up to his/her ego-ideal. Guilt has more to do with the superego. They also explored the anthropological notion of "shame-based" vs. "guilt-based" cultures. For example, they classified Western cultures as guilt-focused because of the emphasis on rules and control. But this distinction has not held up empirically (Johnson, Danko, Huang, Park et al., 1987).

The self psychology view on the other hand, pays more attention to the whole self rather than emphasizing prohibition regarding specific acts. For Kohut (1977), shame has to do with a perceived defectiveness of the self. It serves the function of restoration of a cohesive self 
following overstimulation of self-expansive strivings (Goldberg, 1991). This view is similar to Tomkins's (1987) hypothesis of shame as arising from the incomplete reduction of the interest-excitement affects.

Lewis (1971) was one of the first psychologists to emphasize the clinical importance of shame and to explore it empirically. Her 1971 book, Shame and Guilt in Neurosis, is considered by many to be a landmark study in the field of shame research. She linked shame with the self and guilt with behavior. She found supporting evidence for the hypothesis that shame-prone individuals would be more field-dependent while guilt-prone individuals would be more field-independent. Clinically, she expressed the view that treatment failures could be traced to an avoidance of dealing with the shame in the treatment setting, both on the part of the therapist and the patient. This would be a natural phenomenon since shame carries with it implicitly a desire to hide. Lewis in fact reinterpreted some of Freud's case failures from this perspective. Many clinical writers talk about the patient's shame, not only about their particular problem, but also about being in therapy for it.

\section{Shame and Family Dysfunctioning}

Current hypotheses on shame derive mainly from the psychodynamic and systemic perspectives on human behavior 
and psychopathology. Many researchers have posited a negative correlation between family functioning in childhood and later levels of shame (e.g., Fossum \& Mason, 1986; Kaufman, 1985, 1989; Stierlin, 1974). The basic hypothesis is that high levels of family dysfunctioning (e.g., parental alcoholism, physical and sexual abuse) will cause the child to experience intense feelings of shame. For example, Stierlin (1974) suggests that shame can be transmitted generationally and that the child can essentially function as a container for the parents' shame (e.g., the child becomes a "carrier" for the shame of a parent's alcoholism while the parent may remain in denial). Similarly, Broucek (1991) asserts that it is not uncommon for families to choose one child as the repository for the shame of the parents and other family members. Fossum \& Mason (1986) suggest that compulsive disorders in families (e.g., alcoholism) can cause these families to become "shame-bound," leaving the children more likely to be "shame-prone" (i.e., to experience shame as a trait rather than as an occasional state) as adolescents and adults. Naiditch (1987) maintains that self-esteem is a "family affair," and that a child will feel shame when s/he fails to perceive that the parent wants to have a relationship with him/her as a separate individual. Such approaches reflect a view of psychopathology that incorporates both 
individual variables (e.g., alcoholism in the parent) and family or systemic variables (e.g., the shame-bound system in which the alcoholism occurs).

Shame and Disruption in Boundary Functioning

Many of the hypotheses regarding shame and family functioning arise out of the literature on substance abuse and focus on disruptions in boundary functioning (e.g., Nielsen, 1987; Fossum \& Mason, 1986). The notion of "boundaries" is an important concept in clinical theory, and one that cuts across theoretical divisions. However, it is particularly germane to systemic theory. It is believed that one aspect of healthy psychological functioning is that of appropriate boundaries; i.e., individuals with good boundaries are those who can differentiate their own needs from those of others, and who are able to treat others in ways that respect their separateness. This concept might best be understood in terms of violation of good boundaries. An example of a minor boundary violation might be to stand too close to someone (intruding on their physical and/or psychological territory); a moderate violation might be that of reading someone else's personal mail. Incest would be an example of an extreme boundary violation.

Alcohol and drugs disrupt aspects of psychological functioning, including boundaries. Indeed, it is commonly 
believed that one of the reasons that individuals use alcohol is to provide a social lubricant; that is, the disinhibition that accompanies alcohol use may enable the individual to engage in more intimate contacts than $\mathrm{s} / \mathrm{he}$ otherwise might be able to while sober. The line between greater intimacy and boundary violation is not always clear. It is thought that boundary violations of the type that often occur in alcoholic families (e.g., violation of physical, emotional, or sexual boundaries) invariably produce feelings of guilt and shame. When the violator is in an authoritative role, as in the parent-child relationship, the intensity of shame for the victim often increases, because the victim is more likely to blame him/herself in this situation. Potter-Efron (1987) maintains that shame and guilt are salient issues for ACOAs. In order to stave off feelings of despair and embarrassment as children, this view suggests that they are compelled to develop strong defense systems (e.g., denial, justification, control, dissociation, compulsive behaviors).

\section{Shame and Psychopathology}

Inherent in the notion of the relationship between shame and boundary violation is the idea of a connection between shame and psychopathology, since good boundary functioning is an important indicator of psychological 
health. This hypothesized connection between shame and psychopathology has been a recurring theme in the clinical literature.

For example, Lewis (1971) and Tangney (1988) report empirical findings that indicate that shame is associated with depression. Lewis (1971) maintained that shame, along with guilt and anger, are the key affects at work in the development of psychopathology. Shame has also been connected to hopelessness, powerlessness, suicide ideation (Campbell, 1984), eating disorders (Kaufman, 1985) and narcissistic personality disorder (Broucek, 1982).

It is partially the secretive nature of shame that functions to maintain the pathology. Shame is accompanied by a desire to hide, thus creating shame about shame. While there seems to be a societal injunction toward the expression of negative emotions in general, shame seems to be especially restricted. Scheff (1984) dubbed shame, along with fear, grief, and anger, one of the "coarse" emotions. He was in agreement with William James $(1890 / 1965)$ that coarseness is associated with those emotions that are more biologically determined and have less of a cognitive concomitant. Scheff also viewed a social taboo as common to the coarse emotions. If this is the case, it would make sense that shame would be an important affect in the genesis and maintenance of 
psychopathological syndromes, because it would mean that individuals would be less willing to discuss, and thereby to resolve, issues about which they feel ashamed. So, for example, the bulimic who is too embarrassed about her disorder does not talk about it with others or seek treatment, and the cycle is thus sustained and amplified. It should be noted, however, that the experience of shame is not considered to be inherently maladaptive. Indeed, it is thought to be a universal human emotion (Tomkins, 1963) and one that is vital for socialization. The child first experiences shame as the result of the parents' efforts to modulate the young child's unbridled enthusiasm, and the socialization process begins. Furthermore, it is believed that moderate feelings of shame are necessary for growth; the ability to tolerate feelings of shame is seen as a prerequisite for autonomy (e.g., Severino, McNutt, \& Feder, 1987). Scheff (e.g., 1988) maintains that shame and its converse, pride, are the most ubiquitous emotional and social experiences, but also the most invisible because they go unacknowledged. Psychodynamic theorists, particularly those who utilize an object relations or self psychology point of view, assert that the child first experiences shame when $s /$ he becomes aware of his/her psychological separateness as a human being. In order to experience shame, self-other 
differentiation must be present. On a societal level, Broucek (1991), who views shame as a response to objectification, points to increased objectification as an important correlate of increased "shamelessness."

Relationships Among Family Functioning, Shame, and

\section{Psychopathology}

Kaufman (e.g., 1985, 1989) has explicitly tied together the relationships between family dysfunctioning and psychopathology as they are related to shame. He draws on the work of Tomkins (e.g., 1963, 1987) regarding the primacy of affect over drive in human motivation. Kaufman suggests that shame is first experienced interpersonally as the result of the breakdown of the "interpersonal bridge" between two people, and that this usually occurs within the context of the family. This interpersonal bridge between two people represents the bonds or connections that they have with each other which define their relationship. As noted above, most shame researchers view shame as a necessary byproduct of the socialization process. That is, everyone experiences shame on occasion. However, in dysfunctional families, there are fewer mechanisms for the expression and release of shameful feelings (and more instances of their occurrence). If the individual then experiences many instances of shame which are not resolved adequately within the context of repairing the broken bonds 
between individuals, the affect of shame may become internalized.

The process of internalization is one in which an individual develops a mental representation of important relationships through imagery of significant events and emotional experiences. For example, the voice of a critical parent may become internalized as part of a child's self-concept. Internalization thus results from identification with significant others and is an important aspect of identity formation. Lewis (1971) believes that both shame and guilt are identification phenomena. She contends that guilt occurs as a result of the identification with the negative, critical parental object, while shame occurs via the identification with the positive, revered object (hence the desire for reconnection with this object) (Lewis, 1971). It makes sense then that the experience of shame is one of feeling diminished in the eyes of another, because of the positive identification with the real or imagined other. The positive identification and the negative affect associated with a shame experience underlie the ambivalent nature of this emotion. Shame is a most ambivalent emotion, because while it is a very negative experience affectively, it is theorized that the individual simultaneously longs to reunite with the real or imagined other in front of whom 
s/he has felt ashamed. The internalization of shame via the binding of this affect with other affects, needs, and drives, can cause it to then be induced indirectly, with or without an external event. Kaufman (1989) postulates that family dysfunctioning can lead to the internalization of shame, and may eventually cause the individual's identity to be "shame-based."

Kaufman (1989) hypothesizes that an individual whose identity is shame-based will be susceptible to a class of disorders that he calls "shame-based syndromes." These include (1) compulsive disorders (e.g., addictions); schizoid, paranoid, and depressive disorders; (3) phobic disorders; (4) sexual dysfunction disorders; (5) splitting disorders (e.g., borderline and narcissistic personality disorders); and (6) sociopathic and psychopathic disorders. He also asserts that there are many possible defenses against shame, including (1) striving for perfection or power, (2) rage, and (3) interpersonal withdrawal (Kaufman, 1985). Fisher (1985) points to the "porous" nature of personal boundaries when the character structure is based on shame. Fossum and Mason (1986) also make an explicit connection between shame-bound families and poor boundary functioning. 


\section{Focus of the Study}

The primary purpose of this investigation was to illuminate the nature of shame and its relationship to other important psychological constructs. Much attention has been accorded shame in the last decade or so, but its popularity renders it vulnerable to overuse and therefore dilution of its utility as a construct. Its indiscriminate use in the popular self-help press may be inevitable, but clinicians and academic researchers at least have a responsibility to apply it to theoretical and clinical problems in a way that is justifiable empirically. One of the aims of this study therefore is to establish greater construct validity for shame.

This study combines theory and research that connects shame to family dysfunctioning and to psychopathology. The conceptualization used here is generally consistent with Kaufman's framework, but also incorporates the thinking of Lewis (e.g., 1971, 1987), Morrison (1989), Tomkins (1987), Nathanson (1987) and others. Family functioning serves as the independent variable in each model, shame as the mediating variable, and five separate psychosocial outcomes as the dependent variables in each of the five models. These outcomes include (1) Substance Use, (2) Depression, (3) Suicide Ideation, (4) Risk-Taking Propensity, and (5) Achievement orientation. The first three dependent 
variables represent examples of the types of shame-based disorders to which Kaufman refers. The last two are more neutral in their operationalization and provide a basis for comparison with the first three variables.

\section{Related Research}

Previous research has provided support for psychosocial variables as important correlates of the outcomes under investigation here. There has been increasing substantiation for a general model of maladaptive outcomes involving self-concept and existential variables (e.g., Kaplan, Martin, \& Johnson, 1986; Harlow, Newcomb, \& Bentler, 1986; Fitts, 1989; Fitts \& Harlow, 1989). In this research, self-concept has been found to have direct and indirect impacts on substance use, depression, suicide ideation, and AIDS-risking behaviors, via the mediation of existential situation (purpose in life and hopelessness variables). There are some similarities between the constructs of self-concept and shame, and thus it is reasonable to hypothesize that shame will be positively correlated with maladaptive outcomes in a similar manner. The general framework proposed here has the added advantage of incorporating family functioning variables, in addition to the more subjective variables (self-concept and existential situation) that have been used in the earlier framework. Previous research on maladaptive behaviors 
(e.g., Fitts \& Harlow, 1989) has shown that the basic model has general application across various behaviors but lacks predictive power in some instances (i.e., it holds up better with depression and suicide ideation than with substance use). The exploration of shame and family functioning is expected to increase the power of this general model to predict maladaptive behaviors. Hence the general model derived here also draws on other strains of research that do not focus explicitly on shame, but have important theoretical implications for this study.

Research Questions

This study comprises several research questions. The first question concerns the general nature of the relationship among family dysfunctioning, shame, and both maladaptive and adaptive psychosocial outcomes. Overall, it was hypothesized that there would be a negative correlation between family functioning and current levels of shame. That is, higher levels of family functioning were expected to be related to lower levels of shame. In turn, it was expected that there would be a positive association between level of experienced shame and the first three of the five maladaptive outcomes.

A second question pertains to the differentiation of the impact of shame on the five outcome variables. The first three dependent constructs, Substance Use, 
Depression, and Suicide Ideation, are more clearly maladaptive. The final versions of Risk-Taking Propensity and Achievement Orientation on the other hand, are more neutral in their operationalizations. Accordingly, it was hypothesized here that there would not be a significant positive relationship between shame and Risk-Taking Propensity or Shame and Achievement Orientation, as there theoretically should be for the other three outcomes. They are included here for exploratory reasons and for purposes of discriminant validity. That is, in order for the construct of shame to have explanatory power in regard to certain kinds of psychopathology, it should have discriminant as well as convergent validity. To provide some evidence for the discriminant validity of shame, it is important to discern what shame is not related to as well as what it is related to. Of course, a non-significant relationship between Shame and Risk-Taking Propensity or Shame and Achievement Orientation does not necessarily imply that there is no relationship between these constructs. It is possible that they have a curvilinear or complex relationship. This possibility was addressed with all five outcome variables.

The third question is more methodological in nature and involves the psychometric properties of the two shame measures to be used: Cook's Internalized Shame Scale (1989) 
and Tangney, Wagner, and Gramzow (1989) Self-Conscious Affect and Attribution Inventory - Revised (SCAAIR). These instruments have been carefully developed and preliminary psychometric evidence has been reported. A goal of this study was to evaluate further their reliability and validity. Internal consistency estimates were calculated for both measures. Since two measures of shame were employed, it was possible to explore concurrent validity by examining correlations between them. The elusive nature of the construct of shame is one of the reasons that it has received little empirical attention thus far. The development of psychometrically sound instruments represents an important initial step in empirical research in this area.

Justification for and Significance of the study

This study can be justified on several levels. First, as noted above, the empirical investigation of the construct of shame is timely, given the recent proliferation of theories regarding shame and its hypothesized contribution to both healthy and unhealthy behavior. Now that carefully constructed measures have been developed, it is appropriate and clinically useful to examine the ways in which shame is related to various psychosocial outcomes. Clinically, it is believed that shame has to be addressed directly in the safety of the 
therapeutic setting in order for it to be resolved. Therefore knowing more about this construct is important, both for diagnostic and treatment purposes.

Second, it is appropriate to build on previously established models of maladaptive outcomes. The determinants of maladaptive functioning, both in terms of subjective feelings of distress and actual behavioral correlates, are clearly complex and interrelated. Familial, genetic, developmental, personality and current situational factors all play a contributing role in an individual's overall level of functioning. While this study does not purport to examine all of the relevant variables involved in maladaptive functioning (e.g., genetic and physiological variables are not being evaluated here), it does provide a comparative analysis of several models that examine theoretically relevant and/or empirically derived correlates of negative psychological and behavioral outcomes. Elucidation of the relative contribution of these variables through continued empirical research may contribute to the clarification of the factors involved in the development of maladaptive functioning, from low-level distress to full-blown psychopathology. Choice of Population

A college population is aptly suited for the examination of these models. According to Kaufman (1985), 
adolescence is a time of heightened self-consciousness, making the adolescent vulnerable to shame and/or increasing the likelihood that s/he will interpret negative experiences in the context of shame. Spero (1984) cites weakened self-boundaries and the development of secondary sex characteristics as the distinctive aspects of adolescence that make it a period of heightened vulnerability to shame. Other researchers also refer to the potentially shame-inducing nature of adolescence (e.g., Severino et al., 1987; Shreve \& Patton, 1988; Shreve \& Kunkel, 1989), as the individual struggles to achieve autonomy and forge adult relationships. The dependent variables chosen for inclusion here are ones that are appropriate for a primarily nonclinical college-age population. With the possible exception of suicide ideation, all of them represent salient themes for large numbers of college students.

\section{Gender Differences}

While it seems theoretically and clinically relevant to examine a young adult population in regard to shame, it was considered important to explore theoretical and empirical differences according to gender as well. It has long been believed that men and women differ in their differential proneness to shame and guilt, with women supposedly more prone to shame and men more prone to guilt. Lewis (1971) 
explains this difference according to the differential identification and socialization processes for males and females in our culture, with women raised to be more sensitive to the needs of others, and more desirous of approval from others. Boys on the other hand, are more likely to be taught to be autonomous and to express their aggression in more direct ways, which theoretically makes them more guilt-prone. Tangney (1988) found that women were more prone to both shame and guilt. Cook (1988) also reports sex differences in the experience of shame of sufficient magnitude that he advocates the separate testing of models regarding shame according to gender.

This issue was handled in two ways. First, mean values on the shame indices were examined separately for men and women to ascertain the presence of any significant sex differences. Second, separate structural modeling analyses were conducted according to gender. This was done in order to provide some clarification regarding the pattern of relationships across genders.

\section{Subjective and Objective Measures}

A criticism of psychological research is that it so often involves variables that represent subjective inner states, of which shame is a prime example. An attempt was made in this study to operationalize the variables in objective behavioral terms wherever possible. For example, 
Achievement Orientation was operationalized using a measure of achievement motivation, which could be construed as more subjective, and a measure regarding actual participation in various activities. Given the design of this study, it was not really possible to operationalize shame in such a way as to include more objective behavioral indices. Exploratory Nature

This study is exploratory. A more accurate picture of shame and its vicissitudes would incorporate longitudinal considerations and would include objective indices of shame and its correlates in addition to the subjective self-report measures used here. However, this cross-sectional study was deemed useful on its own merits for the information it could provide regarding the nature of shame and its relationship to clinically relevant psychological variables. 
Method

\section{Participants}

The participants for this cross-sectional study were solicited through various undergraduate courses at the University of Rhode Island, a small state university in a rural setting. The majority of the students were recruited through psychology courses, although a small minority were recruited through non-psychology courses (i.e., engineering, economics). This venue was used because such a setting represents the most convenient access to the large number of participants that were needed. They were asked to complete a confidential paper-and-pencil questionnaire, consisting of the measures detailed below. Participation was strictly voluntary and confidential. Most respondents received extra course credit in return for their taking part in a research study.

Because the particular statistical methods employed for the analyses - structural equation modeling techniques require a large number of participants in order to obtain stable results, several hundred participants were needed. Bentler (1985) suggests that a minimum ratio of $5: 1$ participants to parameter estimates be used, but a ratio of at least $10: 1$ is preferable, especially when nonnormality is present in the variables. Since some nonnormality was expected in these data (e.g., suicide ideation, illicit 
substance use), the 10:1 minimum was more appropriate for this study. The largest hypothesized model had 21 free parameters, suggesting a minimum of 210 participants. As noted above, it was considered appropriate to test these models separately by gender, suggesting a goal of at least 210 women and 210 men for the study. This goal was vastly exceeded for women $(N=536)$ and met for men $(N=214)$, with a total of 750 participants. However, the final operationalization of the constructs involved some changes in the number of indicators, which in turn affected the number of free parameters. Model 1 (Substance Use) turned out to be the largest one, with 11 factor loadings, 11 measurement errors, and 3 regressions among factors. Hence with 25 free parameters, a minimum of 250 participants would have been optimal.

Table 1 provides descriptive statistics for the sample. In sum, the sample was $71 \%$ female (526 respondents) and $29 \%$ male (214 respondents). Most of the participants were less than 20 years of age (68\%), with $95 \%$ being younger than 24 years old. The average age was approximately 20 years old. Accordingly, most of the respondents were in the first two years of college, with $44 \%$ freshmen, and $25 \%$ sophomores. Twenty-one percent were juniors, $9 \%$ were seniors, and $1 \%$ were non-matriculating students. Most students were living in campus housing $(72 \%)$, with the remainder living 
off-campus with others $(15 \%)$, with parents $(10 \%)$, alone or other $(3 \%)$. Catholicism was the predominant reported religious preference (59\%), followed by Protestant (16\%), No religious affiliation (10\%), Other (9\%), and Jewish $(7 \%)$. The overwhelming majority of participants were white (95\%) and single $(95 \%)$. The majority grew up in intact families $(77 \%)$, with $11 \%$ in single parent families, $8 \%$ in reconstituted or blended families, and $5 \%$ in other configurations. Fifty percent reported an annual family income in excess of $\$ 50,000$. Forty-four percent reported a birth order of youngest child, $38 \%$ oldest or only child, and $19 \%$ in the middle.

Insert Table 1 about here

\section{Measures}

The measures used were all self-report instruments. (See Appendices A through $\mathrm{W}$ for the actual items contained in each measure.) All were presented in a Likert-type format, ranging from 2-5 response choices. Unless otherwise indicated, participants were requested to use the previous six-month period as their frame of reference in answering the questions. This time interval was chosen so that a relatively stable estimate of the constructs under investigation could be obtained. For all variables used in 
this study, reliability estimates were calculated, using Cronbach's alpha as an indication of internal consistency. When available, previous estimates of internal consistency are provided. A preliminary principal components analysis (PCA) was conducted to verify the factor structure of each construct, the results of which are detailed below.

Demographic Information. Ten questions were asked regarding age, sex, religion, academic status, marital status, ethnicity, residential status, annual family income, position in family of origin, and classification of family of origin (intact/single parent/reconstituted) (see Table 1).

Social Desirability (Jackson, 1984). The Jackson Social Desirability Scale (JSDS) is a 20-item measure which serves as one of the validity scales on the Jackson Personality Research Form (PRF; Jackson, 1984). This index provides a measure of response bias and has been found to be largely independent of psychopathology. It was included in this study in order to assess whether participants were using a response set of social desirability when completing the various measures described below. Sample items include "I always try to be considerate of the feelings of my friends" and "I believe people tell lies any time it is to their advantage." Participants were asked to rate the statements using a 4-point scale, ranging from "Definitely 
true" to "Definitely false." Jackson (1984) reported Kuder-Richardson reliabilities ranging from .59 to .62 on two separate samples.

\section{Family Functioning}

\section{Family Functioning Scale (FFS) (Tavitian,} Lubiner, Green, Grebstein, \& Velicer, 1987). This 40-item scale is designed to measure perceptions of one's family, including positive family affect, family communication, family conflicts, family worries, and family rituals. Participants were asked to respond on a 5-point scale, ranging from "Never" to "Always." Higher scores (following recoding of negatively worded items) suggest better family functioning. Sample items include: "My family is proud of me" and "People in my family argue about doing household chores." Internal consistency estimates range from .72 to .93 (Tavitian et al., 1987). This scale was developed and validated on an undergraduate population and thus was an appropriate measure for the sample used here. Validity studies indicate that the FFS can discriminate between schizophrenics and alcohol-troubled individuals (Tavitian et al., 1987). Because the five subscales are orthogonal, the two that were retained for the SEM analyses were used as separate indicators. (See Results section.) 
2. Family Awareness Scales (FAS) (Kolevzon \& Green, 1987). This is a 14-item instrument designed to measure family competence. It is based on the Beavers-Timberlawn Model of Family Competence which postulates that family competence is composed of several dimensions, including family structure, mythology (the way the family views itself), goal-directed negotiation, autonomy of members, and the nature of family expression (Corcoran \& Fischer, 1987). Sample questions include "How good is your family at talking over and solving problems?" and "How often do the members of your family speak for one another or act like they can read each other's minds?" Participants were asked to respond using 5-point scales that were mostly in the form of "Always" to "Never." Higher scores on this scale are purported to indicate greater family competence. Alpha coefficients ranging from .85 to .88 have been reported, indicating good internal consistency. Some degree of concurrent validity is suggested by low but significant correlations with trained raters using the Beavers-Timberlawn model (Corcoran \& Fischer, 1987).

3. Family Perceptions Scale (Harlow, 1989). This 6-item scale focuses on individuals' perceptions of the atmosphere in their family of origin while growing up. Sample items include, "My family was supportive of my choices" and "There was a lot of emotional turmoil in my 
family." A 4-point response scale was used, ranging from "Rarely or none of the time" to "Most or all of the time." Negatively worded statements were reversed so that higher final scores indicate more positive perceptions. Internal consistency has been estimated at .81 , using coefficient alpha (Harlow, 1989).

4. Family Information portion of the ISS (see Shame measures below) (Cook, 1989). This section contains 9 items regarding objective and subjective information about negative family circumstances, including parental alcoholism, divorce/separation, early loss of parent due to death, and atmosphere in the family. It was thought that this information could be used to supplement the other indicators of family functioning described above in order to obtain objective information regarding dysfuntional circumstances. Higher scores were hypothesized to indicate greater probability of disruption in family functioning. It should be noted that this is a rough measure of family functioning whose reliability and validity are unknown at this point. For example, no effort is made here to quantify various events according to impact on the individual. (e.g., Is death of a parent more disruptive of functioning than chronic alcohol use in terms of its impact on the child?) Because of the unfavorable results of the preliminary PCA, this measure was not retained for the 
final analyses. This will be discussed further in the Results section.

Shame

1. Internalized Shame Scale (ISS) (Cook, 1989).

This is a 30-item scale which includes two basic scales, Shame (24 items) and Self-Esteem (6 items), and two Shame subscales, Failure (15 items) and Alienation ( 9 items).

Sample items include "I see myself as being very small and insignificant" and "I feel I have a number of good qualities." A 5-point response scale was used, ranging from "Never" to "Almost always." The entire scale was administered, but only the 24 items measuring shame were considered for inclusion in the analyses as an indicator of shame. All of the Shame items are worded negatively so that higher scores indicate greater levels of shame. The 6 Self-Esteem items are worded positively. Cook (1988) reports Cronbach's alpha reliabilities of .94 for the total Shame score, .88 for Self-Esteem, .92 for the Failure subscale, and .89 for the Alienation subscale. Validity studies indicate that the ISS correlates significantly with depression and eating disorders. In clinical samples, alcoholic inpatients, male sex offenders, and depressed patients all scored higher than their respective control groups (Cook, 1988). 
2. Self-Conscious Affect and Attribution InventoryRevised (SCAAIR) (Tangney et al., 1989). This instrument contains 15 scenarios and has a total of 65 items. It is designed to assess the cognitive, affective, and behavioral components of shame and guilt in a young adult population. It contains six dimensions: Shame, Guilt, Externalization, Detachment/Unconcern, Alpha Pride (pride in self), and Beta Pride (pride in behavior). Participants were asked to respond in a Likert-type format for four or five dimensions on each of the 15 scenarios. A sample scenario is: "You walk out of an exam thinking you did extremely well. Then you find out you did poorly. a) You would think: 'Well, it's just a test' (Detachment/Unconcern). b) You would think: 'The instructor doesn't like me' (Externalization). c) You would think: 'I should have studied harder' (Guilt).

d) You would feel stupid (Shame). A 5-point response format was used, ranging from "Not likely" to "Very likely." The shame dimension contains 15 items and is scored such that higher scores are indicative of greater feelings of shame. Only this subscale was considered for inclusion in the structural modeling analyses. However, the entire scale was administered, for the purpose of investigating its psychometric properties. Internal consistency estimates for the shame dimension range from .73 to .82 and test-retest reliability over a $1-5$ week 
period was reported at .79 (Tangney, 1988a).

\section{Substance Use}

1. Alcohol Use (adapted from Stevenson, 1989; and Harlow, 1987, 1989). Five items assessing the frequency, quantity and maximum amount of alcohol consumed were used. All statements were positively scored such that higher scores indicate greater alcohol use. Sample questions include "About how many drinks of alcohol do you have on those days when you drink alcohol?" (response choices range from "None" to "More than 10 drinks") and "How often do you have three or more drinks on one occasion?" (possible responses range from "Never" to "Daily or almost daily")

2. Illicit Substance Use (adapted from Johnston, O'Malley, \& Bachman, 1986). This is a nine-item index designed to assess the frequency and quantity of use of several categories of illicit substances, including marijuana, cocaine, psychedelic drugs, amphetamines, quaaludes, barbituates, tranquilizers, narcotics, and glue and aerosol sprays. Participants were asked to indicate how often they had used each of the nine classes of substances in the previous six months using a 5-point response scale ranging from "Never" to "Daily." Higher scores indicate greater substance use. This measure is part of a larger survey conducted yearly on a nationwide basis through the University of Michigan's Institute for 
Social Research (Hawkins \& Nederhood, 1987).

3. Alcohol-and Drug-Related Problems (Presley, Harrold, Scouten, \& Lyerla, 1990). This is a 17-item scale which assesses the extent of problems experienced in connection with alcohol or drug use. Respondents were asked to indicate how often in the preceding six months they had experienced each of the stated problems, rating their responses on a 5-point scale from "Never" to "More than 6 times." Examples include "Performed poorly on a test or important project" and "Tried unsuccessfully to stop using." Test-retest reliabilities ranging from .59 to 1.00 for the 17 items have been reported (Presley et al., $1990)$

\section{Depression}

1. Center for Epidemiological studies - Depression (CES-D) (Radloff, 1977). This 20-item scale was used as an indicator of depression. Items include positively worded statements (e.g., "I was happy"), negatively worded statements (e.g., "I was bothered by things that don't usually bother me"), and several statements regarding interactions with others (e.g., "I talked less than usual"). A 5-point response format was used, ranging from "Rarely or none of the time" to "Most or all of the time." Positively worded items were reverse-scored such that higher final scores indicated greater levels of depression. 
Radloff (1977) reports substantial evidence of construct validity and excellent concurrent validity as assessed by clinical and self-report criteria. Moderate test-retest reliability values of .54 have been reported (Radloff, 1977). Internal consistency estimates have ranged from .84 using coefficient alpha (Fitts, 1989) to .95 using the Spearman-Brown correction (Radloff, 1977).

2. Brief Symptom Inventory - Depression subscale.

(BSI: Derogatis \& Spencer, 1982). This is a 6-item subscale on a 53-item measure which assesses psychopathology or psychological distress in clinical and nonclinical populations. The BSI constitutes an abbreviated form of the Symptom Check List-90 (SCL-90; Derogatis, 1977). The BSI is well-validated for both research and clinical purposes and, in fact, may be overtaking the SCL-90 in terms of research use (Derogatis \& Melisaratos, 1983). There are nine primary symptom subscales and three global indices of distress contained in the BSI. Respondents were asked to rate how much they were bothered in the previous week by various symptoms. Sample items on the Depression subscale include "Feeling no interest in things" and "Feelings of worthlessness." Participants were asked to rate their responses on a 5 -item from "Not at all" to "Extremely." Internal consistency on the Depression subscale is high, with a reported value of 
.85 (Peterson, 1987). Cochran and Hale (1985) fourd that college students reported greater levels of distress on all subscales of the BSI than did a comparable adult sample.

\section{Suicide Ideation}

1. Suicide Ideation Index (SII). Three items from the Zung Index of Potential Suicide (1974) plus two items from Harlow et al. (1986) were used as the first variable on the Suicidal Ideation factor. Statements include "I have been thinking of ways to kill myself" and "I imagine my life will end with suicide." A 5-point response scale was used, ranging from "Never" to "Always." Higher scores are indicative of greater amounts of suicidal ideation. Internal consistency for this measure has been estimated at .80 (Harlow, Newcomb, \& Bentler, 1987; Fitts, 1989).

2. Reasons for Living Inventory (RFL) - Survival and Coping Beliefs subscale (Linehan, Goldstein, Nielsen, \& Chiles, 1983). This measure is a 48-item scale that assesses potential reasons for not committing suicide. The subscale that was used in this study comprises 23 items that are designed to assess survival and coping beliefs. Sample items on this subscale include " I believe I can find other solutions to my problems" and "I have the courage to face life." Participants were asked to rate the strength of each potential reason on a 4-point scale ranging from "Not at all important" to "Extremely 
important." This subscale was chosen because it is the one with the strongest concurrent validity; that is, it correlated most highly with indicators of suicide ideation or behavior in both clinical and nonclinical samples (Corcoran \& Fischer, 1987). Internal consistency estimates for the 6 subscales of the RFL range from .72 to .89 (Corcoran \& Fischer, 1987). Higher scores on this measures indicate less suicidal ideation, so that this measure was used as a negative indicator of suicide ideation.

\section{Risk-Taking Propensity}

\section{AIDS-Risking Attitudes and Behaviors Scale}

(ARBAS) (Harlow, Quina, \& Morokoff, 1990). This is a 20-item scale assessing five dimensions related to AIDS attitudes and behaviors, including AIDS high-risk behavior, perceived risk, prevention efficacy, preventive behavior, and proximity. This scale was included since there are clearcut ways to reduce the risk of contracting AIDS and higher scores would be associated with more reckless behavior. Sample items include "When engaging in sexual intercourse, I (would) use condoms" and "I am fairly selective of my sexual partner(s)." A 4-point response scale was used, ranging from "Definitely true" to "Definitely false." In the initial use of this scale, internal consistency values for the five subscales ranged from .63 to .78 (Harlow et al., 1990). Because a 
preliminary PCA showed little support for this measure overlapping with the other two measures of Risk-Taking Propensity, it was not retained as an indicator for the SEM analyses. (See Results section.)

2. Sensation Seeking Scale - Form V (Zuckerman, Eysenck, \& Eysenck, 1978). This is a 40-item scale assessing individual differences in optimal levels of stimulation and arousal. It has undergone several revisions. The version used here, Form V, was designed so that there are four putative subscales with 10 items loading on each dimension. The four factors are: (1) propensity for engaging in activities with some physical risks (Thrill and Adventure Seeking - TAS); (2) desire for new experiences (Experience Seeking - ES); 3) social disinhibition (Disinhibition - DIS); and 4) aversion to repetitive experiences (Boredom Susceptibility - BS). The scale is constructed in a forced choice ( $A / B$ ) format. Examples of items are "A sensible person avoids activities that are dangerous" vs. "I sometimes like to do things that are a little frightening" and "I often wish I could be a mountain climber" vs. "I can't understand people who risk their necks climbing mountains." Zuckerman et al. (1978) report internal consistency estimates ranging from .59 to .82 for the four factors and values of .83 (males) and .86 (females) for the total scale. Corulla (1988) reports 
coefficient alphas ranging from .58 to .79 for the four subscales and values of .83 (males) and .80 (females) for the overall scale. Corulla (1988) found that the factor structure held up better for females than for males in his sample and suggests that this scale is most useful as an overall measure of a general sensation seeking trait. He also reports some differences for males and females, again suggesting that it would be most appropriate to evaluate the results separately for men and women.

3. Revised Reducer-Augmenter Scale (RRAS) (Clapper, 1990). This is a 21-item scale measuring stimulation modulation. It represents an operationalization of Petrie's (1967) reducing-augmenting construct. This construct is based on the premise that the human nervous system varies on a continuum from individuals who magnify incoming stimuli (augmenters) to those who attenuate incoming information (reducers), with moderates in the middle. Reducers then would be more likely to take risks, whereas augmenters would show a preference for lower stimulus arousal. Participants were asked to use a 4-choice scale to rate their preferences between activities that are more or less arousing. Sample items include: loud music vs. quiet music, and hard rock music vs. pop rock music. Clapper (1990) reports Chronbach's alpha and split half reliability values of .79. Some evidence also exists for 
convergent and discriminant validity (Clapper, 1990).

\section{Achievement Orientation}

1. Perfectionism Scale (Burns, 1980, 1983). This is a 10-item index measuring subjective standards associated with perfectionism. Items include the statements "People will probably think less of me if I make a mistake" and "An average performance is bound to be unsatisfying to me." Participants indicated the extent of their agreement with each statement using a 5-point scale, ranging from "I disagree strongly" to "I agree very much." Higher scores suggest greater levels of perfectionism. Cronbach's alpha values of .73 (Broday, 1988a) and .76 (Broday, 1988b) have been reported. Broday (1988a) also reported a correlation of .71 between this scale and the perfectionism subscale of the Common Beliefs Survey III (Bessai, 1977), a strong indication of concurrent validity. This measure was not retained for the final SEM analyses, because of the results of the preliminary PCAs. (See Results section.)

2. College Activities. Ten items were included to obtain an objective estimate of the individual's academic success and involvement in various school activities. These include GPA, number of credit hours being taken in the current semester, number of hours per week spent at a paid job, involvement in athletic, social, political, 
religious, and volunteer organizations, and amount of money contributed by the student toward education. The rationale behind these questions was that an individual scoring on the high end of these questions could probably be classified as 'achievement-oriented' while an individual scoring on the low end, while perhaps not an 'under-achiever,' would most likely not fit the profile of high-achievement. This scale was constructed by this author specifically for this project. Internal consistency was evaluated using coefficient alpha.

3. Personal Values Questionnaire - Academic Recognition (PVACR) (Jessor, 1969). This is a 10-item measure that assesses desire for academic recognition. It is one of three 10-item subscales on the Personal Values Questionnaire. Higher scores reflect greater desire for academic recognition. Items include: "How strongly do you like to get at least a B average this year?" and "How strongly do you like to be thought of as a good student by the other students?" Respondents were asked to record their answers on a 5-point scale, ranging from "Neither like nor dislike" to "Like very much."

Analyses

Structural equation modeling (SEM) techniques were used to evaluate overall model appropriateness for the five proposed models and the individual pathways between the 
independent, mediating, and dependent variables in each model. This statistical procedure is also known as latent variable modeling, causal modeling, or analysis of covariance structures. Structural equation modeling can best be conceptualized as a combination of multiple regression and factor analysis in a path analytic framework. Multiple regression involves the prediction of one dependent variable from several independent variables. Path analysis allows for the simultaneous assessment of several independent variables and dependent variables. However, both multiple regression and path analysis involve measured variables. Factor analysis, in contrast, can be used to assess the relationship between hypothetical (latent) constructs and several observed (measured) variables (e.g., Harlow et al., 1986).

\section{Advantages of Structural Equation Modeling}

Structural equation modeling combines the best of these three technologies into one methodology. Relationships between several measured and latent independent variables and dependent variables can be assessed simultaneously. Regressions among latent constructs are relatively unbiased since measurement error is taken into account through the factor analytic portion of the model. Structural modeling is a useful technique for theory testing, especially in the evaluation of more complex phenomena. 
Structural modeling has several unique advantages that make it an appropriate choice for data analysis in this study. First, it is particularly appropriate for use with variables that are not easily manipulated experimentally, such as those being used in this study (e.g., shame, substance use, suicide ideation).

Second, it allows for the assessment of both direct and indirect (i.e., mediating) effects (e.g., Harlow et al., 1986). Thus it will be possible to assess the direct relationship between family functioning and maladaptive outcomes as well as the indirect relationship via the mediation of shame. Such mediational relationships cannot be assessed using a multiple regression framework.

Third, hypothetical or latent constructs can be differentiated from the concrete operationalization of those constructs in the form of manifest or observed variables. That is, an explicit distinction is made between the latent constructs and manifest variables.

Fourth, a latent construct can be operationalized in a number of ways allowing for the inclusion of a number of indicators of the same construct. This provides a more robust and valid method of assessment. For example, there are four indicators of the latent construct of Family Functioning in the present study.

Fifth, measured variables always contain a certain 
degree of error which means that any predictions made between these measures are likely to be biased or unreliable. A latent variable modeling approach reduces the potential for both random and nonrandom measurement error when several manifest indicators of the same latent construct are used. In this way, it is a more robust approach than multiple regression. This ensures a more accurate operationalization of constructs, which is especially important for ones which may be more nebulous and harder to capture using self-report (e.g., substance use) .

Finally, structural modeling is useful in situations in which it is difficult to capture the theoretical construct(s) under investigation in isolation from other variables. Through a latent variable modeling approach, the presence and influence of other potentially 'causal' variables can be accounted for (James, Mulaik, \& Brett, 1982). It should be pointed out that neither the design nor statistics used here allow for causal conclusions. Still, the plausibility of the models can be rigorously evaluated.

The two most widely used computer programs for structural equation modeling are LISREL (Joreskog \& Sorbom, 1986) and EQS (Bentler, 1985). EQS was used here because of its straightforward setup and the several estimation 
options available. The most common estimation procedure is Maximum Likelihood, which is appropriate to use under conditions of relatively normal data. Two additional estimators are provided by EQS for use with very nonnormal data. Elliptical estimation (ERLS) assumes equal kurtosis among the variables, thus relaxing some of the distributional requirements of ML. Arbitrary distribution free estimation (ADF) has the least stringent distribution requirements, allowing for both skewness and kurtosis in the data, and correcting for kurtosis. ML was the estimator employed in these analyses because few of the variables were nonnormal (and those that were nonnormal were transformed logarithmically), and because $M L$ is the most well-known estimator and is robust to some degree under violations of normality (e.g., Harlow, 1985). Evaluation of Significance

The evaluation of the significance in structural equation models is controversial and still evolving. There is no one overall index of significance which takes into account 1) how good the model is, 2) how good the data is, 3) the parsimony of the model, and 4) the number of participants (L. L. Harlow, personal communication, fall, 1988). Thus the models will be assessed using several currently accepted criteria for the evaluation of overall model fit, including the ratio of chi-squared to degrees of 
freedom, incremental fit indices, the root mean squared residual, and $R$-squared values for the outcome variable. The ratio of chi-squared to degrees of freedom should be low. Values of $2: 1$ are good; values up to $5: 1$ are acceptable (Wheaton, Muthen, Alwin, \& Summers, 1977). Incremental fit indices provide an estimate of the model fit when compared with a null model that posits no significant relationships. EQS provides three fit indices: the Normed Fit Index (NFI) (Bentler \& Bonett, 1980), the Nonnormed Fit Index (NNFI), and the Comparative Fit Index (CFI) (Bentler, 1988). The CFI was used here because it has the advantage of the NNFI in taking sample size into account and it has less of a probability than the NFI of underestimating true model fit (Bentler, 1989). Tanaka (1987) indicates that fit index values of .9 or greater are indicative of well-fitting models. The root mean squared residual (RMSR) provides an estimate of the proportion of unexplained variances and covariances in the data that are not explained by the model. Values of .06 or less are considered acceptable (Hayduk, 1987). R-squared, the proportion of variance in a construct that is explained by other constructs, will also be examined for each dependent variable. This is calculated as: (1 - standardized prediction error variance). A comparison of R-squared values across models will allow an assessment of the degree 
of prediction for each of the five psychosocial outcomes. Within the models themselves, both the value and significance level of the individual pathways, along with estimates of prediction error and measurement error, will be taken into account. In general, when evaluating structural equation models, both the validity of the measurement model (the factor analysis portion, involving measurement error) and the structural model (the regression portion, involving prediction error) need to be evaluated. The validity of the measurement portion of the model is critical. Without it, the results of the structural model are more difficult to evaluate. Therefore it is important that the factor loadings are statistically significant and that the measurement model holds up well.

Comparisons Across Models and Gender

Cross-model comparisons were made by contrasting individual pathways, error terms, and the indices for overall model fit described above. In this way, the differential impact of shame on the five psychosocial outcomes (Substance Use, Depression, Suicide Ideation, Risk-taking Propensity, and Achievement Orientation) could be examined. Gender comparisons were also made across the five models, using the same indices. The five dependent outcomes were evaluated within the context of the general theoretical frameworks and the hypothesized relationships 
among the constructs of family functioning, shame, and psychosocial outcomes. In addition, a one-way MANOVA with sex as the independent variable and the measured variables as dependent variables was conducted. This analysis allowed for an assessment of the presence of any significant mean differences between men and women. Combination Models

Two additional models were analyzed. The first included all five of the dependent constructs. This was done in order to provide a comparative assessment of the relationships among Family Functioning, Shame, and the outcome variables within the same model. The second combination model included only the three maladaptive outcomes: Substance Use, Depression, and Suicide Ideation. Reciprocal Models

A question naturally arises regarding the reciprocal influence of shame and the various outcomes being studied here. This might be conceptually represented by having a two-way arrow for the pathway between shame and each dependent variable. Using Substance Use as an example, what is the impact of shame on level of substance use, and in turn, what is the impact of substance use on feelings of shame? The answer to this question is beyond the scope of this cross-sectional investigation. The one-way arrows reflect the hypothesized process but this is somewhat 
misleading. A cross-sectional study can say only what is the structural correlation between the two variables, and cannot make a definitive statement about the direction of the relationship. In order to address this question, a longitudinal framework would be needed, in which, for example, shame was measured at more thar one time point, and outcome variables were also measured at one or more points in time.

Additional Analyses

Since structural equation modeling is a correlational technique, it can only discern significant relationships that are of a linear nature. While it was generally expected that linear relationships would be found among the three sets of variables, it is clearly possible that curvilinear or other complex associations could exist among several constructs. This might be especially true for the relationships among Family Functioning, Shame, and Achievement Orientation. In order to elucidate the nature of potentially significant, but nonlinear associations, two additional sets of analyses were conducted. First, scatterplots were constructed to examine the patterns of bivariate relationships among these variables. Second, several chi-squared tests were conducted to make pairwise comparisons among high, medium, and low levels of Family Functioning, Shame, and the outcome variables. 
Results

Psychometrics of the shame scales

Both the ISS and the SCAAIR were evaluated psychometrically in order to contribute to the data already gathered on the nature of these two scales. Reliability was examined using Chronbach's alpha to determine internal consistency at the item level. Factorial validity was assessed through exploratory factor analysis. Construct validity was explored by examining both convergent and divergent validity. However, it should be noted that construct validity is a complex issue in this study. In some ways, the study overall represents construct validation of shame as it is operationalized here. Therefore it is difficult to tease out convergent and divergent validity between scales when those same correlations are also a part of the hypotheses being tested on a model level.

\section{Internalized Shame Scale (ISS) (Cook, 1989).}

In general, this scale appeared psychometrically sound. Internal consistency, as measured by Chronbach's alpha, looks very good. See Table 2 for results of reliability and factor structure at the item level. Chronbach's alpha for the entire, 30-item measure is .96 , which is quite high. As discussed in the Methods section, Cook postulates a two-tiered scale structure. On the first level, there are 
24 Shame items and 6 Self-esteem items (the only positively worded items in the scale). The shame scale is further broken down into subscales of Failure (15 items) and Alienation ( 9 items). As can be seen from Table 2 , the alpha values for the two scales and the two subscales are quite good, ranging from .88 (Self-Esteem) to .95 (Shame)

Insert Table 2 about here

The putative factorial structure was basically confirmed (see Table 2), both for the overall scale and for the subscales. The screeplot for the total 30 items revealed three to four factors, accounting for $57 \%$ (three-factor solution) to $64 \%$ (four-factor solution) of the variance. Various subsets of the 30 -item IsS were factor analyzed separately, using Promax rotation. The 24 Shame items can be explained by a single dimension that accounts for $48 \%$ of the item variance. The 6-item Self-esteem subscale represents a single dimension, accounting for $63 \%$ of the item variance. A final three-factor solution with Promax rotation produced the hypothesized subscales of: Shame (Failure), Shame (Alienation), and Self-Esteem. However, there were several items that loaded complexly, 5 of the Failure items, and 1 Alienation item. In general, these findings support the 
hypothesized structure of the ISS.

Table 3 summarizes the evidence for convergent and divergent validity. The ISS Shame items are highly correlated with the two Depression indicators, the CESD $(.73, \underline{p}<.001)$ and the BSI Depression subscale $(.73$, p $(.001)$. In fact, such high correlations suggest conceptual overlap with depression. More will be said about this in the structural modeling results. The ISS Shame items are also highly negatively correlated with the six Self-esteem items $(-.69, \mathrm{p}<.001)$ of the same scale. Given that the correlation was based on two parts of the same overall scale, it is harder to interpret this finding, as some overlap would be expected. The ISS Shame items were moderately correlated with the two Suicide Ideation measures, the Suicide Ideation Index $(.39, \mathrm{p}<.001)$ and the RFL Survival and Coping Beliefs subscale (-.31, $\mathrm{p}<.001)$. These correlations are in the predicted direction and add to both the convergent and divergent validity of the ISS. The ISS shame items were also compared to Jackson's Social Desirability scale. This produced a moderate correlation of .48 ( $\mathrm{p}<.001)$, which is not optimal as it indicates that participants respond to the ISS in a socially desirable fashion. 
Insert Table 3 about here

Self-Conscious Affect and Attribution Inventory Revised (SCAAIR) (Tangney et al., 1989).

Reliability, as measured by internal consistency, is not as strong as with the ISS. See Table 4 for alpha values and factorial structure information. Chronbach's alpha for the overall scale is good, with a value of .81 . Both the Shame-proneness and Guilt-proneness subscales have adequate reliability for research purposes, with alpha values of .71 and .76 , respectively. The remaining four subscales have alpha values that are lower than desirable, ranging from .62 for Externalization to .53 for Alpha Pride.

Insert Table 4 about here

The putative factor structure of the SCAAIR did not hold up well in this sample. Based on the screeplot, the overall scale appears to have eight or nine factors, accounting for $37 \%$ to $39 \%$ of the variance. A six-factor solution yielded mixed results. Fully half of the 65 items loaded complexly. The first three factors clustered generally into: 1) Pride (both Alpha and Beta) and 
Detachment, 2) Shame, anc 3) Externalization. The fourth, fifth, and sixth factors were not categorizable according to the six hypothesized subscales.

In a separate factor analysis, the 15-item Shame-proneness subscale consisted of three to four factors, accounting for $38 \%$ to $45 \%$ of the variance. Efforts were made to categorize these factors by various groupings (e.g., cognitive vs, behavioral components), but the obtained factors were not conceptually categorizable. The remaining five subscales also contain multiple factors, accounting for anywhere from $35 \%$ to $57 \%$ of the variance.

Indices of convergent and divergent validity appear to be good. As can be seen from Table 3, the Shame subscale of the SCAAIR has the expected moderate correlations (using Pearson correlation coefficients) with the two indicators of depression, the $\operatorname{CESD}(.34, \mathrm{p}<.001)$ and the BSI Depression subscale $(.32, \mathrm{p}<.001)$. There is also a moderate negative correlation with the six Self-Esteem items on the ISS $(.30, \mathrm{p}<.001)$. Contrary to expectations, there are not meaningful correlations with the two indices of Suicide Ideation, the SII $(.09, \mathrm{p}<.05)$ and the RFL Survival and Coping Beliefs subscale $(.01, p>.05)$. Responses have little to with social desirability, as assessed by the low correlation between the SCAAIR Shame subscale and Jackson's Social Desirability measure (.15, 
$\underline{p}(.001)$. In comparison to the ISS, the SCAAIR appears to be less vulnerable to producing a response set that is socially desirable.

\section{Distributional Characteristics}

Table 5 provides information regarding descriptive statistics for all measured variables. Most of the variables were normally distributed. Three showed high levels of skewness and kurtosis: DRUGS, DRUGPROB2, and SII. These three variables were transformed using logarithmic transformations, resulting in a distribution closer to normality. The logarithmic versions of these variables were the ones used in the structural modeling analyses. Tabachnick and Fidell (1989) provide a rationale for transforming nonnormal variables: given that the metric of most psychosocial variables is arbitrary, it does not confuse the issue to transform them. Transformations may provide greater empirical credence to the overall results since SEM is based on an assumption of multivariate normality.

Insert Table 5 about here 
Measurement Model

Principal Components Analyses. Prior to the structural modeling analyses, preliminary, item-level principal components analyses (PCAs) were carried out in order to assess the factor structure of each of the measures to be considered for the proposed seven latent constructs. Measured variables were then developed that consisted of item composites; each of these represented a specific factor on the corresponding latent variable. Each latent variable or construct was represented by two or more measured variables. The actual composites formed were both theoretically and empirically driven. That is, efforts were made where possible to keep entire scales intact. However, several of the scales did not yield neatly to factor analysis. In this instance, decisions regarding composites were made by evaluating both variance accounted for and the internal consistency of the given subscale. These decisions were made in the interest of developing the most robust measurement model possible as a strong measurement model is a necessary prerequisite for obtaining usable structural modeling results.

Table 6 provides information about the results of the preliminary PCAs. The final composites are shown along with their variance accounted for and Chronbach's alpha. This table also shows the results of a second-level 
principal components analysis, in which the original composites were then treated as individual variables in order to determine cohesiveness with the other variables on the same construct. (Essentially this means that the item composites were treated as though they were single items.) In this second column are listed the factor loadings, the variance accounted for, and alpha levels of the composite scales. This secondary PCA was done as a check on the hypothesized operationalization of the latent constructs. Each construct is reviewed separately below.

Insert Table 6 about here

Family Functioning. This construct represents a composite of retrospective functioning in the family of origin. The first and second indicators are derived from the Family Functioning Scale (FFS). A preliminary PCA of the FFS produced the five hypothesized factors so that all of the five subscales could stand alone as indicators. Two of the five were retained on the final construct: Positive Family Affect (FFSPFA) and Conflicts (FFSCON). The remaining three were not used because of redundancy with another factor (Communication) or less direct relevancy to this study (Worries, Rituals). The two subscales chosen consist of eight items each and represented the entire 
subscale as designed by the authors. The third indicator on this construct consists of five items culled from the Family Awareness Scales. Together they represent an index of communication among family members (FASCOM). The final indicator is the FPS, which is included in its entirety. Of the four Family Functioning scales on the survey, only the Family Information portion of Cook's ISS was not retained on the final construct. It did not fit cohesively with the other indicators (i.e., intercorrelations were low between this scale and the other indicators discussed above). This may be because it reflects demographic information while the other three measures focus specifically on the respondent's subjective perception of the family of origin environment. As Table 6 shows, alpha levels and variance accounted for (with the exception of FFSCON, which has a value of .35) are fairly high. At the second-order level of analysis, the four indicators hold together quite well, as indicated by the factor loadings, a high proportion of variance accounted for $(67 \%)$ as a single-factor solution, and Chronbach's alpha (.83).

Shame. The two scales measuring shame, the ISS and the SCAAIR, assess this construct in different ways, the ISS in terms of statements regarding internalized shame, and the SCAAIR in terms of responses to several hypothetical scenarios. Unfortunately, perhaps because of their 
distinctive approaches to capturing shame, they did not fit cohesively as a single construct. In part at least, as noted above, this occurred because the SCAAIR did not respond well to factor analysis. The IsS on the other hand, held up fairly well to factor analysis. The two hypothesized subscales of the ISS, Failure and Alienation, were retained in partial form, with 9 of the 15 Failure items as one indicator, and 5 of the 9 Alienation items as a second indicator. These two indicators form a cohesive composite, with $88 \%$ of the variance accounted for and an alpha level of .86 at the second-level PCA (see Table 6). The SCAAIR subscales were not retained in the final operationalization of the Shame construct.

Substance Use. Five indicators of substance use were gleaned from the three original scales of Alcohol Use, Drug Use, and Alcohol/Drug Use Related Problems. Alcohol Use (ETOH) represents the first indicator and it was retained in its entirety. The second indicator, Marijuana Use (POT), is a one-item indicator, taken from the Drug Use scale. It appears that marijuana use has a different pattern than either alcohol use or other drug use. This division of alcohol use, marijuana use, and other drug use, into three factors, was supported by the preliminary PCAs. The third indicator is made up of 7 of the 17 items on the Drug Problem scale (DRUGPROB1), and represents a factor of 
less serious drug-related problems (e.g., having a hangover, missing a class). The fourth indicator, Drug Use (DRUGSL), is comprised of the remaining 8 items on the Drug Use measure. As noted above, this indicator was used in the SEM analyses in its logarithmic form, due to the nonnormal distribution in this sample. The final indicator was formed from 7 items of the Drug Problem measure and was also transformed logarithmically (DRUGPROB2L). This variable represents more serious substance use-related problems (e.g., legal difficulties). The substance use indicators are psychometrically sound as shown by the PCAs and Chronbach's alpha (see Table 6). Of all the indicators on any of the measures, ETOH has the highest level of variance accounted for $(74 \%)$ and the highest alpha (.91). Variance accounted for by the other indicators is $48 \%$ or above and Chronbach's alpha is .82 or greater. On the secondary PCA level, a single-factor solution for the five indicators accounts for $50 \%$ of the variance and yields an alpha of .75.

Depression. The two depression scales were retained in their original form for the SEM analyses. The 20-item CESD was used as the first indicator of depression. A preliminary PCA suggested that this scale could be used as several factors (e.g., positively-worded items, negatively-worded items, social items), but that it also 
works well methodologically as a unitary indicator of depression ( $40 \%$ variance accounted for; Chronbach's alpha value of .91). As noted in the Methods section, the BSI is comprised of 9 subscales representing distinct symptom categories. The six-item (out of the 53 total items) Depression subscale (BSIDEP) represents a cohesive factor, with $59 \%$ of the variance accounted for and an alpha of .86 . The second-level PCA corroborates the appropriateness of this operationalization of two indicators, with $86 \%$ of the variance accounted for and an alpha value of .84 .

Suicide Ideation. Along with Depression, Suicide Ideation represents the only other construct in which the indicators were retained in their original form. The 5-item Suicide Ideation Index (SII) adapted by Harlow et al. (1986) from Zung (1974) is a unitary variable, with $61 \%$ of the variance accounted for and an alpha of .83 . The 23-item Survival and Coping Beliefs subscale from the RFL (RFLSCB) is also unitary and provides a good counterpoint to the negatively worded SII (51\% variance accounted for, alpha $=.95)$. The secondary PCA produced an alpha of .66 for the two scale composites and accounted for $75 \%$ of the variance.

Risk-Taking Propensity. This construct was difficult to capture methodologically. Three scales were administered in the survey: the SSSV, the RRAS, and the 
ARBAS. None of these scales was intended to be a unitary scale. The SSSV and the RRAS especially, did not yield smoothly to PCAs. The ARBAS does partial out empirically into the five putative factors and holds together fairly well as a unitary indicator, but did not fit in well as part of the overall construct when included with the SSSV and the RRAS. Consequently, the final construct was comprised of two indicators from the SSSV and two from the RRAS. The SSSV is theoretically a four-factor scale. Two of these ten-item subscales were retained as indicators: Thrill and Adventure Seeking (SSSTAS) and Disinhibition (SSSDIS). On the RRAS, two indicators were empirically derived, one having to do with music preferences (e.g., loud vs. soft) and one having to do with athletic preferences (e.g., contact vs. non-contact), labelled RRASM and RRASS, respectively. Variance accounted for ranges from . 28 to .48 , and Chronbach's alpha ranges from .64 to .74 for the item-level PCA. At the second-order, construct level, the factor loadings for each indicator range from .64 to .69 . These values are less than optimal. This construct also represents the one with the least variance accounted for $(.44)$. Chronbach's alpha is .57 , which is low. 
Achievement Orientation. Along with the Risk-Taking Propensity construct, this variable is the least well-defined methodologically. Three original scales were proposed for inclusion: Burns's Perfectionism Scale, the PVACR, and the College Activities Scale developed for this study by the author. While this last scale appears to provide salient information, it is not cohesive or unitary. Two of the ten items were retained as an indicator (COLACTA): current GPA and credit hours being taken in the semester the survey was completed. Variance accounted for by this indicator is good (57\%) but internal consistency is very poor (Chronbach's alpha $=.25$ ). The PVACR was retained in its original form, with all 10 items included. Variance accounted for is good (.47) and internal consistency is high (.87). On the construct level, these two indicators account of $58 \%$ of the variance. Chronbach's alpha is .28 , the lowest of the seven constructs and empirically weak.

The poor operationalization of this construct probably accounts for the fact that Achievement Orientation was the only variable that produced nonsignificant measurement model results. That is, the two indicators retained did not load significantly on the overall construct, a finding which calls into question the validity of the structural modeling results. This will be discussed further below. 
Third-level Principal Components Analysis

In addition to the PCAs described above for composite formation, an overall, or tertiary, PCA was carried out in order to evaluate on a preliminary basis, the natural groupings of the composite variables. The 21 composite variables were factor analyzed, with each composite being treated as though it were a single item. This produced a six-factor solution (based on the number of eigenvalues $\geq$ $1.00)$, with $66 \%$ of the variance accounted for. The results of this analysis are summarized in Table 7 . For ease of exposition, only those loadings with a value of .20 or above are reported.

Insert Table 7 about here

The obtained factor structure can be interpreted conceptually, with some indicators grouping together in discrete, predictable. ways, and others loading complexly (i.e., on more than one factor). The first factor is comprised of the two Shame indicators, the two Depression variables, and the two suicide Ideation indicators (complex). This factor can be characterized as a negative affect factor. The second factor is a family functioning one (all four indicators are included) and represents the cleanest of the six empirically-derived factors. No other 
indicators load or this factor, and only one of these factors (FFSCON) is complex (also loading on the sixth factor). The third factor is primarily a substance use factor, with four of the five Substance Use variables loading here. DRUGSL is the only one that does not load at all on this factor. DRUGPROB2L is a complex variable, loading primarily on the fourth factor. In addition, SSSDIS loads on the third factor. It makes intuitive sense that a disinhibition variable would be correlated with drug use variables. COLACTA, also a complex variable, loads negatively on this factor, suggesting a negative relationship between substance use and academic performance. The fourth factor represents a combination of substance use (in particular the more serious indicators) and the suicide ideation indicators. PVACR loads slightly on this variable as well, indicating a similar negative correlation between substance use and academic achievement as was found on the third factor. This factor comprises what could be defined as the most problematic behaviors and suggests that serious drug-related issues are connected to suicidal feelings/behaviors.

The fifth factor, made up of three of the four Risk-Taking Propensity indicators (all but SSSDIS) and COLACTA, appears to represent a risk-taking factor. Interestingly, academic achievement appears directly 
correlated with risk-takingi propensity. The sixth, final factor is the least neatly categorized, with achievement orientation variables predominating, but with elements of risk-taking and small loadings for FFSCON and RFLSCB.

This analysis provides general justification for the hypothesized models while also portending some of the problems encountered in the SEM analyses. Family Functioning, Shame, and Depression are well-defined, discrete constructs. Shame is correlated with both Depression and Suicide Ideation. Substance Use is split among two factors, that could generally be conceptualized as less serious and more serious drug-related issues. Risk-Taking Propensity and Achievement Orientation are the least well-operationalized constructs.

Summary Characteristics of the Composites

Prior to evaluating the measurement and structural modeling results, it would be useful to consider the summary characteristics and distributional qualities of the measured variables finally decided upon based on the preliminary PCAs. Refer to Table 5 for the means, standard deviations, range, skewness, and kurtosis for the 21 measured variables used in the five hypothesized models. In addition, the $F$ value and $p$ level are given for a MANOVA conducted to determine any significant gender differences. Participants report fairly high levels of positive family 
affect, moderate levels of conflicts, and moderate levels of overall family functioning as indicated by the means for FASCOM and FPS. Low levels of shame are reported. Moderate levels of alcohol use and less serious drug problems are reported, along with low levels of marijuana and other drug use, and more serious drug problems. Low levels of depression and suicidal ideation are reported and moderately high levels of reasons for living. Moderate levels of risk-taking propensity are reported. Moderately high levels of academic achievement are reported along with fairly high levels of achievement motivation. Overall, the reported values appear to be in line with expectations for a nonclinical college population.

\section{Gender Differences}

Table 5 also provides information regarding gender differences. A MANOVA was conducted on the measured variables using sex as the independent variable. A value for Wilks' lambda of .62 was obtained ( $F=7.98, d f=53$, p $(.001)$. This indicates that $38 \%$ of the variance in this set of variables is explained by gender differences. There are basically no gender differences on the Family Functioning variables, with the exception of women reporting higher levels of Positive Family Affect (FFSPFA). Contrary to predictions, the differences for the Shame variables are not very pronounced. Women report higher 
levels of ISS/Failure (ISSF), but there is no difference on the ISS/Alienation (ISSA) factor. There are more pronounced gender differences among the dependent variables. The two constructs most affected are Substance Use and Risk-Taking Propensity. Men report higher levels of alcohol and drug use, along with significantly higher drug use-related problems. Similarly, men report consistently higher levels of risk-taking propensity than do women. Men also report significantly higher levels of suicide ideation and lower levels of reasons for living. There are no significant gender differences for academic achievement but women report significantly higher levels of achievement motivation. Depression is the only latent variable for which no gender differences were obtained for the measured variables, indicating that, in this sample, men and women report similar levels of depression.

These overall results indicating significant sex differences across several of the measured variables provide justification for evaluating the structural models by gender. Interestingly, this justification comes not so much from pronounced differences in reported levels of shame, which was the postulated reason for conducting separate analyses, but from the significant differences on the outcome variables. 


\section{Structural Equation Modelling Results}

Overall Results. In order for structural model results to be considered valid, the underlying measurement model results must be stable. All factor loadings should be significant at $p$ less than .05 . These data yielded very strong measurement models (i.e., p values met the criterion), except for the Achievement Orientation indicators, which produced $p$ values greater than .05 . Therefore, with the exception of the Achievement Orientation model, all of the SEM results obtained are potentially interpretable.

As noted above, EQS provides three different estimation procedures: Maximum Likelihood, Elliptical, and Arbitrary Distribution Free, the choice of which is based on how well the measured variables meet distributional assumptions. Because only three of the measured variables showed significant nonnormality (SIIL, DRUGSL, AND DRUGPROB2L) and this nonnormality was somewhat reduced using logarithmic transformations (see Table 5), Maximum Likelihood (ML) estimation was chosen. ML is used when distributional assumptions are basically met and has been found to be robust against moderate violations of nonnormality (Harlow, $1985)$.

In all five models, there was a significant negative relationship between the Family Functioning and Shame 
constructs, with a parameter estimate of -.48 ( $\mathrm{p}<.001)$ for the total sample, -.56 ( $p<.001)$ for men, and -.47 ( $p<.001)$ for women (see Figures 2-6), indicating a very significant moderate negative correlation between perceived levels of family functioning and shame. This finding suggests that, as predicted, lower levels of reported family functioning are associated with higher levels of shame in both men and women. The prediction error for Shame was relatively high across all five models, ranging from .69 for men to .79 for women. Thus Family Functioning accounts for $21-31 \%$ of the variance in shame in these models.

No technical difficulties were encountered in the running of these analyses. Convergence upon a solution (successful iteration) was achieved. No condition codes were reported. The presence of condition codes would indicate that one or more of the parameter estimates had become linearly dependent on other parameters, or that a parameter was being constrained artificially at an upper or lower bound (Bentler, 1985).

Results across models. In the following presentation, overall model results are presented first, with parameter estimates discussed second. Table 8 summarizes evidence for overall model fit for Models 1 - 5. As noted above, in all of the models the pathway between Family Functioning and Shame was negative and significant at the .001 level. 
This pathway will not be discussed individually since the results are equivalent across the five models.

Insert Table 8 about here

Model 1 (Substance Use). Indices of model fit were the weakest in this model (see Table 8 ). The ratio of chi-squared to degrees of freedom was 11.56 for the total sample, 6.73 for women, and 4.88 for men. Only the last value is within the guidelines recommended by wheaton et al. (1977) and even that value is at the high end. The CFI values were .86 for the total sample, .90 for the women, and .82 for the men. Prediction error for Substance Use was high (ranging from .94 to .96), indicating that only 4 to $6 \%$ of the variance in Substance Use is accounted for by the model. RMSR values were .06 for the total sample, .05 for the women, and .08 for the men. The first two are within normal limits; the last is on the high side.

Figure 2 provides the structural parameter estimates. The path between Shame and Substance Use is significant and in the predicted direction for the total sample (.16, $\mathrm{p}<.001)$ and for women $(.21, \mathrm{p}<.001)$, with a parameter estimate of .18 (NS) for men. In none of the models was the direct path from Family Functioning to Substance Use found to be significant. This suggests that for women, 
shame mediates the relationship between family functioning and substance use such that lower reported levels of family functioning and higher levels of shame are correlated with higher levels of substance use. Men's substance use however, is not correlated with family functioning or shame in this sample.

Insert Figure 2 about here

Model 2 (Depression). This model produced the lowest values for the chi-squared/degrees of freedom ratio of the five models tested, with a value of 3.29 for the overall sample, 1.71 for women, and 2.47 for men. This indicated a good fit between the data and the model. A $p$ value of .03 was obtained for the women, which is the highest of any of the models tested, and an additional indicator of good model fit. The CFI values were also very good: .99 for the overall sample, .99 for women, and .97 for men. The variance accounted for ( $R$ squared) in Depression by Family Functioning and Shame was also high: .86 for the total sample, .89 for women, and .81 for men. RMSR values were low: .03 for the overall sample, .02 for women, and .05 for men.

Consistent with the excellent overall model fit, this model also produced the strongest path between shame and 
the outcome variable of the five models (see Figure 3 ). The parameter estimate for the Shame-Depression pathway was .92 ( $\mathrm{p}<.001)$ for the overall sample, .95 ( $\mathrm{p}<.001)$ for women, and .95 ( $\mathrm{p}<.001)$ for men. Moreover, the direct pathway between Family Functioning and Depression was nonsignificant for the overall sample (-.02) and for women (.03), while significant, but low, for men (-.19, p<.01). This pattern suggests that shame is an important mediator between family functioning and depression, with greater family dysfunctioning being correlated with more reported shame, and in turn, higher levels of depression.

\section{Insert Figure 3 about here}

There is a caveat on these findings however. Hayduk (1987) warns that parameter estimates of .9 or greater might be an indicator of colinearity problems. The fact that the ISS correlates so highly with the CESD and the BSI Depression subscale (both .73) strongly suggests conceptual overlap between Shame and Depression. However, technical difficulties in the analyses, such as lack of convergence or condition codes, both of which would suggest colinearity problems, were not encountered. An appropriate conclusion then would be to consider the basic pattern represented here as accurate, though inflated by the conceptual overlap 
between the Shame and Depression constructs.

Model 3 (Suicide Ideation). Model fit indices again appear strong. The values for the chi-squared/df ratio are 4.82 for the total sample, 3.35 for women, and 2.47 for men. CFI values are .97 for the overall sample, .98 for the women, and .96 for the men. RMSR values are .03 (total), .03 (women), and .04 (men). Percentage of variance accounted for ( $R$ squared) in Suicide Ideation by Family Functioning and Shame is: $36 \%$ (total sample), $42 \%$ (women), and $26 \%$ (men). This model holds up very well and is superseded only by the Depression model in terms of overall fit.

Refer to Figure 4 for the structural pathway results. The pathway between shame and Suicide Ideation is in the predicted direction and very significant: .49 ( $\mathrm{p}<.001)$ for the full sample, $.57(\mathrm{p}<.001)$ for women, and .38 ( $\mathrm{p}<.001)$ for men. This is the only model in which the direct pathway (Family Functioning to Suicide Ideation) is significant across all three analyses, with values of -.20 $(\mathrm{p}<.001)$ for the total sample, $-.16(\mathrm{p}<.001)$ for women, and $-.20(\mathrm{p}<.05)$ for men. These results suggest that shame is an important mediating variable between family functioning and suicide ideation, and that lower family functioning alone is significantly correlated with suicide ideation. 
Insert Figure 4 about here

Model 4 (Risk-Taking Propensity). For this model, the chi-squared/df ratio is adequate, with values of 3.91 (full sample), 3.13 (women), and 1.78 (men). A $p$ value of .004 was obtained for the men. Although clearly not high, it was one of the few models tested that resulted in a $p$ value greater than .001, and suggests slightly improved model fit over others with lower $p$ values. This model produced equivalent CFI indices across all three models, with a value of .96. RMSR values were in the acceptable range, with values of .05 (total sample, women) and .06 (men). Variance accounted for in Risk-Taking Propensity by Family Functioning and Shame was very low for the combined sample $(2 \%)$ and for women $(1 \%)$, but more significant for men $(15 \%)$.

The structural parameter estimates produced an interesting result (see Figure 5). The path from shame to Risk-Taking Propensity was significant for the total sample $(-.13, \mathrm{p}<.05)$ and for men $(-.30, \mathrm{p}<.05)$. This same pathway was not significant for the women $(.07, \mathrm{p}<.05)$. This finding suggests that, for men, higher levels of shame are correlated with lower levels of risk-taking, but that for women, shame is not a significant concomitant of 
risk-takin. The significant finding for the men is not in the direction originally predicted, but that is confounded by the fact that the final operationalization of this construct is different than initially proposed. The direct path from Family Functioning to Risk-Taking Propensity was nonsignificant across all three analyses, with values of .03 for the full sample, -.02 for women, and .14 for men. These results suggest that family functioning is not an important correlate of risk-taking propensity, although it could be that a mediational effect of shame is in operation here.

Insert Figure 5 about here

Model 5 (Achievement Orientation). As noted above, the instability of the measurement model for this construct renders suspect the results of the structural model. The findings are included here for the purpose of evaluating the relationships among the variables on a preliminary basis, but further refinement of this construct is clearly needed in order to more accurately discern any significant correlations among family functioning, shame, and achievement orientation.

The chi-squared/df ratios were all within acceptable limits, with values of 4.47 (full sample), 2.65 (women), 
and 2.29 (men). p values of .004 for the men and .002 for the women were obtained, which are slightly above the values of $p<.001$ produced by most of the models. CFI estimates ranged from .97 (total) to .98 (women) to .96 (men), all of which are high. RMSR values were .03 for the overall sample and for women, and .05 for men. The amount of variance of Achievement explained by Family Functioning and Shame was $6 \%$ for the full sample and for men, and $8 \%$ for women.

The path between Shame and Achievement is non-significant across all three models (see Figure 6), with values of .07 (total), .16 (women), and -.19 (men). There is however, a significant direct relationship between Family Functioning and Achievement for the overall sample $(.27, \mathrm{p}<.05)$ and for women $(.30, \mathrm{p}<.05)$. This pathway is nonsignificant for men, with a value of .08. These results suggest that shame is probably not an important mediator of achievement as these constructs are operationalized here, but it is likely that there is a significant positive relationship for women between reported level of family functioning and achievement.

Insert Figure 6 about here 
Results of Combination Models

Two combination models were analyzed in addition to the five separate hypothesized models discussed above. In the first, all five outcome variables served as dependent constructs. This was done in order to assess comparative contributions of the dependent variables. In other words, how do these variables compare to each other in terms of their correlations with Family Functioning and with shame? Table 9 summarizes the model fit indices; Figure 7 provides parameter estimates. Model fit is not optimal, although there are no glaring problems (e.g., no condition codes nor lack of convergence). Chi-squared values are high, producing chi-squared/df ratios of 8.89 for the total sample, 5.85 for the women, and 3.71 for the men, with only the men falling into an acceptable range. Accordingly, the values for the Comparative Fit Index (CFI) are somewhat low: .77 (total sample), .80 (women), .72 (men). RMSR values are slightly high (.07 to .09), indicating that there is variance in the data not being explained by the hypothesized model.

Insert Table 9 about here

Figure 7 provides parameter estimates for the structural pathways. This composite model essentially 
mirrors the results of the individual models. Significant mediating relationships between shame and the outcome variables occur for Substance Use, Depression, and Suicide Ideation. In contrast, no such mediating relationships appeared between Shame and Risk-Taking Propensity or Achievement Orientation. (Again, the factor loadings for the Achievement Orientation indicators have $p$ values greater than .05 , making the structural coefficients for this variable untrustworthy.) The strongest relationship was between Shame and Depression, followed by Suicide Ideation, and then Substance Use. These relationships held up across all three sample variations of the model (total sample, women, men). Three significant direct relationships emerged: Family Functioning is negatively correlated with Depression for men, negatively related to Suicide Ideation in the overall sample, and positively related to Achievement Orientation in the total sample. As expected, a significant negative relationship was found between Family Functioning and Shame. Prediction errors were high for Substance Use, Risk-Taking Propensity, and Achievement Orientation, indicating that much of the variance is being explained by factors other than those operationalized here. Prediction error for suicide Ideation was lower, indicating about $43 \%$ of the variance, over the total sample, was being explained by the contributions of 
Family Functioning and Shame. Prediction errors were lowest by far for Depression, indicating that $85 \%$ of the variance for the men and $92 \%$ for the women is explained by the independent variables of Family Functioning and Shame.

Insert Figure 7 about here

Because Risk-Taking Propensity and Achievement Orientation were so poorly explained by this model, a second combination model was run which included only Substance Use, Depression, and Suicide Ideation. Comparison of model fit indices in Table 9 suggests some improvement in CFI (ranging from .80 to .90) and RMSR (.05 to .08 ), while the chi-squared/df ratio remains high. Figure 8 shows that not much change occurred in parameter estimates. Again, Depression is explained best by this model, followed by Suicide Ideation, and then Substance Use. Interestingly, in both combination models, the Shame-Substance Use pathway is significant for men, while it is not in the individual model.

Insert Figure 8 about here 


\section{Assessment of Linearity}

Structural equation modeling is based not only on an assumption of normality, but also one of linearity. That is, if curvilnear relationships exist among the constructs, SEM analyses would not be able to detect them. While the examination of nonlinear relationships is beyond the scope of this study, two measures were taken to check for non-linear relationships: scatterplots and chi-squared tests. The purpose of the scatterplots was to assess qualitatively the presence of linearity between Shame and each of the measured variables in turn. The purpose of conducting the chi-squared tests was to examine whether any significant relationships (i.e., dependence) existed between pairwise variables. In the event of significant findings (i.e., a chi-squared value with $\mathrm{p}<.05$ ), the nature of the relationship can be evaluated by the pattern of frequencies. A linear relationship would be suggested by a linear pattern of highest frequencies along a diagonal of a cross-tabulation table, while a curvilinear relationship would be suggested by a nonlinear (e.g., inverted) pattern of highest frequencies. The results of the scatterplots and chi-squared tests were then viewed together in order to assess the associations between pairwise variables and therefore to draw some conclusions regarding linearity vs. curvilinearity or whether there was no decipherable 
relationship. These methods are more qualitative than quantitative but is sensitive enough to catch any blatant nonlinear trends.

Three sets of chi-squared tests were conducted. In the first set, pairwise comparisons were made between low, moderate, and high levels of Shame, and low, moderate, and high levels of each of the outcome variables. In the second set, similar pairwise comparisons were made between Family Functioning and the five dependent variables. Finally, a pairwise comparison was made between shame and Family Functioning. Table 10 provides the results of these pairwise comparisons.

Insert Table 10 about here

In general, the results of these analyses were consistent with the SEM results described above. The scatterplots for Shame/Substance Use revealed no clear relationship. The chi-squared tests showed no evidence of a significant association among the Family Functioning and Substance Use variables. The significance level of .067 obtained for the Shame/Substance Use pairwise comparisons is a trend in the direction of an association and is consistent with the significant relationships found for the Shame-Substance Use parameter in the SEM analyses. 
In contrast, a clear linear trend between shame and Depression was seen in the scatterplots and was supported by the chi-squared results. Indeed, Table 10 reveals a significant relationship between Shame and Depression $(\mathrm{chi}$-squared $=354.10, \mathrm{p}<.001)$, a finding that corroborates the strong results obtained in the SEM analyses for the Depression model. A strong association was also found between Depression and Family Functioning in the pairwise comparisons (chi-squared $=107.97, \underline{p}<.001$ ). This path was nonsignificant in the SEM analyses, suggesting again the powerful mediational effect of shame in this model.

Similarly, a slight linear trend was evident in the scatterplot for suicide Ideation and Shame. The significant SEM results are confirmed by the pairwise comparison results for both Shame and Family Functioning, in which significant chi-squared values were obtained (85.48, $\mathrm{p}<.001$ for Shame; 74.55, $\mathrm{p}<.001$ for Family Functioning), and patterns of high frequencies were consistent with linear relationships.

The scatterplots for Risk-Taking Propensity revealed no decipherable relationship. The pairwise comparisons with Family Functioning were consistent with the structural modeling results in lack of significance. Interestingly, the structural modeling results reveal a significant negative relationship between Shame and Risk-Taking 
Propensity (in the overall sample and for men), while the pairwise comparisons showed no significant association (chi-squared $=.69, \mathrm{p}>.05)$. This discrepancy does not disconfirm the latent variable modeling results (it would be problematic if the reverse situation were true), but corroborates the comparatively weaker association than is found in the Depression or Suicide Ideation models.

The findings for Achievement Orientation also mirrored the structural modeling results. No discernable relationship was evident between Achievement Orientation and Shame in the scatterplots. Pairwise comparisons with Shame revealed no significant association, a finding consistent with this same parameter in the structural modeling analyses. Again, there was a slight difference, this time in the association with Family Functioning, between the chi-squared tests and the SEM results, with the pairwise comparisons essentially not picking up the significant correlation between Family Functioning and Achievement Orientation found in the structural modeling results. As with a similar result noted above for Achievement Orientation, this discrepancy points to the comparatively weaker relationships in this model than those in the models focusing on more explicitly maladaptive outcomes (i.e., Depression, Suicide Ideation, Substance Use ) . 


\section{Discussion}

This discussion parallels the Results section, with the psychometrics of the ISS and the SCAAIR considered first, followed by a discussion of the structural modeling results. Strengths and limitations of this research and its relevance to the literature are also considered. Finally, clinical implications and directions for future research are discussed.

\section{Psychometrics of the Shame Measures}

\section{Internalized Shame Scale (ISS)}

The ISS is a basically well-constructed, psychometrically sound scale. It is quite reliable, as assessed by Chronbach's alpha, both at the overall scale level and at the subscale level. Its factor structure generally holds up, along the hypothesized divisions of Shame and Self-Esteem. The shame scale further breaks down into the putative subscales of Failure and Alienation. Still, there are a couple of problems with this measure. It is fairly highly correlated with social desirability, which means that results obtained from it may be biased. Secondly, there is a great deal of empirical overlap with depression, as assessed by the two depression measures (the CESD and the BSI) that were considered here. This may affect its utility as a measure of a distinctly separate construct in some instances. However, the fact that 
colinearity problems were not encountered in the SEM analyses suggests that any conceptual overlap was not problematic in this study.

Self-Conscious Affect and Attribution Inventory Revised (SCAAIR)

The SCAAIR was constructed in a very different masner than the ISS. It is scenario-based, and as such, does not factor analyze cleanly. The exploratory PCAs conducted here revealed three basic factors of detachment/unconcern, pride, and shame. Together these could be described as points along a continuum of self-consciousness or self-reflectiveness, with pride representing positive self-reflection, shame representing negative self-reflection, and detachment representing either a lack of self-reflection or perhaps neutral self-reflection. (Further work on the scale would need to be done in order to assess fully these possibilities.) It has an advantage over the ISS of not being as explicit in what it is trying to measure. Evidence for this is reflected in a lack of correlation of the shame-proneness subscale with social desirability. There is also a more moderate correlation with depression which in this sense reduces its conceptual overlap with depression.

Because structural modeling must be based on a solid measurement model, and because the ISS is the stronger 
measure from a factor analytic point of view, the two shame subscales of the ISS (Failure and Alienation) were the most appropriate choices as the indicators on the Shame construct. It could be that, in other types of research not based on factor analysis, the SCAAIR would be an appropriate measure for shame.

\section{Structural Equation Modeling Findings}

This study was designed as a cross-sectional view of how family functioning and shame variables correlate with various outcome variables in a nonclinical college population. The results generally support the framework suggested by many writers and made explicit by Kaufman (1985, 1989) that family dysfunctioning and shame are important concomitants of maladaptive psychological outcomes. In general, the predictions that were confirmed in this investigation were those related to the outcomes that could be more clearly identified as maladaptive (depression, suicidal ideation, and substance use).

Family Functioning and Shame

All five models revealed the expected negative relationship between Family Functioning and Shame, suggesting that perceived dysfunction in one's family of origin is positively correlated with the experience of shame in the college student. Because only the general correlation between family functioning and shame was 
examined, it is not possible to determine the causal direction of this relationship in this study. But these results clearly support the general notion that retrospective perceptions of family functioning by the young adult are linked to current affective states.

Clinicians have long recognized the important role that family functioning plays in the psychological development of the individual. From classical psychoanalytic viewpoints which are more intrapsychically oriented, to systemic theories which explicitly take into account the family's impact on both normal and pathological development, to object relations perspectives which specifically address the confluence between the intrapsychic and the interpersonal, the individual is considered within the context of his or her environment (e.g., Fossum \& Mason, 1986; Kaufman, 1985, 1989; Stierlin, 1974 ; Naiditch, 1987 ).

\section{Shame and the outcome Variables}

The relationship between shame and the various outcome variables is the primary focus of this investigation. Correlations were strongest for the two most clearly identifiable maladaptive outcomes, Depression and Suicide Ideation, and mixed but still significant for substance Use. The relationship between Shame and Risk-Taking Propensity was significant (for men), but in the opposite 
direction than predicted. Because of the problematic measurement model results obtained in the Achievement Orientation model, the nonsignificance of the shame -Achievement Orientation pathway, though predicted, cannot be interpreted with confidence. Each of the outcomes will be discussed in turn.

1. Depression. The Depression model in particular is a classic example of a mediational model in latent variable modeling analysis. This is the case when there is a strong correlation between the mediating and dependent variables, but little or no significant relationship between the independent and dependent variables. The correlations between Shame and Depression are quite strong, especially for women $(.95, \mathrm{p} \leq .001)$, while the relationship between Family Functioning and Depression is nonsignificant except for the men.

These results suggest that, for women in particular, shame is a very powerful mediator between family functioning and depression, such that individuals with lower reported levels of family functioning and higher levels of shame will experience greater levels of depressive symptomatology. Interestingly for the men, the relationship between Shame and Depression is also high $(.78, \mathrm{e}<.001)$, but there remains a small but significant negative direct relationship between Family Functioning and 
Depression $(-.19, \underline{p}<.01)$. So for the men, it appears that shame is an important mediator, but level of perceived family discord is also directly related to level of depression. The R-squared values for Depression were by far the highest of the five models, with Shame and Family Functioning explaining $89 \%$ of the variance for women and $81 \%$ for men in level of depression.

The high correlation between the ISS and the two depression indicators (BSIDEP, CESD) should be taken into account. Clearly the strength of the relationship between these two constructs is due in part to some overlap between these measures. However, if that was the only influence, the analyses would not have yielded stable results because high colinearity would have introduced model instability. This was not the case. In fact, this model yielded the best indices of overall fit. Therefore it is appropriate to conclude that shame has a very important role in depression. This finding is consistent with many theoreticians' views that depression has a strong component of shame (Lewis, 1971, 1987; Tangney, 1988; Kaufman, 1989 ; Morrison, 1989). Morrison (1989) for example, views shame as an important aspect of, and precursor to, depression.

2. Suicide Ideation. Not surprisingly, the Suicide Ideation model turned out to be the second strongest one and results were in the predicted direction. There was a 
strong positive relationship between shame and suicide Ideation for both sexes, with the correlation somewhat stronger for women $(.57, \mathrm{p}<.001)$ than for men $(.38$, $\mathrm{p}(.001)$. This model also exhibited a mediational relationship, in that the correlation between shame and Suicide Ideation was stronger than the direct relationship between Family Functioning and Suicide Ideation. However, in contrast to depression, level of family functioning appears to have a more significant direct relationship with suicide ideation, as evidenced by a significant correlation between these two constructs: $-.16(\mathrm{p}<.001)$ for women, -.20 ( $p<.05$ ) for men. These results suggest that independent of shame, there is a relationship between perceived family functioning and suicide ideation for the young adult. Shame plays an additional mediating role, such that individuals who believe their families to have functioned adequately, but who have higher levels of shame, are still more likely to experience suicide ideation. The R-squared values of $42 \%$ for women and $26 \%$ for men corroborate the fact that family functioning and shame are important correlates of suicide ideation in young adults.

As with depression, suicide has long been linked in the clinical literature with shame. Chasseguet-Smirgel (1985) believes that overwhelming shame and humiliation may lead to suicide; consider the expression "to die of shame." 
Similarly, Kohut $(1 \$ 77)$ refers to the suicides fueled by narcissistic rage and the accompanying intense levels of shame.

3. Substance Use. The Substance Use model produced mixed results, with moderate levels of significance. This was also the model that manifested the most interesting gender differences. For women, there was a significant correlation of .21 ( $\mathrm{p}<.01)$ between Shame and Substance Use, while there was a nonsignificant relationship for men. This suggests that the experience of shame plays a role in substance use for women, but not for men. Shame in women is more directly linked with their substance use, whereas it does not have the same significance for men. Neither of the genders showed significant correlations between Family Functioning and Substance Use, suggesting that perceived family emotional health plays no role in college students' level of alcohol or drug use. Overall, these two variables do not appear to represent important correlates of substance use, as indicated by the low R-squared for both women $(4 \%)$ and men $(6 \%)$.

Gender differences in substance use patterns may contribute to the results found here. Significant sex differences were found for all five indicators of substance use, with men consistently reporting higher levels of substance use (see Table 5). Moreover, substance use for 
women is much more nonnormal than it is for men, as indicated by the high levels of skewness and kurtosis (see Table 5). It can be hypothesized that substance use is a more or less ubiquitous phenomenon among college students, which may account for the lack of significant findings for the overall sample and for the men. For men, it is more normally distributed (i.e., men are more likely to experiment with and/or use a wide variety of substances) and appears to be accounted for largely by factors others than the two studied here. For women, it can be hypothesized that substance use may be more related to affective state, and thus more particular (i.e., less ubiquitous) than it is for men. These findings support the view of Gomberg (1987) whose research on women alcoholics suggests that women use substances as a way to assuage feelings of shame. Furthermore, she believes that the problem then becomes circular, with the substance use serving to reinforce the sense of shame.

4. Risk-Taking Propensity. This model represented the only one of the five to produce results in the direction opposite from what had been predicted. The findings suggest that, for men, shame is actually negatively related to risk-taking behaviors, as indicated by the negative relationship obtained between shame and Risk-Taking Propensity for men $(-.30, \mathrm{p}<.05)$ and in the total sample 
$(-.13, \mathrm{p}<.05)$. No significant relationship between Family Functioning and Risk-Taking Propensity was found. This model generated the lowest $R$-squared of any of the five models ( $1 \%$ for women, $15 \%$ for men), indicating that the majority of the variance in Risk-Taking Propensity is accounted for by variables other than the two explored here.

These results suggest that shame and risk-taking are meaningfully related for young men, but not so for young women. For men, higher levels of shame are associated with lower risk-taking propensity. These results suggest a hypothesis that men who are shame-prone may be more constricted in their behavior. Some writers view shame as an experience which reminds us of our human limitations. In moderate doses, this is adaptive and serves the purpose of socialization (i.e., if we didn't experience shame, we would be more likely to engage in "shameless" behavior). At more pathogenic levels however (and it is admittedly difficult to determine how to delineate "healthy" shame from pathogenic shame), shame may serve unduly to restrict or constrict behavioral responses, causing individuals to avoid healthy risks as well as unhealthy ones. Or perhaps it makes it more difficult to know the difference between healthy and unhealthy risk-taking. Shame may adversely affect the spirit of adventurousness in men more than in 
women.

There are other factors, primarily methodological in nature, that should be considered when evaluating the results of this model. This construct was not as clearly defined as were the maladaptive outcomes. It was originally intended to be focused on the more maladaptive aspects of risk-taking, i.e., reckless behaviors. However, the one measure administered in the survey that is most primarily a measure of recklessness, the ARBAS (Harlow et al., 1990), was not retained as an indicator because of the findings from the preliminary PCA that indicated it did not work cohesively with the RRAS and the SSS. Hence the final operationalization of the construct was more of a general measure of risk-taking propensity rather than a maladaptive one of recklessness. Conceptually at least, there is a difference between more adaptive risk-taking and less adaptive recklessness. This makes sense clinically as well: the ability and willingness to take risks and try new things is an aspect of healthy psychological functioning. Reckless behavior, on the other hand, can be viewed as being self-destructive.

5. Achievement Orientation. Achievement Orientation was the least well-defined and operationalized of the five outcome variables, as suggested by the weak measurement modeling results. An improved construct might produce 
different findings. But it also makes sense theoretica.ly that there would be fewer significant findings in this model as Achievement Orientation was not predicted to be significantly related to shame. Furthermore, as was the case with Risk-Taking Propensity, the final operationalization of this construct differs in tone from its original conception. At first intended to be a construct that represents more maladaptive forms of achievement-seeking behavior (i.e., overachievement), the items retained for the $S E M$ analyses were not maladaptive in nature. Burns's Perfectionism Scale (Burns, 1980; 1983) which may have reflected more maladaptive levels of achievement motivation, did not fit cohesively with the other indicators, and was excluded from the final composite.

Keeping in mind the strong caveat on interpretation suggested by the poor measurement model, the following conclusions can be cautiously offered. The findings from this model suggest that shame is not related to achievement orientation. No significant relationship was found between Shame and Achievement Orientation. R-squared was again low in this model (.08 for women, .06 for men) but is hard to interpret since it was also nonsignificant. An interesting finding was obtained regarding Family Functioning and Achievement Orientation. In the overall sample and for the 
women, Family Functioning was positively correlated with Achievement Orientation $(.27, \mathrm{p}<.05$ for total sample; .30 , p<.05 for women). No such relationship was found for men. This finding suggests that college women who perceive their family of origin to be high in functioning are more likely also to be oriented toward academic achievement. However, academic achievement for college men does not appear to be related to perceived family functioning. This finding is supported by the followup MANOVA as well. Women report significantly higher levels of desire for academic recognition as suggested by their higher scores on the PVACR (see Table 5).

Kaufman (1985, 1989) considers over-achievement to be a defense against shame. Morrison (1989) speaks of the shame-prone individual as ambitious and driven to succeed. He views shame as integrally related to narcissism. Fossum and Mason (1986) believe that perfection is one of the rules by which shame-bound families operate, and that there is often a premium placed on high achievement in such families. Thus a theoretical connection between achievement motivation and shame could be postulated, but it may be that attained achievement needs to be taken into account. For example, high achievement motivation coupled with low level of achievement may be correlated with shame. 
Strengths of the Study

In many ways, the study of shame is still in its infancy. While the concept of shame has long been pondered by philosophers, sociologists, and biologists, little empirical research has been undertaken. This investigation can be considered an exploratory one. The results can be used to guide further research in this area, especially regarding the often-postulated connection between shame and psychopathology.

Definitional issues abound in the field of affects in general and shame is no exception. Most research has been based on experiential or phenomonological inquiries. This study is one of many efforts to quantify shame and to explore hypothesized concomitants that may eventually be shown to be cause and effect relationships. As this is clarified through research and clinical observation, we can more clearly direct clinical interventions and broaden educational efforts to identify shame and work to reduce its malignancy.

One strength of this investigation is the large number of individuals who were surveyed. Structural equation modeling requires a large sample size in order to assure stability of the models, and the goal of a large sample was met. Similarly, many variables were included. Such a large, multivariate investigation has the advantage of 
examining a wide variety of variables in order to obtain a more accurate assessment of the phenomenon of shame. The results provide a large data bank, with comprehensive information on a variety of psychosocial variables important in the experience of the college-age individual.

This study also has the advantage of including variables that are both systemic and individually focused. In this sense, the general flow of the models postulated here represents the reality of development and experience. The importance of the family influence is taken into account, but the individual aspects are not ignored, in terms of their effect upon behavioral and developmental outcomes. The family functioning variables, while obviously seen retrospectively through the eyes of the individual, provide some indications of participants' perceptions of the atmosphere in which they grew up and came of age. The shame construct on the other hand, is a very individual construct, indeed a private one, taking into account an intensely personal, affective state/trait. Limitations of the Study

Methodological limitations have been discussed. Most relevant are issues regarding the operationalization of the constructs postulated for inquiry here. Specifically, as noted above, there is some empirical overlap between the ISS and the depression indices used here. This likely 
contributes to some colinearity and in turn an exaggeration of parameter estimates for the Depression model in particular. In addition, both the Risk-Taking Propensity and the Achievement Orientation constructs were more experimental in nature than the other three and thus not operationalized optimally. For both of these constructs, the final version, as determined by preliminary PCAs and theoretical considerations, were neutral in tone rather than in the direction of the maladaptive end of the spectrum (i.e., generic risk-taking instead of recklessness and achievement orientation rather than over-achievement).

In order to obtain such a large number of participants, a self-report, multiple-choice survey format was chosen. This methodology clearly has its drawbacks. Behavioral markers of the outcome variables would provide clarifying information and allow for more standardized (i.e., researcher-generated) data-gathering. Corroborating reports from individuals familiar with the respondents would also provide useful information, especially for such variables as substance use.

The conclusions regarding shame that can be drawn from this data are limited by the fact that it is cross-sectional. While structural modeling is a useful method to obtain theoretically error-free relationships among several latent constructs, especially mediational 
relationships, its greatest benefit derives from longitudinal investigations in which some inferences can be made regarding cause and effect. This study is limited to the exploration of the concomitants or correlates of shame, but it unable to delineate the process or reciprocal impact of shame and various psychosocial outcomes.

Finally, as is the case with the investigation of any broad construct such as shame, many variables were necessarily left out of consideration. For example, no other affective experiences aside from shame were considered as potential mediators between family functioning and the various outcomes. Nor were other contributing factors of the outcomes considered, such as availability of drugs and peer use for Substance Use, or situational factors for Depression or Suicide Ideation. Theoretical Implications

In an attempt to be parsimonious, theoretical and clinical approaches to human behavior often make the classic "either/or" error. For example, psychopathology is frequently simplistically and inappropriately relegated completely to the individual. This individualistic focus arises out of the medical model; witness the DSM-III-R, the nosological and diagnostic system for assessing mental illness most widely accepted and used by clinicians. Conversely, systemic thinkers view psychopathology as 
arising in the context of the family. Recently there have been more efforts at integrating these two approaches, both in terms of theory and intervention.

Object relations theory provides a good bridge between systemic and individual variables. For example, the ISS is based on "internalized" shame. "Internalized" is an object relations concept; those self/other object representations that we carry around with us, that are at our very core, derive from early, recurrent experiences of ourselves and significant others in the family setting. Several writers incorporate object relations into their ideas about shame (e.g., Kaufman, 1985, 1989; Morrison, 1989; Spero, 1984).

The point is that individuals are both self-contained and part of a system. A basic human dilemma is that of fitting the concept of self comfortably into the concept of other. Shame is a very good example of that overlap.

Shame is at once an acutely private phenomenon, but at the same time, is decidedly social as well. It is impossible to talk about the phenomenology of shame without at least implicitly taking into account the other, or the shadow of the other.

This dual nature of shame suggests that investigations regarding this construct, both theoretical and empirical, should take into account the individual (intrapsychic) and the interpersonal or systemic perspectives on shame. 


\section{Clinical Impiications}

Schecter (1979) commented, "There is no problem so great as the shame of it" (p. 377). And yet, as several authors have suggested, shame has been collectively underestimated in the clinical literature. Different hypotheses have been proposed to explain this phenomenon. Some believe (e.g., Lewis, 1987) that this is the legacy of Freud, who chose to pursue the study of guilt and its place in neurosis and who had little to say about shame. Others point to the nature of shame itself. Shame is a secretive emotion that involves painful feelings of inadequacy accompanied by the desire to hide. Moreover, there is a secondary shame - the shame about shame itself - that often prevents shame from being openly acknowledged. Both of these processes likely affect the extent to which shame is addressed in clinical settings. Taylor (1987) calls shame "the emotion of self-protection" (p. 81). Because it is inextricably linked with integrity and self-respect, it represents a fundamentally important clinical construct. Shapiro (1989) attests to the clinical importance of articulating subjective affective experience in reducing psychopathology. Shame is clearly central to this concept, as its secretive, self-protective aspects make it less amenable to direct exploration and clinical intervention. If so, how can such an important but often covert 
experience be illuminated in a clinically relevant way?

This research has several implications for clinical intervention strategies. First, the findings here suggest that shame is an important correlate of depression and suicide ideation for both women and men, and an important correlate of substance use for women. It would behoove clinicians to listen and look for shame when maladaptive behavior is evident and vice versa. For, with shame, more so than for any other of the negative affects, including guilt, there is no naturally occurring interpersonal process which can alleviate it. This makes clinical attention to shame all the more important; the clinician must be able and prepared to assist the client in coping with a feeling that may have no outlets in other relationships in the person's life. Furthermore, the clinician must be alert to masked expressions of shame, since it is not very likely that the individual will articulate directly the experience of shame. Does the student or client who presents to a university counseling center or other mental health clinic use terms that imply a felt sense of shame, such as: "embarrassment," "humiliation," feeling "foolish"? Do they avert their gaze, make poor eye contact, keep their head lowered, show excessive timidity? If these behavioral manifestations are present, is there also evidence of depressive affect or 
suicide ideation? What is the student's level of substance use? Important events in the individual's history should also be taken into account. The presence of shame may reveal clinically significant events/experiences in the family, which should also be inquired about.

\section{Future Research Directions}

One of the issues currently facing the shame literature is that of defining and differentiating this construct more precisely. That is, in the excitement of a new discovery, shame is being implicated in many psychopathological syndromes, from depression to personality disorders to psychotic disorders. Such broad usage dilutes the impact this construct can have on theory, research, and clinical interventions. It loses definition in a way similar to that of the humanistic psychotherapies; every good therapy is humanistic at root. In order for any construct to be useful, it must have discriminatory power. From what does shame arise? How is it manifested? Is there such a thing as a "shame-prone" identity? If so, what form do non-shame-prone identities take? Or is it simply dichotomous? Shame is an important construct, but it does not explain all of psychopathology or even the majority of the variance. Should shame be subsumed under our current nosological systems for psychopathology, or should we reorganize our systems (currently very individually, 
medical-model based) along affective lines?

It would be useful to delineate further the particular aspects of family functioning or dysfunctioning that contribute to maladaptive levels of shame in family members. One way of exploring this question would be to compare levels of shame in individuals across categories of hypothesized family dysfunctioning. Relevant categories might include alcoholic families or incestuous families, both of which are thought to produce high levels of shame in children who grow up in such environments. These could be compared to individuals who grew up in families where a divorce occurred or a parent died before the child reached adulthood. While levels of shame could certainly be higher in such individuals than for those who didn't have such experiences in their families, hypotheses regarding differential shame-proneness could be made based on current clinical conceptualizations.

Conversely, if there is a non-spurious relationship between shame and family functioning, it should be possible to classify individuals according to categories of family functioning, using methods such as discriminant function analysis or perhaps cluster analysis. Another important issue is criterion validity or the predictive value of knowing about an individual's level of shame. What can be predicted about an individual's behavior from his/her level 
of shame-proneness?

It was clear from the outset of this investigation that family functioning and shame would not account for all of the variance in any of the dependent variables. Future studies could expand on the theme examined here by evaluating additional independent and/or mediating variables. For example, several factors in substance use are known to be important determinants. These include: substance availability, and peer and family usage. In terms of psychopathology, it would be useful to include information about family history of mental illness. Values placed on risk-taking behaviors and achievement orientation both in the family and in the peer setting would be important information. It would be useful to explore how family functioning variables are correlated with other personality characteristics, such as hopefulness, self-efficacy, self-esteem.

The period of adolescence and young adulthood is an appropriate time in the life span to explore the phenomenon of shame, as it represents a self-conscious developmental phase. Because shame is ubiquitous, it could be usefully studied in any age group. Two others however, represent equally appropriate targets: young children and older adults. The advantage of studying shame in young children is that the developmental process is very accessible, and 
the young child expresses emotions in very direct fashion, with an emphasis on nonverbal ways. In older adults, the issues of declining bodily functioning are relevant, along with increased dependence on others (Spero, 1984). This could therefore also represent a productive developmental phase in which to explore shame.

In all developmental phases, cultural differences would be relevant dimensions of study as well. While shame is universal and innate, as with the other affects, its specific entrainment is culturally determined (Tomkins, 1987; Darwin, 1872/1965). Cross-cultural differences may affect the nature of the shame-psychopathology relationship.

The fact that significant results were obtained for these models in a nonclinical sample suggests that the framework hypothesized here has some validity. It could be reasonably hypothesized that the models might produce even stronger results in clinical populations, at least for the three maladaptive outcomes of substance use, depression, and suicide ideation. There are certain clinical populations that would be especially appropriate for an investigation about shame. The phenomonology of eating disorders includes shame about body image and often about the disorder itself, especially in bulimia. The literature on sexual abuse is replete with references to the 
survivors' experience of shame which often persists well into adulthood.

There are several ways in which longitudinal studies of shame could be devised. For example, participants could respond at two or more time points on the variables presented here. At Time 1 (perhaps at the start of freshman year), they could report on level of family functioning, shame, and various maladaptive and adaptive outcome variables. At Time 2 (perhaps at the end of the freshman year), they could again report on levels of shame and outcome variables. Shame could be examined in several areas, including academic, familial, and interpersonal functioning.

A more ideal conceptualization of this study would be to use a longitudinal design by measuring family functioning in childhood ( $\mathrm{T}$ ime 1 ), shame at $\mathrm{T} 1$ and $\mathrm{T} 2$, and maladaptive and adaptive outcomes at $\mathrm{T} 1$ and $\mathrm{T} 2$ (psychological functioning overall). There could be several additional time points at which these constructs could be measured. This would allow for exploration of the genesis of shame, its relationship to family functioning and personality development, and to strategies adopted to deal with shame. 


\section{Final Conclusions}

Shame is a construct that has persisted over boundaries of time and academic discipline. It is the province not only of psychologists but also of philosophers, biologists, anthropologists, and sociologists. Like other basic affects, it permeates all aspects of functioning either by its presence or its absence, and as such, represents a relevant construct for personal, clinical, and empirical exploration. It poses not only psychological/clinical questions, but also moral and sociologic ones.

In the various forums of pop psychology, we are continuously being exhorted to rid ourselves of shame and get in touch with our "inner child." On a cultural level, the role of shame is an important one. If we are indeed evolutionarily programmed to experience shame in the service of knowing our limitations and reminding us of the boundaries between ourselves and others, then perhaps the behavior of state and national legislators, bank presidents, and national political candidates can be seen as "shameless."

Several writers (Lansky, 1984; Kohut, 1977, Morrison, 1989) have made an explicit link between acts of violence with shame. Individual and/or group humiliation may spark a shame/rage spiral (Retzinger, 1989; Lewis, 1984, 1987) which, if left unchecked, can escalate out of control. 
Coleman (1985) takes this argument further and suggests that shame is an underlying factor not only in isolated acts of violence, but also in war. She contends that war is conducive to the expression of often unacknowledged feelings of rage and hostility in a socially-sanctioned forum. She hypothesizes that the ability to tolerate shaming is inversely related to an individual's potential for violence.

Differentiating between healthy and malignant shame is in part a value judgment, but it is incumbent on psychologists/ clinicians to examine its impact on behavior because that is our purview. We can do this without necessarily being the ones to make the value judgment, although we should be always cognizant of biases implicit in our work. If we choose not to however, either actively or passively, then we must shoulder part of the blame - and shame? - of misguided or incomplete knowledge about an important and basic aspect of human experience. 


\section{References}

Bentler, P. M. (1985). Theory and implementation of EQS, a structural equations program. Los Angeles: BMDP Statistical Software.

Bentler, P. M. (1988). Comparative fit indexes in structural models. Psychological Bulletin, in press.

Bentler, P. M. (1989). EQS: Structural Equations Program Manual. Los Angeles: BMDP Statistical Software.

Bentler, P. M., \& Bonett, D. G. (1980). Significance tests and goodness of $f i t$ in the analysis of covariance structures. Psychological Bulletin, 88, 588-606.

Bessai, J. L. (1977). The Common Beliefs Survey: a factored measure of irrational beliefs. Paper presented at the 2nd National Conference on Rational Psychotherapy, Chicago.

Broday, S. F. (1988a). Perfectionism and Millon basic personality patterns. Psychological Reports, 63, $791-794$.

Broday, S. F. (1988b). A shortened version of the Burns Perfectionism Scale. Psychological Reports, 62, 70.

Broucek, F. J. (1982). Shame and its relationship to early narcissistic developments. International Journal of Psycho-Analysis, 63, 369-378.

Broucek, F. J. (1991). Shame and the self. New York: Guilford Press.

Burns, D. D. (1980). The perfectionist's script for self-defeat. Psychology Today, 14, 34-52.

Burns, D. D. (1983). The spouse who is a perfectionist. Medical Aspects of Human Sexuality, 17, 219-230.

Campbell, F. A. (1984). The concept of shame. Perspectives in Psychiatric Care, 22, 62-64.

Chasseguet-Smirgel, J. (1985) . The ego ideal. New York: Norton.

Clapper, R. L. (1990). Adult and adolescent arousal preferences: The revised reducer-augmenter scale. Personality and Individual Differences, 11, 1115-1122. 
Cochran, C. D., \& Hale, W. D. (1985). College student norms on the Brief Symptom Inventory. Journal of Clinical Psychology, 41, 777-779.

Coleman, M. (1985). Shame: A powerful underlying factor in violence and war. Journal of Psychoanalytic Anthropology, 8, 67-79.

Cook, D. R. (1988, August). The measurement of shame: The Internalized Shame Scale. Paper presented at the meeting of the American Psychological Association, Atlanta, GA.

Cook, D. R. (1989). Internalized Shame Scale, Revised edition.

Corcoran, K., \& Fischer, J. (1987). Measures for clinical practice: A sourcebook. New York: Free Press.

Corulla, W. J. (1988). A further psychometric investigation of the Sensation Seeking Scale Form-V and its relationship to the EPQ-R and the I.7 Impulsiveness Questionnaire. Personality and Individual Differences, $\underline{9}$, 277-287.

Darwin, C. (1965). The expression of the emotions in man and animals. Chicago: University of Chicago Press. (Original work published 1872)

Derogatis, L. R. (1977). The SCL-90 Manual I: Scoring administration and procedures for the SCL-90. Baltimore: Johns Hopkins University School of Medicine, Clinical Psychometrics Unit.

Derogatis, L. R., \& Melisaratos, N. (1983). The Brief Symptom Inventory: An introductory report. Psychological Medicine, 13, 595-605.

Derogatis, L. R., \& Spencer, M. S. (1982). The Brief Symptom Inventory (BSI) Administration, Scoring, and Procedures Manual-I. Baltimore: Johns Hopkins University School of Medicine, Clinical Psychometrics Research Unit.

Erikson, E. H. (1950), Childhood and society. New York: Norton.

Fisher, S. F. (1985). Identity of two: The phenomenology of shame in borderline development and treatment.

Psychotherapy, 22, 101-109. 
Fitts, S. N. (1989). Relationships between measures of self-concept, existential variables, and maladaptive psychosocial outcomes in a college population. Unpublished master's thesis, University of Rhode Island, Kingston, RI.

Fitts, S. N., \& Harlow, L. L. (1989). Structural models of self-esteem, meaning in life, and maladaptive outcomes. Unpublished manuscript.

Freud, S. (1961). Civilization and its discontents. In J. Strachey (Ed. \& Trans.), The standard edition of the complete psychological works of Sigmund Freud (Vol. 21, pp. 64-145). London: Hogarth Press. (Original work published 1930)

Freud, S. (1964). New introductory lectures on psychoanalysis. In J. Strachey (Ed. and Trans.), The standard edition of the complete psychological works of Sigmund Freud (Vol, 22, pp. 3-183). London: Hogarth Press. (Original work published 1933)

Fossum, M. A., \& Mason, M. J. (1986). Facing shame: Families in recovery. New York: W. W. Norton \& Co.

Geppert, U. (1986, July). A coding system for analyzing behavioral expressions of self-evaluative emotions (technical manual). Paper presented at the International Conference on Human Ethology, Tutzing, West Germany.

Geppert, U., \& Heckhausen, H. (1988, December). Self-related and self-evaluative emotions: Embarrassment, shame, guilt, and pride. Paper present at the Conference on the Development of Shame and Guilt, Pacific Grove, CA.

Goldberg, C. (1991). Understanding shame. Northvale, NJ : Jason Aronson.

Gomberg, E. L. (1987). Shame and guilt issues among women alcoholics. Alcoholism treatment Quarterly, 4, 139-155.

Harlow, L. L. (1985). Behavior of some elliptical theory estimators with nonnormal data in a covariance structures framework: A Monte Carlo study. Unpublished doctoral dissertation, University of California, Los Angeles.

Harlow, L. L. (1987). Unpublished questionnaire and raw data, University of Rhode Island. 
Harlow, L. L. (1989). Unpublished questionnaire and raw data, University of Rhode Island.

Harlow, L. L., Newcomb, M. D., \& Bentler, P. M. (1986). Depression, self-derogation, substance use, and suicide ideation: lack of purpose in life as a mediational factor. Journal of Clinical Psychology, 42, 5-21.

Harlow, L. L., Newcomb, M. D., \& Bentler, P. M. (1987). Purpose in Life Test assessment using latent variable methods. British Journal of Clinical Psychology, 26 , 235-236.

Harlow, L. L., Quina, K., \& Morokoff, P. J. (1990, August). Predicting AIDS-Risking behaviors in young adults. Paper accepted for presentation at the annual meeting of the American Psychological Association, Boston, MA.

Hawkins, J. D., \& Hederhood, B. (1987). Handbook for Evaluating Drug and Alcohol Prevention Programs: Staff/Team Evaluation of Prevention Programs (STEPP). U.S. Department of Health and Human Services; Public Health Service; Alcohol, Drug Abuse, and Mental Health Administration, Rockville, MD.

Hayduk, L. A. (1987). Structural equation modeling with LISREL: Essentials and advances. Baltimore, MD: Johns Hopkins University.

Jackson, D. N. (1984). Personality research from manual: Third edition. New York: Research Psychologists Press.

James, W. (1983). The principles of psychology. Cambridge, MA: Harvard University Press. (Original work published $1890)$

James, L. R., Mulaik, S. A., \& Brett, J. M. (1982). Causal analysis: Assumptions, models, and data. Beverly Hills, CA: Sage Publications.

Jessor, R. (1969). General description of junior-senior high school questionnaire and its component measures. University of Colorado, Institute of Behavioral Science.

Johnson, R. C., Danko, G. P., Huang, Y., Park, J. Y., et al. (1987). Guilt, shame, and adjustment in three cultures. Personality \& Individual Differences, 8 , $357-364$. 
Johnston, L. D., O'Malley, P. M., \& Bachman, J. G. (1986). Drug use among American high school students, college students, and other young adults. Rockville, MD: National Institute on Drug Abuse.

Joreskog, K., \& Sorbom, D. (1986). LISREL: Analysis of linear structural relationships by the method of maximum likelihood. Mooresville, Indiana, Scientific Software, Inc.

Kaplan, H. B., Martin, S. S., \& Johnson, R. J. (1986). Self-rejection and the explanation of deviance:

Specification of the structure among latent constructs. American Journal of Sociology, 92, 384-411.

Kaufman, G. (1985). Shame: The power of caring. (2nd ed.). Cambridge, MA: Schenkman Books.

Kaufman, G. (1989). The psychology of shame: Theory and treatment of shame-based syndromes. New York: Springer Publishing.

Kohut, H. (1977). The restoration of the self. New York: International Universities Press.

Kolevson, M. S., \& Green, R. G. (1987). Family Awareness Scale. In K. Corcoran \& J. Fischer (Eds.), Measures for clinical practice: A sourcebook (pp. 436-439). New York: Free Press.

Lansky, M. R. (1984). Violence, shame, and the family. International Journal of Family Psychiatry, 5, 21-40.

Lewis, H. B. (1971). Shame and guilt in neurosis. Psychoanalytic Review, 58, 419-438.

Lewis, H. B. (1984). Freud and modern psychology: The social nature of humanity. Psychoanalytic Review, 11 , $7-26$.

Lewis, H. B. (1987). The role of shame in symptom formation. Hillsdale, NJ: The Analytic Press.

Linehan, M. M., Goldstein, J. L., Nielsen, S. L., \& Chiles, J.A. (1983). Reasons for staying alive when you are thinking of killing yourself: The Reasons for Living Inventory. Journal of Consulting and Clinical Psychology, 51, 276-286. 
Marsh, H. W., Balla, J. R., \& McDonald, R. P. (1988). Goodness-of-fit indexes in confirmatory factor analysis: The effect of sample size. Psychological Bulletin, 103, 391-410.

Morrison, A. P. (1989). Shame: The underside of narcissism. Hillsdale, NJ: The Analytic Press.

Naiditch, B. (1987). Rekindled spirit of a child: Intervention strategies for shame with eleemntary age children of alcoholics. Alcoholism Treatment Quarterly, 4, 57-69.

Nathanson, D. L. (Ed.). (1987). The many faces of shame. New York: Guilford Press.

Nielsen, L. A. (1987). Substance abuse, shame and professional boundaries and ethics: Disentangling the issues. Alcohoism Treatment Quarterly, $\underline{4}, 109-137$.

Nuttin, J. (1950). Intimacy and shame in the dynamic structure of personality. In M. Reynert (Ed.), Feelings and emotions (pp. 343-352). New York: McGraw-Hill.

Peterson, C. A. (1987). Review of the Brief Symptom Inventory. In Ninth Mental Measurements Yearbook.

Petrie, A. (1967). Individuality in pain and suffering. Chicago: University of Chicago Press.

Piers, G., \& Singer, M. B. (1971). Shame and guilt: A psychoanalytic and a cultural study. New York: W. W. Norton.

Potter-Efron, P. S. (1987). Creative approaches to shame and guilt: Helping the adult child of an alcoholic. Alcoholism Treatment Quarterly, 4, 39-56.

Presley, C., Harrold, R., Scouten, E., \& Lyerla, R. (1990). Core Pre/Pst Evaluation Instrument User's Manual. Fund for the Improvement of Post-secondary Education (FIPSE).

Radloff, L. S. (1977). The CES-D scale: A self-report depression scale for research in the general population. Applied Psychological Measurement, 1, 385-401.

Retzinger, S. M. (1987). Resentment and laughter: Video studies of the shame-rage spiral. In H. B. Lewis (Ed.), The role of shame in symptom formation (pp. 151-181). Hillsdale, NJ: Lawrence Erlbaum Associates. 
Retzinger, S. M. (1989a). A theory of mental illness:

Integrating social and emotional aspects. Psychiatry, $\underline{52}$, 325-335.

Retzinger, S. M. (1989b, August). The role of shame in marital conflict. Paper presented at the meeting of the Society for the Study of Social Problems, Berkeley, CA.

Schecter, D. (1979). The loving and persecuting superego. Contemporary Psychoanalysis, 15, 361-379.

Scheff, T. J. (1984). The taboo on coarse emotions. Review of Personality and Social Psychology, 5, 146-169.

Scheff, T. J. (1988). The deference-emotion system. American Sociological Review, 53, 395-406.

Severino, S. K., McNutt, E. R., \& Feder, S. L. (1987). Shame and the development of autonomy. Journal of the American Academy of Psychoanalysis, 15, 93-106.

Shapiro, D. (1989). Psychotherapy of neurotic character. New York: Basic Books.

Shreve, B. W., \& Kunkel. M. A. (1989, August). The role of shame in adolescent suicide: A self-psychological perspective. Paper presented at the meeting of the American Psychological Association, New Orleans, LA.

Shreve, B. W., \& Patton, M. J. (1988, Atlanta).

Shame-proneness among suicidal persons: Psychometric properties of the shame-proneness scale. Paper presented at the meeting of the American Psychological Association, Atlanta, GA.

Spero, M. H. (1984). Shame: An object-relational

formulation. The Psychoanalytic Study of the Child, 39 , $259-282$.

Stevenson, J. F. (1989). Unpublished questionnaire, University of Rhode Island.

Stierlin, H. (1974). Shame and guilt in family relations. Archives of General Psychiatry, 30, 381-389.

Tabachnick, B. G., \& Fidell, L. S. (1983). Using Multivariate Statistics. NY: Harper \& Row. 
Tabachnick, B. G., \& Fidell, L. S. (1989). Using Multivariate Statistics (2nd ed.). New York: Harper \& Row.

Tanaka, J. S. (1987). "How big is big enough?": Sample size and goodness of $\mathrm{fit}$ in strucutral equation models with latent variables. Child Development, 58, 134-146.

Tangney, J. P. (1988). Assessing individual differences in proneness to shame and guilt: Development of the salf-conscious affect and attribution inventory. Paper presented at the meeting of the Eastern Psychological Association, Buffalo, NY.

Tangney, J. P., Burgraff, S. A., Hamme, H., \& Domingos, B. (1988). Assessing individual differences in proneness to shame and guilt: The Self-Conscious Affect and Attribution Inventory. Poster presented at the meeting of the Eastern Psychological Association, Buffalo, NY.

Tangney, J. P., Wagner, P., \& Gramzow, R. (1989). The Self-Conscious Affect and Attribution Inventory Revised. George Mason University, Fairfax, VA.

Tavitian, M. L., Lubiner, J., Green, L., Grebstein, L. C., \& Velicer, W. F. (1987). Dimensions of family functioning. Journal of Social Behavior and Personality, 2, 191-204.

Taylor, G. (1987). Pride, shame, and guilt: Emotions of self-assessment. Oxford: Clarendon Press.

Tomkins, S. S. (1963). Affect/imagery/consciousness: II. The negative affects. New York: Springer.

Tomkins, S. S. (1987). Shame. In D. L. Nathanson (Ed.), The many faces of shame (pp. 133-161). New York: Guilford.

Tucker, L. R., \& Lewis, C. (1973). The reliability coefficient for maximum likelihood factor analysis. Psychometrika, 38, 1-10.

Wheaton, B., Muthen, B., Alwin, D., \& Summers, G. (1977). Assessing reliability and stability in panel models. In D. Heise (Ed.), Sociological Methodology 1977 (pp. 84-136). San Francisco: Jossey-Bass. 
Zuckerman, M., Eysenck, S. B. G., \& Eysenck, H. J. (1978). Sensation seeking in England and America: cross-cultural, age and sex comparisons. Journal of Consulting and Clinical Psychology, 46, 139-149.

Zung, W. W. K. (1974). Index of potential suicide. In A. T. Beck, H. L. P. Resnik, \& D. J. Lettieri (Eds.), The prediction of suicide. Bowie, MD: Charles Press. 


\title{
Informed Consent Statement
}

\author{
The University of Rhode Island \\ Department of Psychology \\ Chaffee Hall \\ Kingston, RI 02881
}

\section{Life Experiences Survey}

\section{Purpose of this project}

I understand that the purpose of this project is to gather information about various aspects of students' life experiences, including family background, emotions, personal attitudes, habits, and preferences.

\section{What my participation invol res}

I understand that $I$ an being asked to complete and return the enclosed questionnaire that contains questions about the areas mentioned above. I know that I should complete the survey as fully and honestly as possible.

This survey contains questions which pertain to sensitive issues. It may be beneficial to me to consider my feelings on these issues, but if answering the questions causes too much discomfort, I may discontinue filling out the survey at any time.

I understand that this survey should take about one and one half hours to complete.

Although there will be no direct benefit to me for taking part in this study, the researcher may learn more about how various aspects of individuals' experience are related to each other.

If I decide to take part in the study, I may quit at any time. Whatever I decide will in no way affect my grade in the course through which I an completing this survey, or my status at the University.

\section{Guarantee of confidentiality}

I understand that all information gathered in this study will be kept strictly confidential and anonymous. My name appears on this consent form only, and will be separated from the rest of the survey as soon as I have completed it. A code number has been assigned to the questionnaire for record-keeping purposes only. All answers will be tabulated, analyzed, and reported anonymously.

\section{If I have questions, complaints, or comments}

If I have any questions or comments, I understand that I may contact Sherri Nelson Fitts at (401) 792-4263 or Dr. Lisa Harlow at (401) 792-4242. If I am not satisfied with the way this study is performed, I may discuss my complaints with Ms. Fitts or Dr. Harlow, anonymously, if I choose.

\section{Certification of participation}

I have read and understood the above information, and myestions have been answered. My signature on this form means that I agree to participate in this study. 


\section{Appendix B}

\section{Index of Measures}

Miscellaneous Scales

1. Demographic Information (10 items)

2. Social Desirability Scale (20 items)

Family Functioning

1. Family Functioning Scale (FFS) ( 40 items)

2. Family Awareness Scales (FAS) (14 items)

3. Family Perceptions Scale (6 items)

4. Family Information portion of the ISS (9 items)

Shame

1. Internalized Shame Scale (ISS) (30 items)

2. Self-Conscious Affect and Attribution Inventory (SCAAIR) (65 items )

Substance Use

1. Alcohol Use ( 5 items)

2. Illicit Substance Use (9 items)

3. Alcohol- and Drug-Related Problems (17 items)

Depression

1. Center for Epidemiological Studies - Depression (CES-D) (20 items)

2. Brief Symptom Inventory (BSI) - Depression subscale (6 items)

\section{Suicide Ideation}

1. Suicide Ideation I (5 items)

2. Reasons for Living Inventory (RFL) - Suicidal and Coping Beliefs subscale ( 23 items)

Reckless Behaviors

1. AIDS-Risking Attitudes and Behaviors Scale (ARBAS) (22 items)

2. Sensation-Seeking Scale (SSS) - Form V (40 items)

3. Revised Reducer - Augmenter Scale (RRAS) (21 items)

Over-Achievement

1. Perfectionism Scale (10 items)

2. College Activities (10 items)

3. Personal Values Questionnaire - Academic Recognition (PVACR) (10 items) 


\section{Appendix C}

\section{Demographic Information}

1. Age at last birthday =
a. less than 20 years old
b. 20-22 years old
c. 23-25 years old
d. 26-30 years old
e. more than 30 years old

2. Sex
a. Male
b. Female

3. Religion
a. Catholic
b. Jewish
c. Protestant
d. Other
e. No religious affiliation

4. Academic Status
a. freshman
b. sophomore
c. junior
d. senior
e. non-matriculating student

5. Marital Status
a. single
b. single, living with intimate partner
c. married
d. divorced/separated
e. widowed

6. Primary ethnic or racial identification (check one)

a. Black/African-American

b. Hispanic

c. Oriental

d. White/Caucasian

e. Other

7. Residential status

a. living in campus housing (dorm/fraternity/sorority)

b. living with friend(s)/housemate(s) or intimate partner off-campus

c. living alone

d. living at home with the family in which you grew up e. other 
8. Annual family income
a. under 5,000
b. $5,000-15,000$
c. $15,000-30,000$
d. $30,000-50,000$
e. over 50,000

9. Your position in the family in which you grew up is:

a. first or oldest child

b. a middle child (not oldest or youngest)

c. youngest child

10. Which best describes the family in which you grew up for the majority of your childhood (0-18 years)?

a. intact family (birth parents remained married and are living together)

b. single parent family (living primarily with one parent)

c. reconstituted or blended family (parent you lived with remarried)

d. none of the above describe your family 


\section{Appendix D \\ Social Desirability Scale \\ Jackson, 1984}

For the items below, choose the most appropriate response from

the following alternatives. Do not mark "E" as an answer.

$A=$ definitely true

$B=$ probably true

C = probably false

$D=$ definitely false

1. I always try to be considerate of the feelings of my friends.

2. Nothing that happens to me makes much difference one way or the other.

3. I often take some responsibility for looking out for newcomers in a group.

4. I have a number of health problems.

5. In the long run, humanity will owe a lot more to the teacher than to the salesperson.

6. I often have the feeling that I am doing something evil.

7. I am seldom ill.

8. I almost always feel sleepy and lazy.

9. My memory is as good as other people's.

10. I am not willing to give up my own privacy or pleasure in order to help other people.

11. Most of my teachers were helpful.

12. We ought to let the rest of the world solve their own problems and just look out after ourselves.

13. My life is full of interesting activities.

14. I often question whether life is worthwhile.

15. I am able to make correct decisions on difficult questions.

16. I believe people tell lies any time it is to their advantage.

17. Rarely, if ever, has the sight of food made me ill.

18. I find it very difficult to concentrate.

19. I am always prepared to do what is expected of me.

20. Many things make me feel uneasy. 


\section{Appendix E \\ Family Functioning Scale \\ Tavitian, Lubiner, Green, Grebstein, \& Velicer (1987)}

For the items below, please use the following alternatives to express how you see the family in which you grew up.
$A=$ never
$B=$ rarely
$\mathrm{C}=$ sometimes
$D=$ frequently
$E=$ always

1. Birthdays were important events in my family.

2. The children in my family fought with each other.

3. People in my family had to be reminded when they were asked to do something.

4. People in my family did not care enough about what I needed.

5. Our family spent holidays together.

6. Members of my family argued about money.

7. My family accepted me as I am.

8. When someone in my family was angry, I felt worried.

9. People in my family listened when I spoke.

10. I worried when I disagreed with the opinions of other family members.

11. I felt respected by my family.

12. We paid attention to traditions in my family.

13. When things were not going well in my family I felt sick.

14. Our family celebrated special events, such as anniversaries and graduations.

15. People in my family hit each other.

16. When I had questions about personal relationships, I talked with family members.

17. I let my family know when I was sad.

18. It was important to know the mood of certain family members. 
19. It is hard for me to forget painful events that have happened in my family.

20. I let family members know when I felt upset.

21. People in my family discussed their problems with me.

22. People in my family used my things without asking me first.

23. In my family we talked about what is right and wrong with regard to sex.

24. People in my family yelled at each other.

25. Family members were critical of each other's eating habits.

26. When things were going wrong in my family, someone got blamed.

27. In my family we talked about the physical changes that go along with growing up.

28. I told people in my family when I was angry with them.

29. Family members ate at least one meal a day together.

30. My family saw me as a hopeless case.

31. Family reunions were important to us.

32. The mood of one family member could spread to everyone in the house.

33. I had trouble sleeping when I thought about family problems.

34. We were interested in the history of our family.

35. I felt loved by my family.

36. When things were not going well in my family it affected my appetite.

37. I felt like a stranger in my own home.

38. I let my family know when I felt afraid.

39. People in my family were not interested in what I did.

40. We were friendly with other families. 
Appendix F

Family Awarenesg Scale (FAS)

Kolevzon \& Green, 1985

PART I

Questions 1 and 2 each contain a group of statements that

describe families. For each question choose the statement that most accurately describes the family in which you grew up.

1. a. No one person was really strong enough to be the leader in our family.

b. Our family had one strong leader. The leader always made the rules and enforced them.

c. Although we had a strong leader, at times we talked over decisions.

d. We frequently talked things over, but in the end one person was usually in charge.

e. Leadership was always shared between the adults in our family depending on the situation.

2. a. In our family it seemed that a parent and a child were always "teaming or ganging" up against other family members.

b. Frequently a parent and a child teamed up against other family members.

c. The adults were usually on the same side, but they were not a strong team.

d. The adults were usually on the same side and generally they made a good learning team.

e. There was always a strong adult team in our family.

PART II

Questions 3 to 14 describe certain characteristics of all

families. Please choose the response that best describes your family.

3. How difficult was it for someone outside of your family to figure out which family members had power over other family members?
a. Very difficult
b. Somewhat difficult
c. Neither difficult nor easy
d. Somewhat easy
e. Very easy

4. How good a judge were individual family members of their own behavior within your family?

a. Very good judge

b. Somewhat good judge

c. Neither good nor poor judge

d. Somewhat poor judge

e. Very poor judge 
5. How good was your family at taking over and solving problems?

a. Very good

b. Somewhat good

c. Neither good nor bad

d. Somewhat bad

e. Very bad

6. How clearly did the members of your family tell one another about their feelings and thoughts?
a. Very clear
b. Somewhat clear
c. Neither clear nor unclear
d. Somewhat unclear
e. Very unclear

7. How frequently did the members of your family say or admit that they were responsible for their own past and present behavior?
a. Always
b. Frequently
c. Sometimes
d. Rarely
e. Never

8. How often did the members of your family speak for one another or act like they can read each other's minds?
a. Always
b. Frequently
c. Sometimes
d. Rarely
e. Never

9. How often were family members open and willing to listen to the statements of other family members?
a. Usually
b. Often
c. Sometimes
d. Rarely
e. Practically never

10. How often did family members share their feelings with one another?
a. Always
b. Frequently
c. Sometimes
d. Rarely
e. Never

11. How would you describe your family?

a. Very warm, humorous, and optimistic

b. Somewhat warm, humorous, and optimistic

c. Somewhat cynical, hopeless, pessimistic

d. Very cynical, hopeless, pessimistic 
12. How much conflict was there generally in you family?

a. Always

b. Frequently

c. Sometimes

d. Rarely

e. Never

13. How often were family members sensitive to, and understanding of, each others' feelings?

a. Always

b. Frequently

c. Sometimes

d. Rarely

e. Never

14. How many emotional problems did your family have compared to most families?

a. Far more

b. Somewhat more

c. About the same

d. Somewhat fewer

e. Far fewer 


\section{Appendix G \\ Family Perceptions Scale \\ Harlow, 1989}

For items 1 - 6, choose from the following responses to indicate how much each of the following statements applied to you while growing up. Do not mark "E" as an answer.
$A=$ rarely or none of the time
$B=$ some or a little of the time
$C=$ occasionally or a moderate amount of time
$\mathrm{D}=$ most or all of the time

1. I felt misunderstood and ignored by my parent(s).

2. My family was supportive of my choices.

3. My home environment had enough discipline and guidance.

4. There were times when my situation at home was unbearable.

5. There was a lot of emotional turmoil in my family.

6. I had a fairly happy childhood. 


\section{Family Information \\ adapted from Cook, 1989}

Below are a few questions about your family of origin experience. Please answer these questions as honestly as you can by checking the response category that is most accurate. (If you are not yet 18 years old, respond for the way things have been so far in your family, )

1. During the years before I was 18 , my father had or may have had an alcohol abuse problem.
a. very untrue
b. mostly untrue
c. mostly true
d. very true

2. During the years before I was 18, my mother had or may have had an alcohol abuse problem.
a. very untrue
b. mostly untrue
c. mostly true
d. very true

3. My father

a. died before I was 6 years old.

b. died when I was between the ages of 5 and 12 .

c. died when I was between the ages of 12 and 18 .

d. died when I was older than 18 .

e. is still living.

4. My mother

a. died before I was 6 years old.

b. died when I was between the ages of 5 and 12 .

c. died when I was between the ages of 12 and 18 .

d. died when I was older than 18 .

e. is still living.

5. My parents

a. divorced or permanently separated before I was 6 years old.

b. divorced or permanently separate when I was between the ages of 6 and 12 .

c. divorced or permanently separated when I was between the ages of 12 and 18 .

d. divorced or permanently separated when $I$ was older than 18.

e. are still married and living together. 
6. I have spent the following number of years living away from home because of difficulty with my family.

a. none; I have always lived with my family.

b. two - six months

c. 6 months to one year

d. one to three years

e. more than three years

7. I felt happy growing up in my family.

a. never

b. seldom

c. sometimes

d. frequently

e. almost always

8. I felt secure growing up in my family.

a. never

b. seldom

c. sometimes

d. frequently

e. almost always

9. I felt loved growing up in my family.
a. never
b. seldom
c. sometimes
d. frequently
e. almost always 


\section{Appendix I}

\section{Internalized Shame Scale (ISS)}

Use the scale below to indicate how much each of the following statements refers to you.
$A=$ never
$B=$ seldom
$\mathrm{C}=$ sometimes
$D=$ frequently
$E=$ almost always

1. I feel'like I am never quite good enough.

2. I feel somehow left out.

3. I think that people look down on me.

4. All in all, I am inclined to feel that I am a success.

5. I scold myself and put myself down.

6. I feel insecure about others' opinions of me.

7. Compared to other people, I feel like I somehow never measure up.

8. I see myself as being very small and insignificant.

9. I feel I have much to be proud of.

10. I feel intensely inadequate and full of self doubt.

11. I feel as if I am somehow defective as a person, like there is something basically wrong with me.

12. When I compare myself to others I am just not as important.

13. I have an overpowering fear that my faults will be revealed in front of others.

14. I feel I have a number of good qualities.

15. I see myself striving for perfection only to continually fall short.

16. I think others are able to see my defects.

17. I could beat myself over the head with a club when I make a mistake.

18. On the whole, I am satisfied with myself. 
19. I would like to shrink away when I make a mistake.

20. I replay painful events over and over in my mind until I am overwhelmed.

21. I feel I am a person of worth at least on an equal plane with others.

22. At times I feel like I will break into a thousand pieces.

23. I feel as if I have lost control over my body functions and my feelings.

24. Sometimes I feel no bigger than a pea.

25. At times I feel so exposed that I wish the earth would open up and swallow me.

26. I have this painful gap within me that I have not been able to fill.

27. I feel empty and unfulfilled.

28. I take a positive attitude toward myself.

29. My loneliness is more like emptiness.

30. I always feel like there is something missing. 


\section{Appendix J \\ Self-Conscious Affect and Attribution \\ Inventory - Revised (SCAAI-R) \\ Tangney, Wagner, \& Gramzow, 1989}

Below are 15 situations that people are likely to encounter in day-to-day life, followed by several common reactions to those situations. As you read each scenario, try to imagine yourself in that situation. Then indicate how likely you would be to react in each of the ways described. Please rate all responses because people may feel or react more than one way to the same situation, or they may react different ways at different times.

Please use the following alternatives to rate each response for the given situations.
$A=$ not likely
$B=$ maybe but probably not
$C=$ neither likely nor unlikely
$\mathrm{D}=$ somewhat likely
$E=$ very likely

Situation A: You make plans to meet a friend for lunch. At 5 o'clock, you realize you stood him up.

1. You would think: "I'm inconsiderate."

2. You would think: "Well, they'll understand."

3. You would try to make it up to him as soon as possible.

4. You would think: "My boss distracted me just before lunch."

Situation B: You break something at work and then hide it.

5. You would think: "This is making me anxious. I need to either fix it or get someone else to."

6. You would think about quitting.

7. You would think: "A lot of things aren't made very well these days."

8. You would think: "It was only an accident."

Situation C: You are out with friends one evening and you're feeling especially witty and attractive. Your best friend's spouse seems to particularly enjoy your company.

9. You would think: "I should have been aware of what my best friend is feeling."

10. You would feel happy with your appearance and personality.

11. You would feel pleased to have made such a good impression.

12. You would think your best friend should pay attention to his/her spouse.

13. You would probably avoid eye contact for a long time. 
Situation D: At work, you wait until the last minute to a project, and it turns out badly.

14. You would feel incompetent.

15. You would think: "There are never enough hours in the day."

16. You would feel: "I deserve to be reprimanded."

17. You would think: "What's done is done."

Situation E: You made a mistake at work and find out a co-worker is blamed for the error.

18. You would think the company did not like the co-worker.

19. You would think: "Life is not fair."

20. You would keep quiet and avoid the co-worker.

21. You would feel unhappy and eager to correct the situation.

Situation F: For several days you put off making a difficult phone call. At the last minute you make the call and are able to manipulate the conversation so that all goes well.

22. You would think: "I guess I'm more persuasive than I thought."

23. You would regret that you put it off.

24. You would feel like a coward.

25. You would think: "I did a good job."

26. You would think you shouldn't have to make calls you feel pressured into.

Situation G: You make a commitment to diet, but when you pass the bakery you buy a dozen donuts.

27. Next meal, you would eat celery to make up for it.

28. You would think: "They looked too good to pass by."

29. You would feel disgusted with your lack of will power and self-control.

30. You would think: "Once won't matter."

Situation H: While playing around, you throw a ball and it hits your friend in the face.

31. You would feel inadequate that you can't even throw a ball.

32. You would think maybe your friend needs more practice at catching .

33. You would think: "It was just an accident."

34. You would apologize and make sure your friend feels better.

Situation I: You have recently moved away from your family and everyone has been very helpful. A few times you needed to borrow money but you paid it back as soon as you could.

35. You would feel immature.

36. You would think: "I sure ran into some bad luck."

37. You would return the favor as quickly as you could.

38. You would think: "I am a trustworthy person."

39. You would be proud that you repaid your debts. 
Situation J: You are driving down the road and you hit a small animal.

40. You would think the animal shouldn't have been on the road.

41. You would think: "I'm terrible."

42. You would feel: "Well, it was an accident."

43. You would probably think it over several times wondering if you could have avoided it.

Situation $\mathrm{K}$ : You walk out of an exam thinking you did extremely well. Then you find out you did poorly.

44. You would think: "Well, it's just a test."

45. You would think: "The instructor doesn't like me."

46. You would think: "I should have studied harder."

47. You would feel stupid.

Situation L: You and a group of co-workers worked very hard on a project. Your boss singles you out for a bonus because the project was such a success.

48. You would feel the boss is rather short-sighted.

49. You would feel alone and apart from your colleagues.

50. You would feel your hard work had paid off.

51. You would feel competent and proud of yourself.

52. You would feel you should not accept it.

Situation M: While out with a group of friends, you make fun of a friend who's not there.

53. You would think: "It was all in fun; it's harmless."

54. You would feel small...like a rat.

55. You would think that perhaps that friend should have been there to defend himself/herself.

56. You would apologize and talk about that person's good points.

Situation N: You make a big mistake on an important project at work. People were depending on you and your boss criticizes you.

57. You would think your boss should have been more clear about what was expected of you.

58. You would feel like you wanted to hide.

59. You would think: "I should have recognized the problem and done a better job."

60. You would think: "Well, nobody's perfect." 
Situation Q: You volunteer to help with the local special Olympics for handicapped children. It turns out to be frustrating and time-consuming work. You think seriously about quitting, but then you see how happy the kids are.

61. You would feel selfish and you'd think you are basically lazy.

62. You would feel you were forced into doing something you did not want to do.

63. You would think: "I should be more concerned about people who are less fortunate."

64. You would feel great that you had helped others.

65. You would feel very satisfied with yourself. 


\author{
Appendix K \\ Alcohol Use \\ adapted from Stevenson, 1989; and Harlow, 1987
}

1. How often in the last 6 months have you had at least one

drink containing alcohol? (One drink is the equivalent of a can of beer, a glass of wine or a shot glass of liquor.)
$A=$ Never
$B=$ Once a month or less
$\mathrm{C}=$ Weekly
$\mathrm{D}=$ Twice weekly
$E=$ Daily

2. About how many drinks of alcohol do you have on those days when you drink alcohol?
$A=$ none - I don't drink alcohol
$B=1-2$ drinks
$\mathrm{C}=3-5$ drinks
$\mathrm{D}=6-10$ drinks
$E=$ more than 10 drinks

3. How often do you have three or more drinks on one occasion?
$A=$ Never
$B=1-2$ times/month
$\mathrm{C}=$ Weekly
$\mathrm{D}=$ Twice weekly
$E=$ Daily or almost daily

4. How often do you have six or more drinks on one occasion?
$A=$ Never
B $=1-2$ times/month
$\mathrm{C}=$ Weekly
D = Twice weekly
$E=$ Daily or almost daily

5. What is the maximum number of drinks you have had on a given occasion in the last six months?
$A=0$ drinks
$B=1-3$ drinks
$\mathrm{C}=4-8$ drinks
$\mathrm{D}=9-12$ drinks
$E=$ More than 12 drinks 


\section{Appendix L \\ Illicit Substance Use \\ adapted from Johnston, O'Malley, \& Bachman, 1986}

On how many occasions in the last six months (if any) have you used the following substances without a doctor's orders? Please use the scale below to rate your answers.
$A=$ Never
$B=$ Once a month or less
$\mathrm{C}=$ Weekly
$D=$ Twice weekly
$E=$ Daily

1. Marijuana (grass, pot) or hashish (hash, hash oil)

2. Cocaine (coke, crack, rock)

3. LSD or other psychedelic drugs (mescaline, peyote, psilocybin, PCP)

4. Amphetamines (uppers, ups, speed, bennies, dexies, pep pills, diet pills) (not including over-the-counter diet pills like Dexetrim or stay-awake pills such as No-Doz)

5. Quaaludes (quads, soapers, methaqualone)

6. Barbituates (downs, downers, goofballs, yellows, reds, blues, rainbows )

7. Tranquilizers (Librium, Valium, Miltown)

8. Heroin (smack, horse, skag) or other narcotics (methadone, opium, morphine, codeine, demerol, paregoric, talwin, laudunum)

9. Sniffed glue, breathed the contents of aerosol spray cans, or inhaled any other gases or sprays in order to get high 


\section{Appendix}

\section{Alcohol- and Drug-Related Problems \\ adapted from Presley, Harrold, Scouten, \& Lyerla, 1990}

Please indicate how often you have experienced the following due to your drinking or drug use during the last six months. Use the following scale to rate your responses.
$A=$ Never
$\mathrm{B}=$ Once
$\mathrm{C}=2$ or 3 times
$D=4-6$ times
$E=$ more $\operatorname{than} 6$ times

1. Had a hangover

2. Performed poorly on a test or important project

3. Been in trouble with police, residence hall, or other college authorities

4. Damaged property, pulled fire alarm, etc.

5. Got into an argument or a fight

6. Got nauseated or vomiled

7. Driven a car while under the influence

8. Missed a class

9. Been criticized by someone I know

10. Thought I might have a drinking or other drug problem

11. Had a memory loss

12. Done something I later regretted

13. Been arrested for DWI/DUI

14. Have been taken advantage of sexually or have taken advantage of another sexually

15. Tried unsuccessfully to stop using

16. Thought about or tried to commit suicide

17. Been hurt or injured 


\section{Appendix $\mathrm{N}$}

\section{Center for Epidemiologic Studies - Depression Scale (CES-D) \\ Radloff, 1977}

For the following items, please indicate how often each pertained to you in the last 6 months using the following alternatives. Do not mark "E" as an answer.
$A=$ Rarely or none of the time
$B=$ Some or a little of the time
$C$ = Occasionally or a moderate amount of time
$D=$ Most or all of the time

1. I was bothered by things that usually don't bother me.

2. I did not feel like eating; my appetite was poor.

3. I felt that I could not shake off the blues even with help from my family or friends.

4. I felt that I was just as good as other people.

5. I had trouble keeping my mind on what I was doing.

6. I felt depressed.

7. I felt that everything I did was an effort.

8. I felt hopeful about the future.

9. I thought my life had been a failure.

10. I felt fearful.

11. My sleep was restless.

12. I was happy.

13. I talked less than usual.

14. I felt lonely.

15. People were unfriendly.

16. I enjoyed life.

17. I had crying spells.

18. I felt sad.

19. I felt that people disliked me.

20. I could not get "going". 


\section{Appendix 0 \\ Brief Symptor Inventory \\ Derogatis, 1975}

(Note: The entire BSI is being included in the survey for the purposes of future research on the relationship between shame and psychological symptoms. However, for the dissertation, only the depression subscale will be used in the analyses. This subscale is comprised of items $9,16,17,18,35$, and 50. )

Please use the following alternatives to indicate how much discomfort each problem has caused you during the past week including today.
$A=$ not at all
$B=a$ little bit
$\mathrm{C}=$ moderately
D = quite a bit
$E=$ extremely

1. Nervousness or shakiness inside.

2. Faintness or dizziness.

3. The idea that someone else can control your thoughts.

4. Feeling others are to blame for most of your troubles.

5. Trouble remembering things.

6. Feeling easily annoyed or irritated.

7. Pains in heart or chest.

8. Feeling afraid of open spaces.

9. Thoughts of ending your life.

10. Feeling that most people cannot be trusted.

11. Poor appetite.

12. Suddenly scared for no reason.

13. Temper outbursts that you could not control.

14. Feeling lonely even when you are with people.

15. Feeling blocked in getting things done.

16. Feeling lonely.

17. Feeling blue. 
18. Feeling no interest in things.

19. Feeling fearful.

20. Your feelings being easily hurt.

21. Feeling that people are unfriendly or dislike you.

22. Feeling inferior to others.

23. Nausea or upset stomach.

24. Feeling that you are watched or talked about by others.

25. Trouble falling asleep.

26. Having to check and double check what you do.

27. Difficulty making decisions.

28. Feeling afraid to travel on buses, subways, or trains.

29. Trouble getting your breath.

30. Hot or cold spells.

31. Having to avoid certain things, places, or activities because they frighten you.

32. Your mind going blank.

33. Numbness or tingling parts of your body.

34. The idea that you should be punished for your sins.

35. Feeling hopeless about the future.

36. Trouble concentrating.

37. Feeling weak in parts of your body.

38. Feeling tense or keyed up.

39. Thoughts of death or dying.

40. Having urges to beat, injure, of harm someone.

41. Having urges to break or smash things.

42. Feeling very self-conscious with others.

43. Feeling uneasy in crowds.

44. Never feeling close to another person. 
45. Spells of terror or panic.

46. Getting into frequent arguments.

47. Feeling nervous when you are left alone.

48. Others not giving you proper credit for your accomplishments.

49. Feeling so restless you couldn't sit still.

50. Feelings of worthlessness.

51. Feeling that people will take advantage of you if you let them.

52. Feelings of guilt.

53. The idea that something is wrong with your mind. 


\section{Suicide Ideation Index \\ adapted from Zung, 1974; and Harlow et al., 1986}

For the following items, indicate how frequently each experience has occurred in the last six months using the following scale.

$$
\begin{aligned}
& A=\text { Never } \\
& B=\text { Rarely } \\
& C=\text { Sometimes } \\
& D=\text { Often } \\
& E=\text { Always }
\end{aligned}
$$

1. I have been thinking about ways to kill myself.

2. I have had recent thoughts about dying.

3. I have told someone I want to kill myself.

4. I imagined my life would end with suicide.

5. I have made attempts to kill myself. 


\section{Appendix Q \\ Reasons for Living Inventory (RFL) - \\ Suicidal and Coping Beliefs Subscale \\ Linehan, Goldstein, Nielsen, \& Chiles, 1983}

Many people have thought of suicide at least once. Others have never considered it. Whether you have considered it or not, we are interested in the reasons you would have for not committing suicide if the thought were to occur to you or if someone were to suggest it to you.

Each reason given below can be rated from 1 (Not at all important) to 4 (Extremely important). If a reason does not apply to you or if you do not believe the statement is true, then it is not likely important and you should put a 1 .

Even if you have never considered suicide or firmly believe you never would seriously consider killing yourself, it is still important that you rate each reason. In this case, rate on the basis of why killing yourself is not or would never be an alternative for you.

Use the following scale to rate the importance to you of each statement for not killing yourself. Do not mark "E" as an answer.
$A=$ Not at all important
$B=$ Somewhat unimportant
$\mathrm{C}=$ Somewhat important
$\mathrm{D}=$ Extremely important

1. I care enough about myself to live.

2. I believe I can find other solutions to my problems.

3. I still have many things left to do.

4. I have hope that things will improve and the future will be happier.

5. I have the courage to face life.

6. I want to experience all that life has to offer and there are many experiences I haven't had yet which I want to have.

7. I believe everything has a way of working out for the best.

8. I believe I can find a purpose in life, a reason to live.

9. I have a love of life.

10. No matter how badly I feel, I know that it will not last.

11. Life is too beautiful and precious to end it. 
12. I am happy and content with my life.

13. I am curious about what will happen in the iuture.

14. I see no reason to hurry death along.

15. I believe I can learn to adjust or cope with my problems.

16. I believe killing myself would not really accomplish or solve anything.

17. I have a desire to live.

18. I an too stable to kill myself.

19. I have future plans I am looking forward to carrying out.

20. I do not believe that things get miserable or hopeless enough that I would rather be dead.

21. I do not want to die.

22. Life is all we have and is better than nothing.

23. I believe I have control over my life and destiny. 


\section{Appendix R}

\section{AIDS-Rigking Behaviors \& Attitudes Scale (ARBAS) \\ Harlow, Quina, \& Morokoff, 1990}

For each of the statements listed below, choose the most appropriate response from the following alternatives. Do not mark " $E$ " as an answer.
$A=$ definitely true
$B=$ probably true
$\mathrm{C}=$ probably false
$D=$ definitely false

1. I feel that I am currently at some risk of getting AIDS.

2. The thought of getting AIDS does not worry me.

3. I know someone who was diagnosed as having the AIDS virus.

4. Someone that I know has died from AIDS.

5. I believe that I can take steps to help prevent myself from getting AIDS.

6. I sometimes suspect that I may have been exposed to AIDS.

7. I am fairly selective of my sexual partner(s).

8. I am cautious and careful about not getting myself into situations that could lead to getting the AIDS virus.

9. I am currently abstaining from sexual intercourse.

10. When engaging in sexual intercourse, I (would) use condoms.

11. I have had intercourse with someone in the last ten years who could possibly have put me at risk for AIDS.

12. I have had sex with a bisexual partner in the last ten years.

13. I (would) make it a point to ask questions about my partner's sexual history.

14. I have used needles to inject drugs.

15. I have had sex with someone who has used needles to inject drugs.

16. I often have sex with someone after using alcohol or drugs.

17. I have had anal sex.

18. I have had sex with a person with hemophilia. 
19. I have had a blood transfusion between 1978 and 1985 .

20. I have had sexual intercourse with several partners in the last ten years.

21. I know someone who has been tested to see if they had the AIDS virus.

22. One or more of my close friends is engaged in a lifestyle that could put them at risk for AIDS. 


\title{
Appendix $S$
}

\author{
Sensation Seeking Scale - Forr V \\ Zuckerman, Eysenck, \& Eysenck, 1978
}

The following items contain two choices, A and B. Please

indicate on your answer sheet which of the choices most describes your likes or the way you feel. In some cases you may find items in which you do not like either choice. In these cases mark the choice you dislike least.

1. a. I like "wild" uninhibited parties.

b. I prefer quiet parties with good conversation.

2. a. There are some movits I enjoy seeing a second or even a third time.

b. I can't stand watching a movie that I've seen before.

3. a. I often wish I could be a mountain climber.

b. I can't understand people who risk their necks climbing mountains.

4. a. I dislike all body odors.

b. I like some of the earthy body smells.

5. a. I get bored seeing the same old faces.

b. I like the comfortable familiarity of everyday friends.

6. a. I like to explore a strange city or section of town by myself, even if it means getting lost.

b. I prefer a guide when I am in a place I don't know well.

7. a. I dislike people who do or say things just to shock or upset others.

b. When you can predict almost everything a person will do and say he or she must be a bore.

8. a. I usually don't enjoy a movie or play where I can predict what will happen in advance.

b. I don't mind watching a movie or play where I can predict what will happen in advance.

9. a. I have tried marijuana or would like to.

b. I would never smoke marijuana.

10. a. I would not like to try any drug which might produce strange and dangerous effects on me.

b. I would like to try some of the new drugs that produce hallucinations.

11. a. A sensible person avoids activities that are dangerous.

b. I sometimes like to do things that are a little frightening. 
12. a. I dislike "swingers."

b. I enjoy the company of real "swingers."

13. a. I find that stimulants make me uncomfortable.

b. I often like to get high (drinking liquor or smoking marijuana).

14. a. I like to try new foods that I have never tasted before.

b. I order the dishes with which I am familiar, so as to avoid disappointment and unpleasantness.

15. a. I enjoy looking at home movies or travel slides.

b. Looking at someone's home movies or travel slides bores me tremendously.

16. a. I would like to take up the sport of water skiing.

b. I would not like to take up water skiing.

17. a. I would like to try surfboard riding.

b. I would not like to try surfboard riding.

18. a. I would like to take off on a trip with no preplanned or definite routes, or timetable.

b. When I go on a trip I like to plan my route and timetable fairly carefully.

19. a. I prefer the "down to earth" kinds of people as friends.

b. I would like to make friends in some of the "far out" groups like artists or "hippies."

20. a. I would not like to learn to fly an airplane.

b. I would like to learn to fly an airplane.

21. a. I prefer the surface of the water to the depths.

b. I would like to go scuba diving.

22. a. I would like to meet some people who are homosexual (men or women).

b. I stay away from people I suspect of being "queer."

23. a. I would like to try parachute jumping.

b. I would never want to try jumping out of a plane with or without a parachute.

24. a. I prefer friends who are excitingly unpredictable.

b. I prefer friends who are reliable and predictable.

25. a. I am not interested in experience for its own sake.

b. I like to have new and exciting experiences and sensations even if they are a little frightening, unconventional or illegal. 
26. a. The essence of good art is in its clarity, symmetry of form and harmony of colors.

b. I often find beauty in the "clashing" colors and irregular forms of modern paintings.

27. a. I enjoy spending time in the familiar surroundings of my home.

b. I get very restless if I have to stay around home for any length of time.

28. a. I like to dive off the high board.

b. I don't like the feeling I get standing on the high board (or I don't go near it at all).

29. a. I like to date people who are physically exciting.

b. I like to date people who share my values.

30. a. Heavy drinking usually ruins a party because some people get loud and boisterous.

b. Keeping the drinks full is the key to a good party.

31. a. The worst social sin is to be rude.

b. The worst social sin is to be a bore.

32. a. A person should have considerable sexual experience before marriage.

b. It's better if two married persons begin their sexual experience with each other.

33. a. Even if I had the money I would not care to associate with flighty rich persons like those in the fast lane."

b. I could conceive of myself seeking pleasures around the world with the "fast lane."

34. a. I like people who are sharp and witty even if they do sometimes insult others.

b. I dislike people who have their fun at the expense of hurting the feelings of others.

35. a. There is altogether too much portrayal of sex in movies.

b. I enjoy watching many of the "sexy" scenes in movies.

36. a. I feel best after taking a couple of drinks.

b. Something is wrong with people who need liquor to feel good.

37. a. People should dress according to some standard of taste, neatness, and style.

b. People should dress in individual ways even if the effects are sometimes strange.

38. a. Sailing long distances in small sailing crafts is foolhardy.

b. I would like to sail a long distance in a small but seaworthy sailing craft. 
39. a. I have no patience with dull or boring persons.

b. I find something interesting in almost every person I talk to.

40. a. Skiing down a high mountain slope is a good way to end up on crutches.

b. I think I would enjoy the sensations of skiing very fast down a high mountain slope. 
Revised Reducer - Augmenter Scale

(Clapper, 1990)

The items below show events and feelings people have. For each pair of events, choose the letter of the response that best tells how you feel.

\section{Examples:}
watch TV
A
B
C D
read a book

The circle around the $D$ shows the person would want to read a book much more than watch TV.
tennis
A
B
C D
baseball

The circle around the $B$ shows the person would want to play tennis a little more than baseball.

Please do not circle the responses on the survey. The examples above are included to show you how the response key works. For each item, fill in the appropriate circle on your answer sheet. Do not mark "E" as an answer.

1. see a fast action movie A B C D see a comedy movie

2. fast blues music

A B C D easy listening music

3. stereo on too loud

A B C D stereo on too soft

4. have many pets

A B C D have one pet

5. play hard contact sports A B C D play sports with little contact

6. get much exercise

A $\quad$ B $\quad C \quad$ D get a little exercise

7. hard rock music

A B C D pop rock music

8. electric guitar solo

A B C D nonelectric guitar solo

9. excitement

A B C D calm

10. be with a crowd

A B C D be alone

11. fast games

A B C D slow games

12. a drum solo

A B C D

a flute solo

13. loud music

A B C D quiet music

14. like sports

A. B C D dislike sports

15. a hard and fast dance beat

$A$ B C D a soft and slow dance beat 
16. crunchy foods

17. drive fast

18. watch football

19. large family

20. be the leader of a group

21. body odors are bad
A B C D soft foods

A B C D drive slow

A B C D watch baseball

A B C D small family

be a small part in a big group

A B C D body odors are good 


\section{Appendix U}

\section{Perfectionism Scale \\ Burns, 1980,1983}

Use the following scale to indicate the amount of agreement or disagreement you have with each of the statements listed below.
$A=I$ disagree strongly
$B=I$ disagree slightly
$C=I$ feel neutral about this
$\mathrm{D}=\mathrm{I}$ agree somewhat
$E=I$ agree very much

1. If I don't set the highest standards for myself, I am likely to end up a second rate person.

2. People will probably think less of me if I make a mistake.

3. If I cannot do something really well, there is little point in doing it at all.

4. I should be upset if I make a mistake.

5. If I try hard enough, I should be able to excel at anything I attempt.

6. It is shameful for me to display weaknesses or foolish behavior.

7. I shouldn't have to repeat the same mistake many times.

8. An average performance is bound to be unsatisfying to me.

9. Failing at something means I'm less of a person.

10. If I scold myself for failing to Iive up to my expectations, it will help me to do better in the future. 


\section{Appendix V}

\section{Colleg Activities}

Fitts, 1990

1. What is your GPA? (If you are a first-semester freshman, use your final high school GPA.)
a. under 1.00
b. $1.00-2.00$
c. $2.01-3.00$
d. $3.01-3.50$
e. $3.51-4.00$

2. How many credit hours are you taking this semester?
a. less than 9
b. $9-12$
c. $13-15$
d. $16-18$
e. more than 18

3. How many hours per week do you spend in a paying job?
a. less than 10
b. $10-15$
c. $16-20$
d. $21-30$
e. more than 30

4. How many hours per week do you spend participating in (formal) social organizations (e.g., fraternities, sororities)?
a. less than 3
b. 3 - 5 hours
c. 6 - 10 hours
d. more than 10 hours

5. How many hours per week do you spend participating in organized athletic teams (intramurals or varsity-level sports)?
a. less than 3
b. 3 - 5 hours
c. 6 - 10 hours
d. more than 10 hours

6. How many hours per week do you spend participating in political organizations?
a. less than 3
b. 3 - 5 hours
c. 6 - 10 hours
d. more than 10 hours 
7. How many hours per week do you spend particiapting in religious organizations?
a. less than 3
b. 3 - 5 hours
c. 6 - 10 hours
d. more than 10 hours

8. How many hours per week do you spend participating in academic organizations, excluding class time (e.g., honor societies)?
a. less than 3 hours
b. 3 - 5 hours
c. $6-10$ hours
d. more than 10 hours

9. How many hours per week do you spend participating in volunteer organizations?
a. less than 3 hours
b. $3-5$ hours
c. 6 - 10 hours
d. more than 10 hours

10. What percentage of your education have you paid for this year?
a. 0 percent
b. 25 percent
c. 50 percent
d. 75 percent
e. 100 percent 


\section{Appendix $W$ \\ Personal Values Questionnaire - Academic Recognition \\ (Jessor, 1969)}

For the items below, choose the most appropriate response from

the following alternatives.
$A=$ Neither like nor dislike
$B=$ Like a little bit
C = Like moderately
$D=$ Like a fair amount
$E=$ Like very much

1. How strongly would you like to get at least a $B$ average this year?

2. How strongly do you like to understand new material quickly in class?

3. How strongly would you like to have good enough grades to go on to graduate school if you want to?

4. How strongly do you like to come out near the top of the class on course exams?

5. How strongly do you like to be thought of as a good student by the other students?

6. How strongly do you like to do well in the more difficult courses here?

7. How strongly do you like to be able to get my ideas across clearly in class discussions?

8. How strongly do you like to be on the Dean's list each semester because of good grades?

9. How strongly do you like to be able to answer other students' questions about school work?

10. How strongly do you like to be considered a bright student by your instructors? 
Table 1

Description of Sample

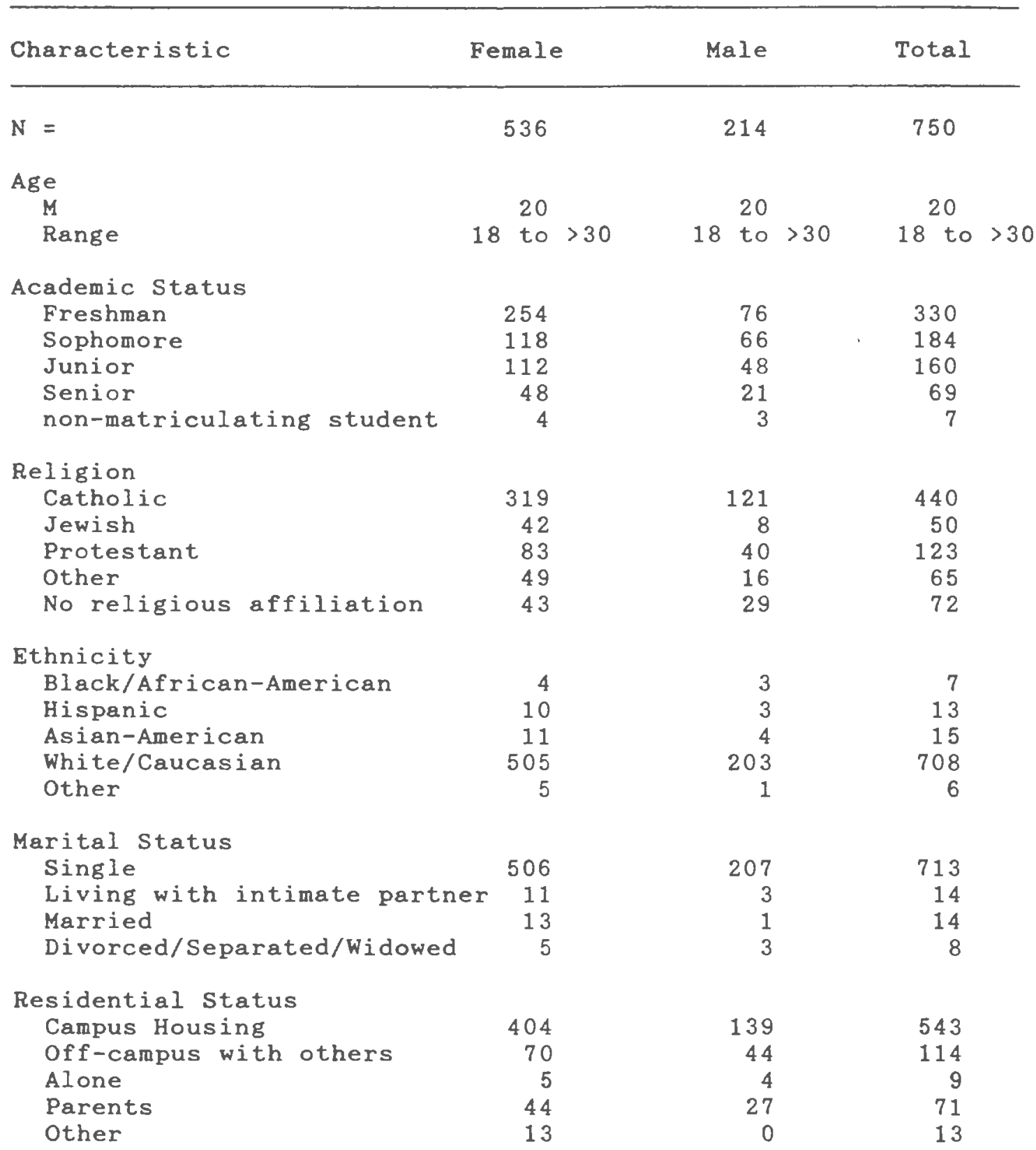


Table 1 (continued)

Characteristic

Annual Family Income

$$
\begin{aligned}
& <\$ 5000 \\
& \$ 5000-\$ 15000 \\
& \$ 15000-\$ 30000 \\
& \$ 30000-\$ 50000 \\
& >\$ 50000
\end{aligned}
$$

Birth Order

Oldest/only child Middle child

Youngest child

Family of Origin Type

Intact

Single Parent

Reconstituted/Blended

Other
Female

Male

Total

201

100

234

407

61

42

25
15

35

106

217

369

64

108

287

141

321
575

168
19

80

$\begin{array}{ll}19 & 80 \\ 11 & 36\end{array}$

$11 \quad 36$


Table 2

ISS Internal Consistency and Factorial structure

\begin{tabular}{|c|c|c|c|c|}
\hline Variable & $\begin{array}{r}\# \text { of } \\
\text { Items }\end{array}$ & $\begin{array}{c}\text { Chronbach's } \\
\text { Alpha }\end{array}$ & $\begin{array}{c}\text { \# of } \\
\text { Factors }\end{array}$ & $\begin{array}{l}\text { Variance } \\
\text { Accntd For }\end{array}$ \\
\hline Total Scale & 30 & .96 & $3-4$ & $.57-.64$ \\
\hline \multicolumn{5}{|l|}{ Subscales } \\
\hline Shame & 24 & .95 & 1 & .48 \\
\hline Failure & 15 & .93 & 1 & .51 \\
\hline Alienation & 9 & .91 & 1 & .58 \\
\hline Self-Esteem & 6 & .88 & 1 & .63 \\
\hline
\end{tabular}


Table 3

Convergent/divergent validity of the ISS and SCAAIR

Using Pearson Correlation Coefficients

ISS

SCAAIR

Correlation between ISS and SCAAIR

$.48 * * *$

Correlation with:

Depression

CESD

$.73 * * *$

$.34 * * *$

BSIDEP

$.73 * * *$

$.32 * * *$

Self-Esteem

ISS S-E subscale

$-.69 * * *$

$-.30 * * *$

Suicide Ideation

SUIC

RFLSCB

$\begin{array}{rl}.39 * * * & .09 * \\ -.31 * * * & .01\end{array}$

Social Desirability

$.48 * * *$

$.15 * * *$

$* \mathrm{p}<.05 . * * * \mathrm{p}<.001$.

Note: ISS refers to the 24 shame items.

SCAAIR refers to the 15 shame items. 
Table 4

SCAAIR Internal Consistency and Factorial structure

\begin{tabular}{lcccc} 
Variable & $\begin{array}{c}\text { \# of } \\
\text { Items }\end{array}$ & $\begin{array}{c}\text { Chronbach's } \\
\text { Alpha }\end{array}$ & $\begin{array}{c}\# \text { of } \\
\text { Factors }\end{array}$ & $\begin{array}{c}\text { Variance } \\
\text { Accntd For }\end{array}$ \\
$\begin{array}{l}\text { Total Scale } \\
\text { Subscales }\end{array}$ & 65 & .81 & $8-9$ & $.37-.39$ \\
$\quad$ Shame-Proneness & 15 & .71 & $3-4$ & $.38-.45$ \\
Guilt-Proneness & 15 & .76 & $3-4$ & $.40-.46$ \\
Externatization & 15 & .62 & $4-5$ & $.41-.48$ \\
Detachment/Unconcern & 10 & .58 & $3-4$ & $.44-.54$ \\
Alpha Pride & 5 & .53 & $1-2$ & $.35-.54$ \\
Beta Pride & 5 & .60 & $1-2$ & $.39-.57$ \\
\hline
\end{tabular}


Table 5

Summary Statistics and Mean Sex Differences for all Observed Variables

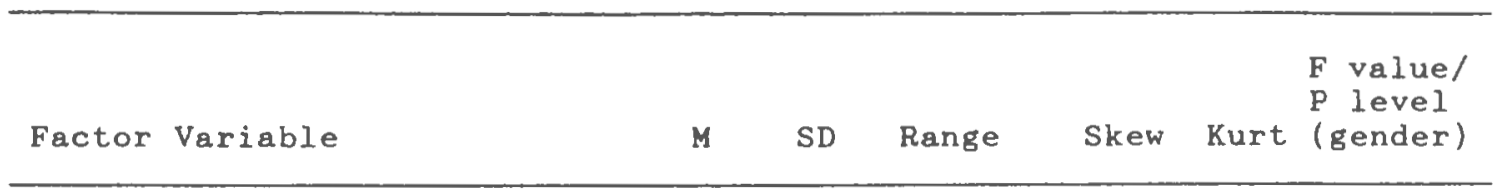

I. Family Functioning (FAM FNG)

1. FFS: Pos. Family Affect (FFSPFA)

Total Sample (750)

4.28

4.34

.68

$1.4-5.0$

$-1.22$

1.27

Men (214)

4.14

.73

$1.4-5.0$

$-1.44 \quad 2.32$

$2.3-5.0-.80-.25$

2. FFS: Conflicts (FFS CON)

Total Sample

Women

3.30

.57

$1.3-4.8$

$-.48$

3.29

.57

$1.3-4$.

$-.48$

.27

3.32

$1.4-4$.

.16

.53

3. Family Awareness Scales (FAS COM)

Total Sample

Women

Men

$3.54 \quad .79$

3.57

79
.81

$1.0-5$.

$-.55-.19$

3.47

.73

$1.0-5.0$

$-.61$

4. Family Perceptions Scale (FPS)

Total Sample

Women

3.33

3.36

.61

$1.0-4.0$

Men

3.27

.63

$1.5-4$.

$-1.00$

.61

$\begin{array}{ll}-1.14 & 1.09\end{array}$

$-.69-.31$

II. Shame (SHAME)

1. ISS: Failure (ISSF)

Total Sample

Women

Men

2.33

2.37

.80

$1 \cdot 0-4 \cdot 9$

.66

2.21

.73

$1.0-4 \cdot 9$

.73

.26
.32

$.31-.50$

2. ISS: Alienation (ISSA)

Total Sample

Women

2.1

2.17

.87

$1.0-5 \cdot 0$

.7

2.07

.86

.88

$1.0-5.0$

.78

.41
-.30

III. Substance Use (DRUGS)

1. Alcohol (ETOH)

Total Sample

Women

Men

$$
\begin{array}{lrrrr}
2.79 & .92 & 1.0-5.0 & -.03 & -.64 \\
2.68 & .85 & 1.0-5.0 & .03 & -.60 \\
3.07 & 1.03 & 1.0-5.0 & -.041 & -.57
\end{array}
$$

2. Marijuana (POT)

Total Sample

Women

1.59 .85

$1.0-5.0$

1.86

3. 94

1.47 .68

1. $0-5.0$

1.73

4.38

1.871 .12

1. $0-5.0$

$1.37 \quad 1.09$
$12.87 * *$

2.15

2.47

$6.33 *$

.78

$31.17 * * *$

$36,90 * * *$ 
Table 5 (continued)

F value/

$P$ level

Factor Variable $M$ SD Range Skew Kurt (gender)

3. Drug Problems I (DRUGPROB1)

Total Sample

Women

Men

4. Drugs (DRUGS)

Total Sample

Women

Men

4. Drugs (Log) (DRUGSL)

Total Sample

Women

Men
$2.25 \quad .86$

2.20

2.37

$1.11 .37 \quad 1.0-4.0$

$1.07 \quad .31 \quad 1.0-4.0$

$1.20 \quad .49 \quad 1.0-3.4$

$$
.47
$$

.54

$-.24$

$-.19$

$.30-.23$

4.56

6.29

2. 86

$22.0018 .00 * * *$

43.82

7.49

$\begin{array}{llllrr}.03 & .09 & 0-.6 & 3.80 & 14.52 & 21.71 * * * \\ .02 & .08 & 0-.6 & 5.07 & 27.99 & \\ .06 & .13 & 0-.5 & 2.44 & 4.87\end{array}$

5. Drug Problems II (DRUGPROB2)

$\begin{array}{lrrrrrr}\text { Total Sample } & 1.24 & .44 & 1.0-4.0 & 2.94 & 10.15 & 42.61 * * * \\ \text { Women } & 1.18 & .36 & 1.0-4.0 & 3.81 & 19.27 & \\ \text { Men } & 1.40 & .57 & 1.0-3.7 & 1.90 & 3.32\end{array}$

5. Drug Problems II ( LOg) (DRUGPROB2L)

Total Sample

Women

$\begin{array}{ll}.08 & .12 \\ .06 & .10\end{array}$

.12 .14

$0-.6 \quad 1.98$

$0-.6 \quad 2.41$

$3.9047 .72 * * *$

6.96

$0-.6 \quad 1.25 \quad .72$

IV. Depression (DEP)

1. CESD (CESD)

Total Sample

Women

Men

$1.96 \quad .55$

1.98

.55

$1 \cdot 0-3 \cdot 9$

$1 \cdot 0-3 \cdot 9$

.56

.63

$-.20$

1.96

1.91

.54

$1.0-3.5$

$.39-.66$

2. BSI: Depression (BSIDEP)

Total Sample

Women

Men

$\begin{array}{lll}1.90 \quad .80 & 1.0-5.0\end{array}$

1.13

1.22

.82

.96

1.11

1. 88

.75

1. $0-4.3$

.21

V. Suicide Ideation (SII)

1. Suicide Ideation Index

Total Sample

Women

Men

$1.38 \quad .54 \quad 1.0-4.44$

$1.35 \quad .51$

$1 \cdot 0-4 \cdot 4$

2.38

$1 \cdot 0-4.4$

2.58

1. 98

6.88

8.60

4. 22

1. Suic Idea Index (LOg) (SIIL)

Total Sample

Women

.12 .13

.11 .13

$0-.6 \quad 1.35$

1.58

$0-.6 \quad 1.42$

.13 .15

$0-.61 .18$

2.04

.71

$6.34 *$

Men 
Table 5 (continued)

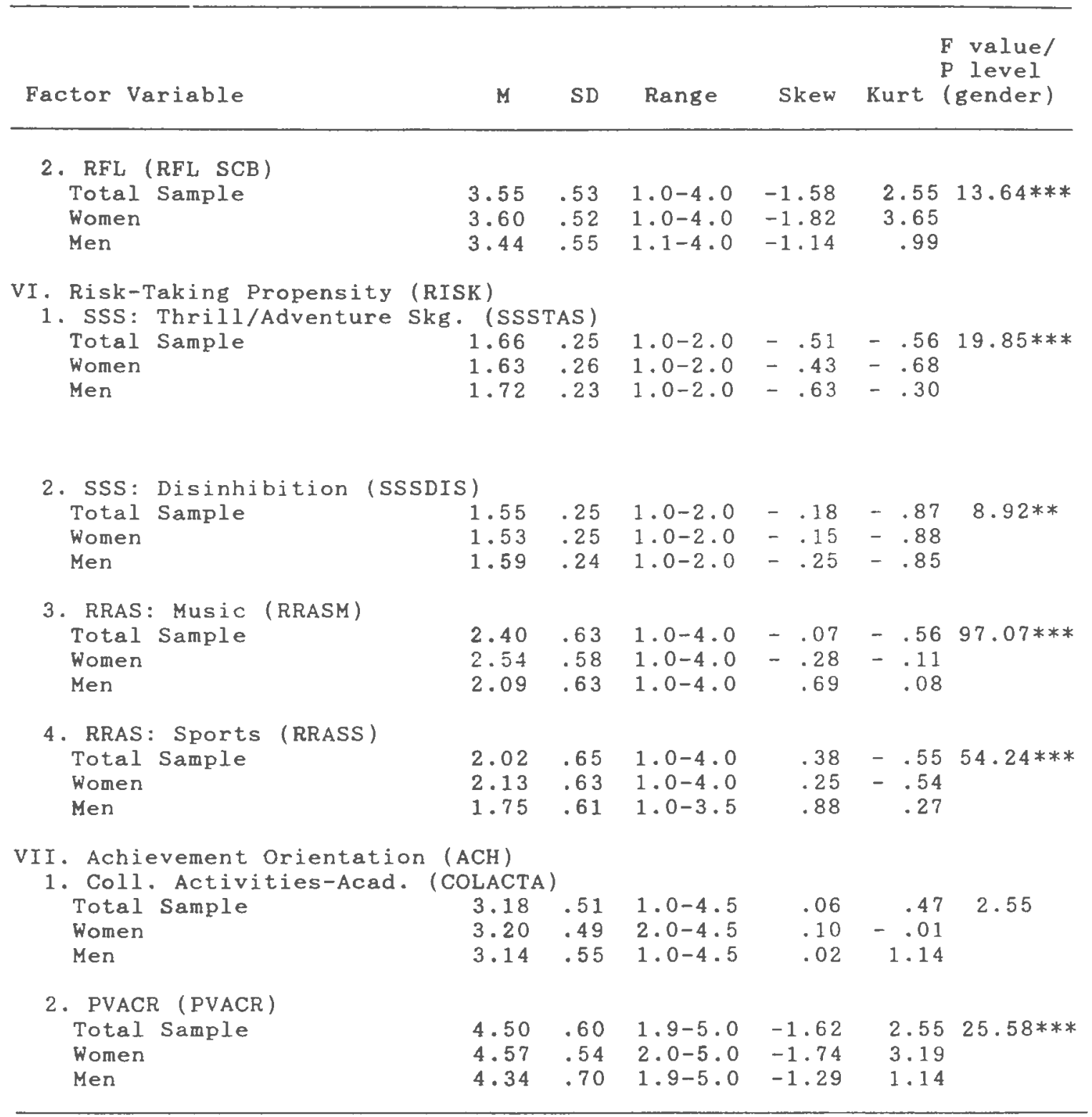

* $\mathrm{p}<.05 . \quad * * \mathrm{p}<.01 . \quad * * * \mathrm{p}<.001$. 
Table 6

Principal Components Analyses

Factor Variable

1st Level PCA

2nd Level PCA

(Item Level)

(Composite Level)

(VAF) (Alpha)

\begin{tabular}{ll}
\hline VAF Alpha Loadings \\
\hline
\end{tabular}

I. Family Functioning

$\begin{array}{lll}\text { 1. FFS: Positive Family Affect } & .53 & .87 \\ \text { 2. FFS: Conflicts } & .35 & .73 \\ \text { 3. Family Awareness Scales I } & .64 & .86 \\ \text { 4. Family Perceptions Scale } & .49 & .79\end{array}$

II. Shame

1. ISS: Failure

2. ISS: Alienation

$.61 \quad .92$

$.61 \quad .87$

$(.67)(.83)$
$.87^{(.83}$
.71
.82
.87

III. Substance Use

1. Alcohol

2. Marijuana

3. Drug Problems I

4. Drugs (Log)

5. Drug Problems II ( Log)

87

73

79

(.88)

.94

.94

$(.86)$

61.87

(.50)

$.74 \quad .91$

.91

$(.75)$

$.49 \quad .83$

.68

.68

.73

$.63 \quad .91$

.64

$.48 \quad .82$

.80

IV. Depression

1. CESD

2. BSI: Depression

.40

.59

$(.86)$

.93

.93

V. Suicide Ideation

1. Suicide Ideation Scale

$.61 \quad .83$

$(.75)$

.51

.95

.86

$-.86$

VI. Risk-Taking Propensity

1. SSS: Thrill/Adventure Seekg .30

.74

(.44)

.66

$.28 \quad .70$

.69

.71

$-.66$

3. RRAS: Music

4. RRAS: Sports

.48

.64

$-.64$

VII. Achievement-Orientation

1. College Activities-Achvmnt

2. PVACR

Note: Promax Rotation was used, with Rotated Factor pattern (Standard Regression Coefficient) values reported here. $\mathrm{VAF}=$ Variance Accounted For

Alpha = Chronbach's Alpha 
Table 7

Third-Level Principal Components Analysis

FACTOR LOADINGS

Factor Variable

I

II III

IV

VI

I. Family Functioning

$\begin{array}{ll}\text { 1. FFS: Positive Family Affect } & .84 \\ \text { 2. FFS: Conflicts } & .67 \\ \text { 3. Family Awareness Scales I } & .89 \\ \text { 4. Family Perceptions Scale } & .82\end{array}$

II. Shame
1. ISS: Failure
.87
2. ISS: Alienation
.88

III. Substance Use

1. Alcohol

.84

.55

.30

2. Marijuana

3. Drug Problems I

.78

4. Drugs (Log)

5. Drug Problems II (Log)

$\begin{array}{ll}.33 & .86 \\ & .76\end{array}$

IV, Depression

1. CESD

2. BSI: Depression

.86

.87

v. Suicide Ideation

1. Suicide Ideation Scale .36

2. RFL: Suicide

VI, Risk-Taking Propensity

1. SSS: Thrill/Adventure Seekg

2. SSS: Disinhibition

.75

.72

3. RRAS: Music

$-.43$

$-.66$

.56

4. RRAS: Sports

VII. Achievement Orientation

1. College Activities-Achvmnt

2. PVACR

$-.35$

.47

.39

$-.21$

.75

Note: Promax Rotation was used, with the values for the Rotated Factor pattern (Standard Regression Coefficient) reported here. Only factor loadings $>.20$ are reported. 
Table 8

Summary of Model Fit Indices (Maximum Likelihood Estimation) for Models 1-5

\begin{tabular}{|c|c|c|c|c|c|c|c|}
\hline Model & chi-square & $\mathrm{d} \mathbf{f}$ & $\begin{array}{l}\text { hi-square/ } \\
\text { df ratio }\end{array}$ & $\mathbf{p}$ & CFI & RMSR & $\begin{array}{c}\mathrm{R}^{2} \text { for } \\
\mathrm{DV}\end{array}$ \\
\hline \multicolumn{8}{|l|}{ Model 1: Substance Use } \\
\hline Total Sample (750) & 474 & 41 & 11.56 & $<.001$ & .86 & .06 & .06 \\
\hline Women & 276 & 41 & 6.73 & $<.001$ & .90 & .05 & .04 \\
\hline Men & 199 & 41 & 4.88 & $<.001$ & .82 & .08 & .06 \\
\hline \multicolumn{8}{|l|}{ Model 2: Depression } \\
\hline Total Sample & 56 & 17 & 3.29 & $<.001$ & .99 & .03 & .86 \\
\hline Women & 29 & 17 & 1.71 & .030 & .99 & .02 & .89 \\
\hline Men & 42 & 17 & 2.47 & $<.001$ & .97 & .05 & .81 \\
\hline \multicolumn{8}{|c|}{ Model 3: Suicide Ideation } \\
\hline Total Sample & 82 & 17 & 4.82 & $<.001$ & .97 & .03 & .36 \\
\hline Women & 57 & 17 & 3.35 & $<.001$ & .98 & .03 & .42 \\
\hline Men & 42 & 17 & 2.47 & $<.001$ & .96 & .04 & .26 \\
\hline \multicolumn{8}{|l|}{$\begin{array}{c}\text { Model 4: Risk-Taking } \\
\text { Propensity }\end{array}$} \\
\hline Total Sample & 125 & 32 & 3.91 & $<.001$ & .96 & .05 & .02 \\
\hline Women & 100 & 32 & 3.13 & $<.001$ & .96 & .05 & .01 \\
\hline Men & 57 & 32 & 1.78 & .004 & .96 & .06 & .15 \\
\hline \multicolumn{8}{|l|}{$\begin{array}{r}\text { Model 5: Achievement } \\
\text { Orientation }\end{array}$} \\
\hline Total Sample & 76 & 17 & 4.47 & $<.001$ & .97 & .03 & .06 \\
\hline Women & 45 & 17 & 2.65 & .004 & .98 & .03 & .08 \\
\hline Men & 39 & 17 & 2.29 & .002 & .96 & .05 & .06 \\
\hline
\end{tabular}

Note: $\mathrm{df}=$ degrees of freedom CFI = Comparative Fit Index RMSR $=$ Root Mean Squared Residual 
Table 9

Summary of Model Fit Indices (Maximum Likelihood Estimation) for Overall Model (5 DVs and 3 DVs)

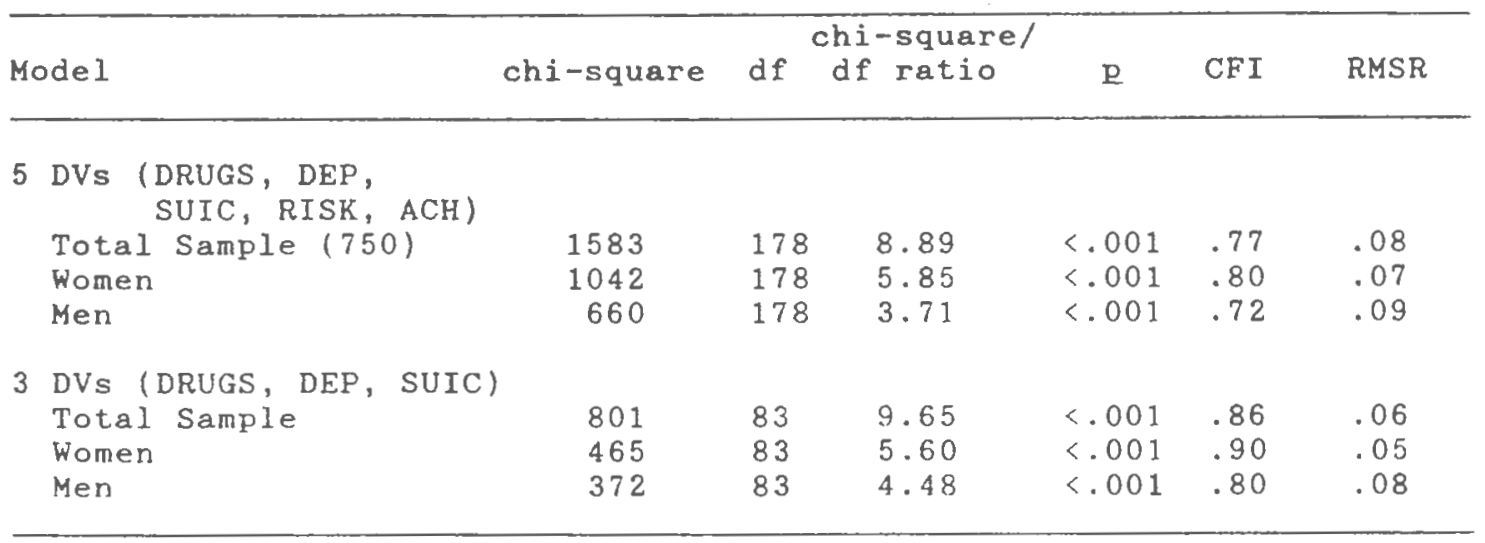

Note: $\mathrm{DV}=$ Dependent Variable

$\mathrm{df}=$ degrees of freedom

CFI = Comparative Fit Index

RMSR = Root Mean Squared Residual 
Table 10

Chi-squared Pairwise Comparisons

\begin{tabular}{|c|c|c|}
\hline Comparison Variables & Chi-square & p value \\
\hline Shame/Substance Use & 8.76 & .067 \\
\hline Shame/Depression & 354.10 & $<.001$ \\
\hline Shame/Suicidal Ideation & 85.48 & $<.001$ \\
\hline Shame/Risk-Taking Propensity & .69 & .952 \\
\hline Shame/Achievement Orientation & .76 & .944 \\
\hline Fam Fng/Substance Use & 6.98 & .137 \\
\hline Fam Fng/Depression & 107.97 & $<.001$ \\
\hline Fam Fng/Suicide Ideation & 74.55 & $<.001$ \\
\hline Fam Fng/Risk-Taking Propensity & 6.24 & .182 \\
\hline Fam Fng/Achievement Orientation & 4.35 & .360 \\
\hline Fam Fng/Shame & 104.34 & $<.001$ \\
\hline
\end{tabular}




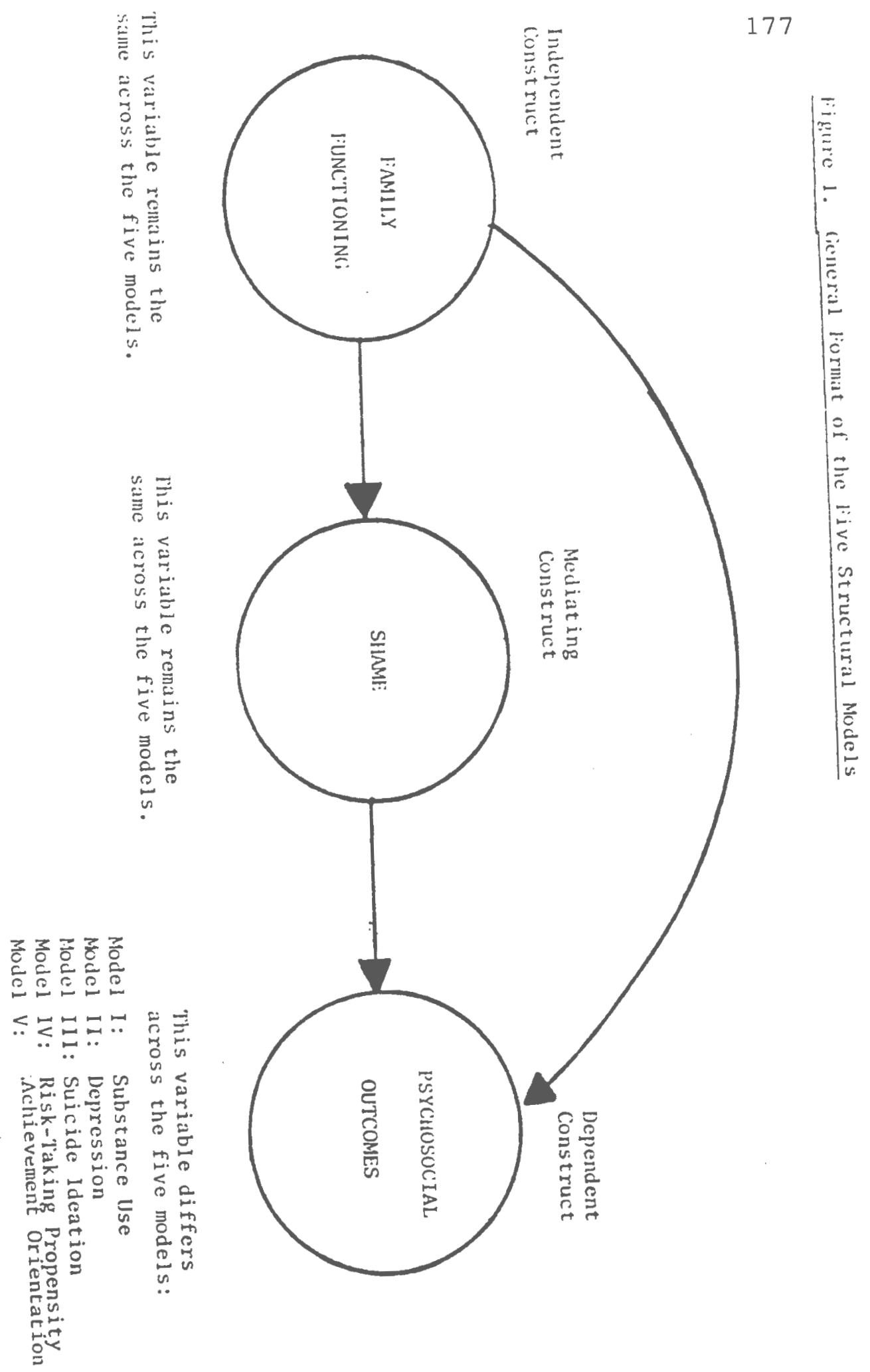




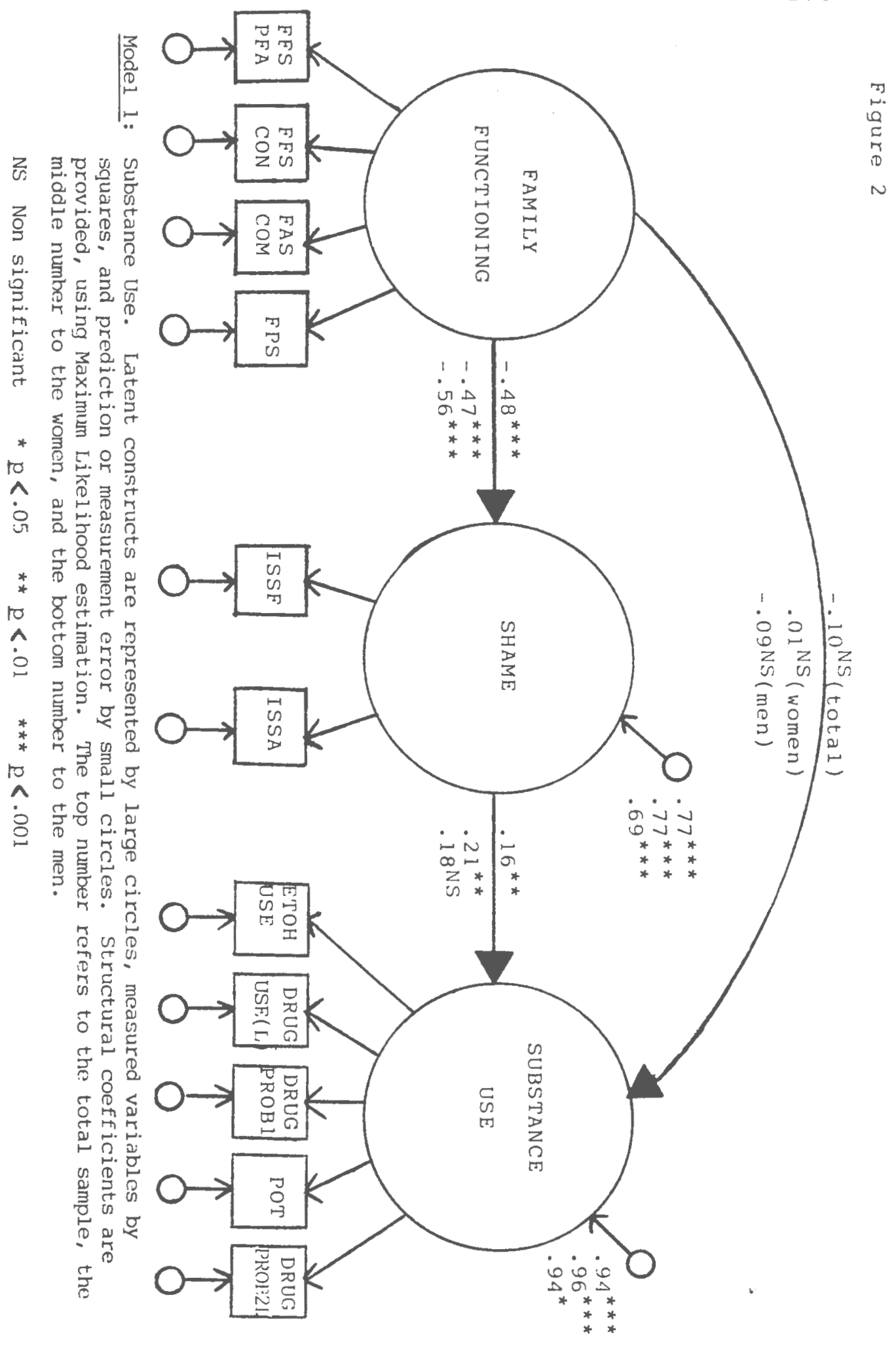




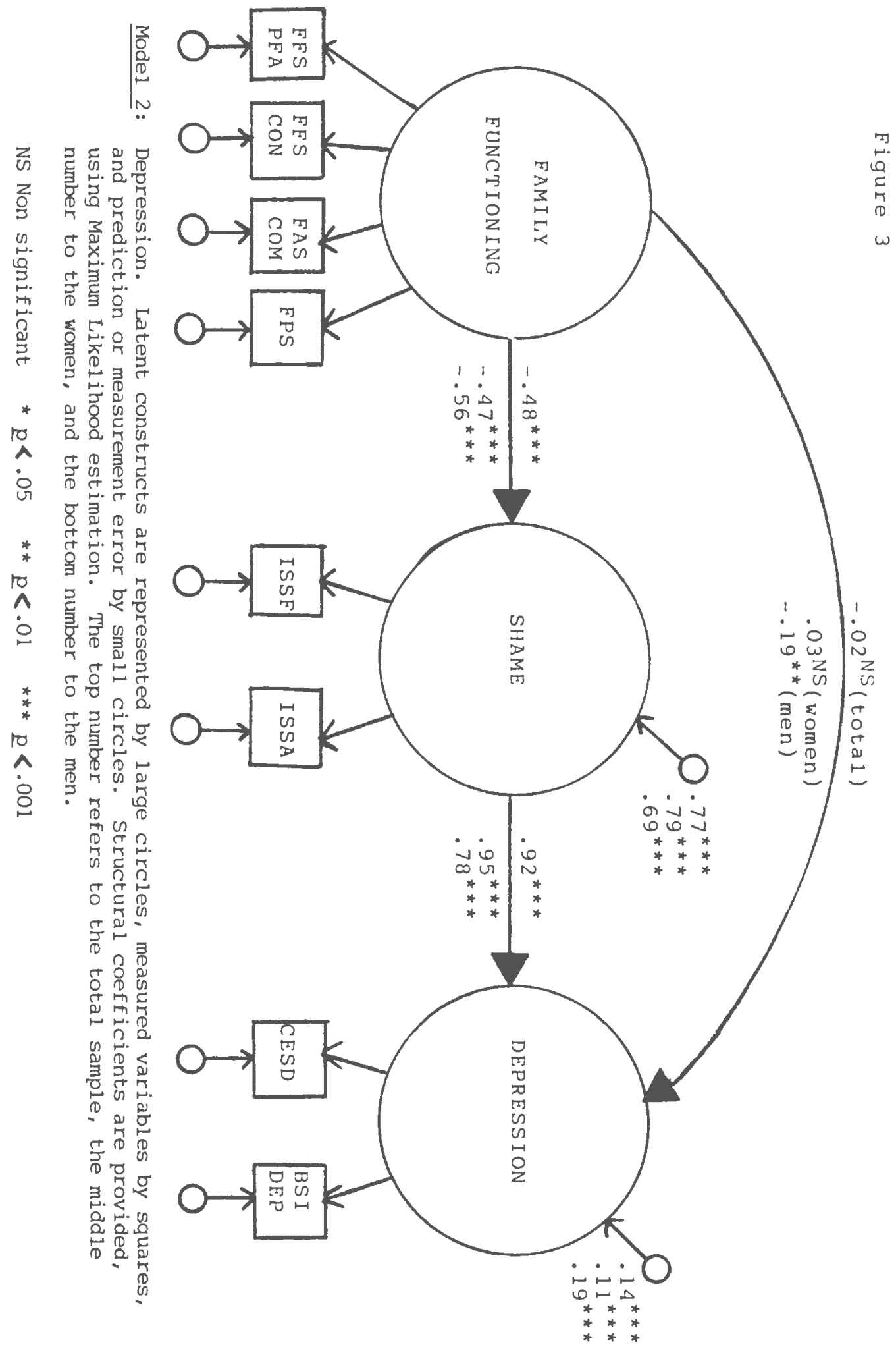




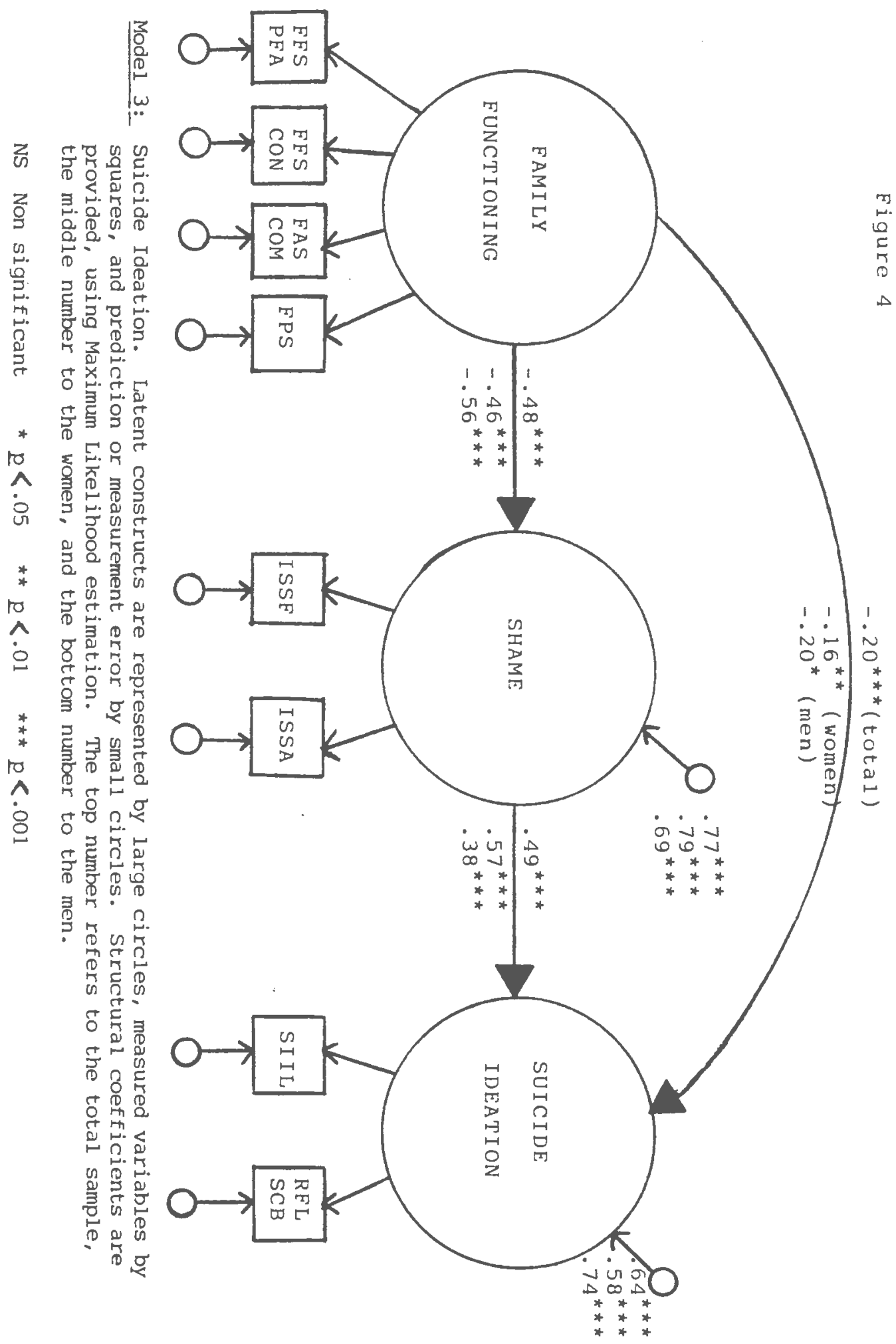




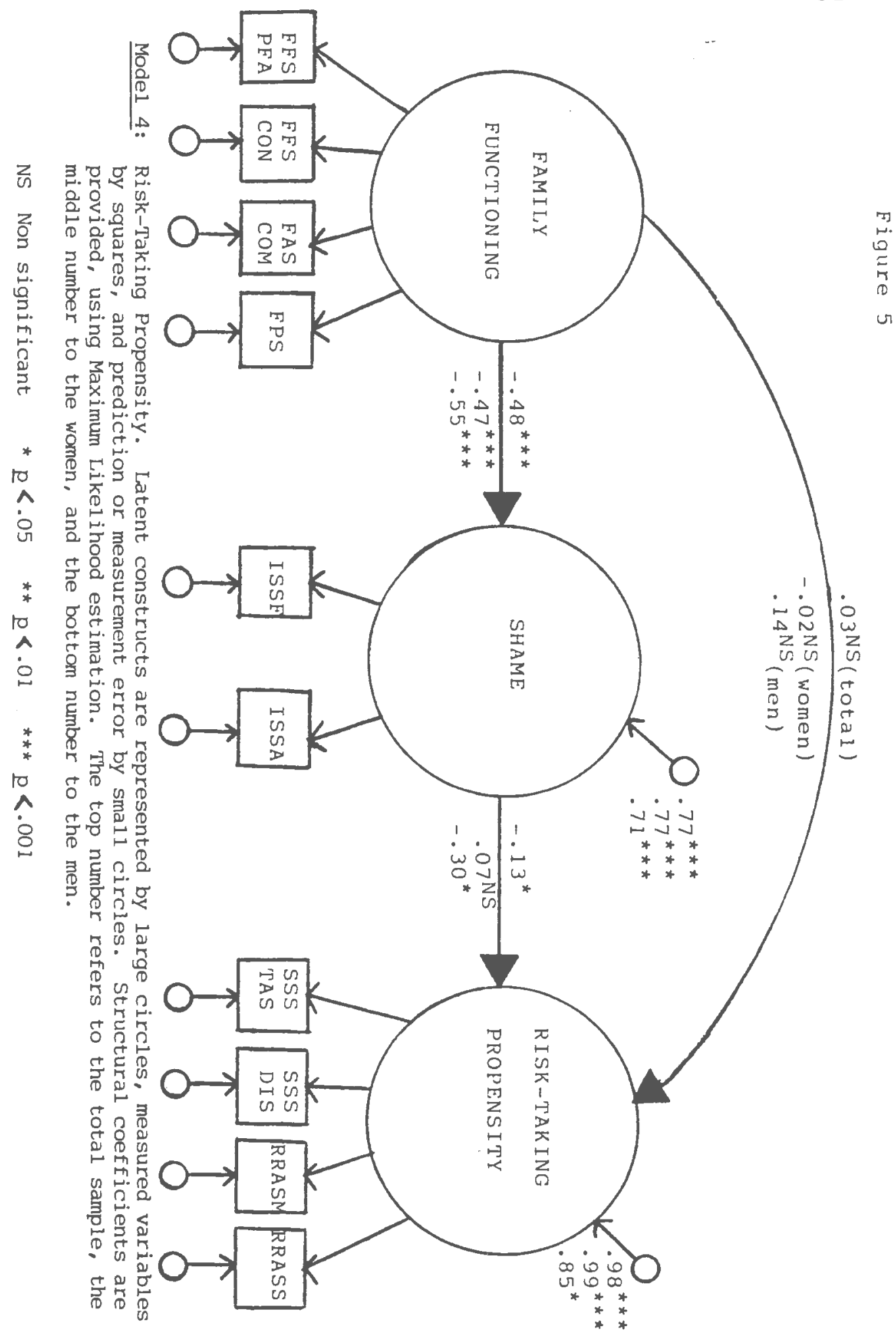




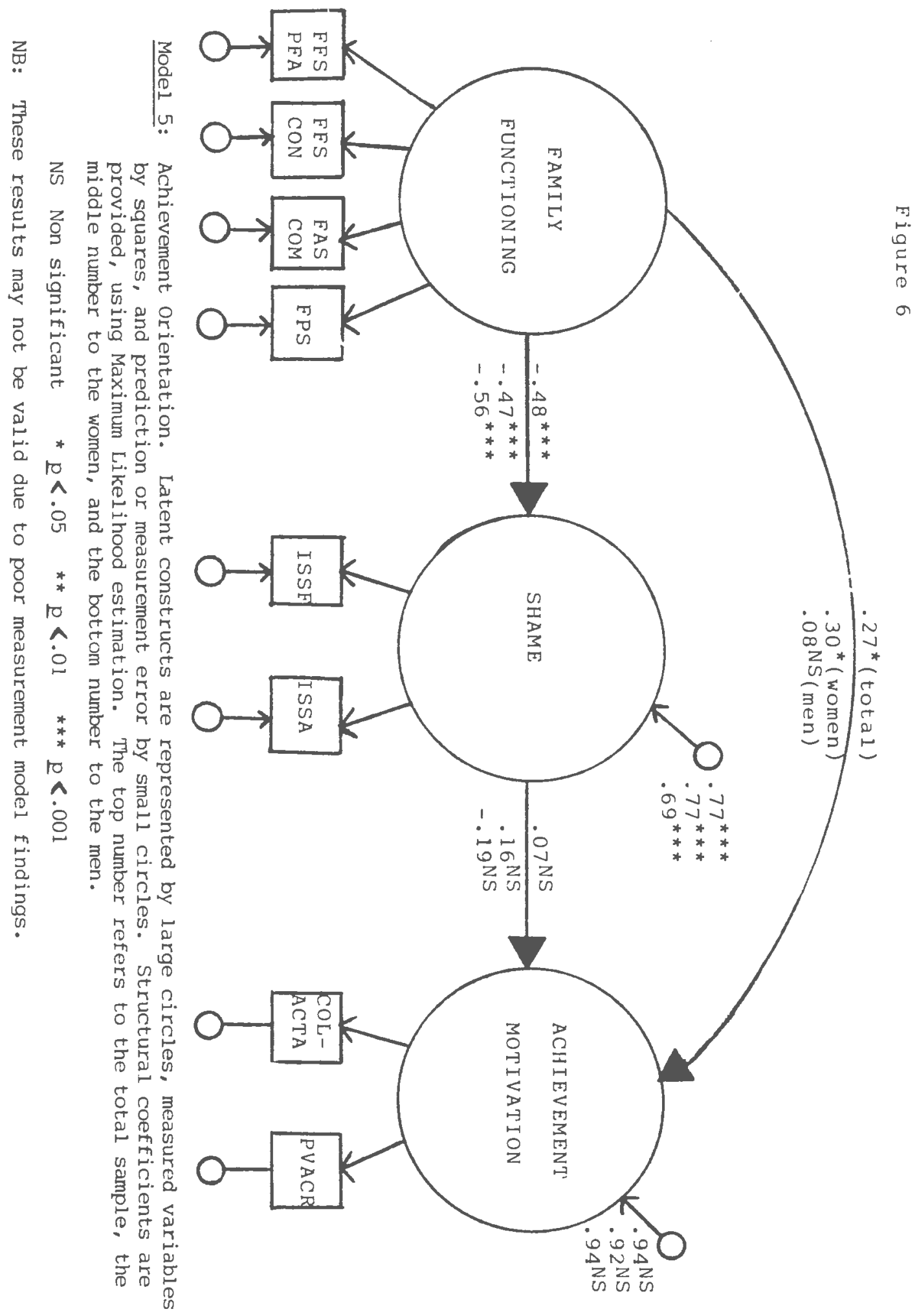




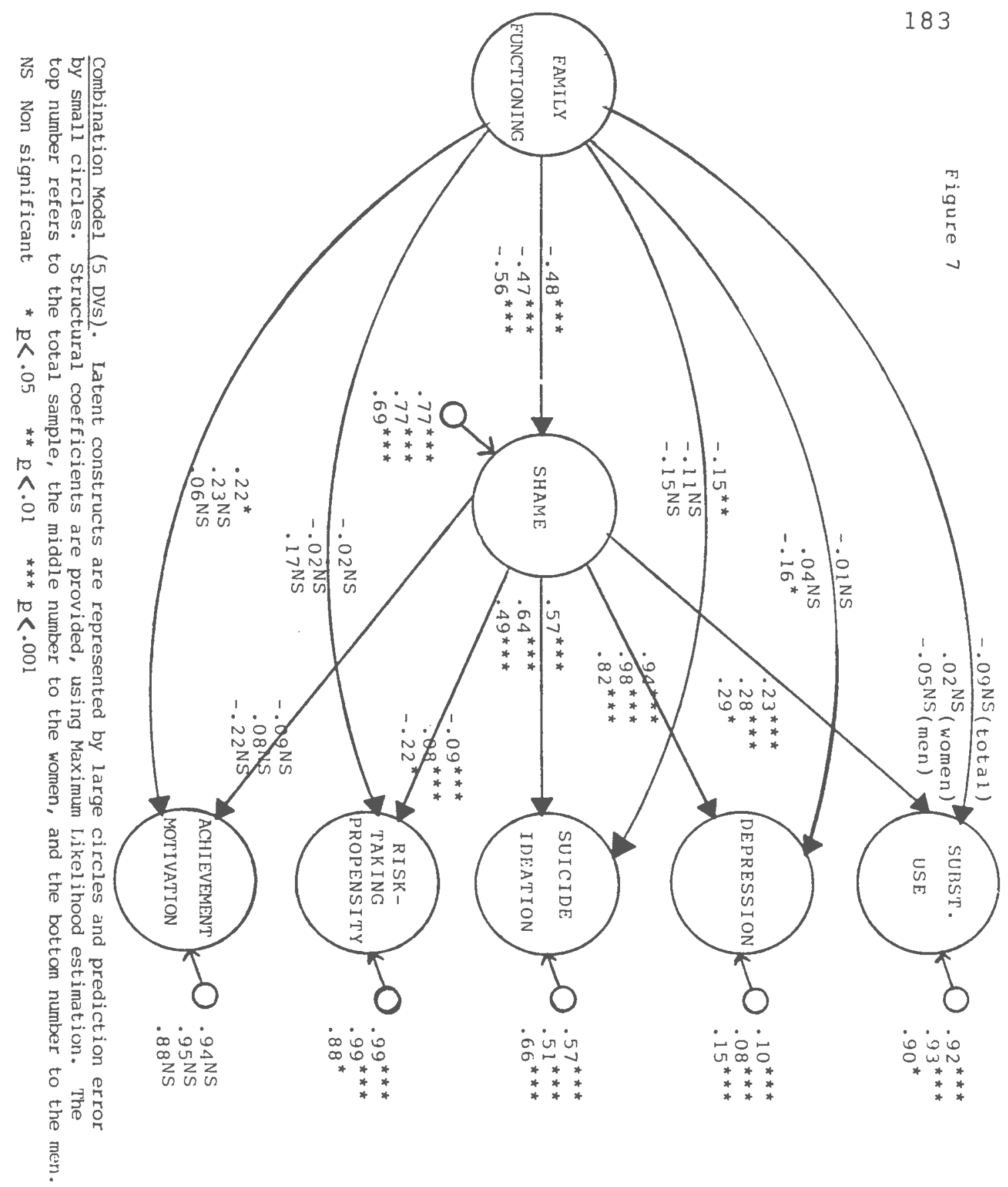




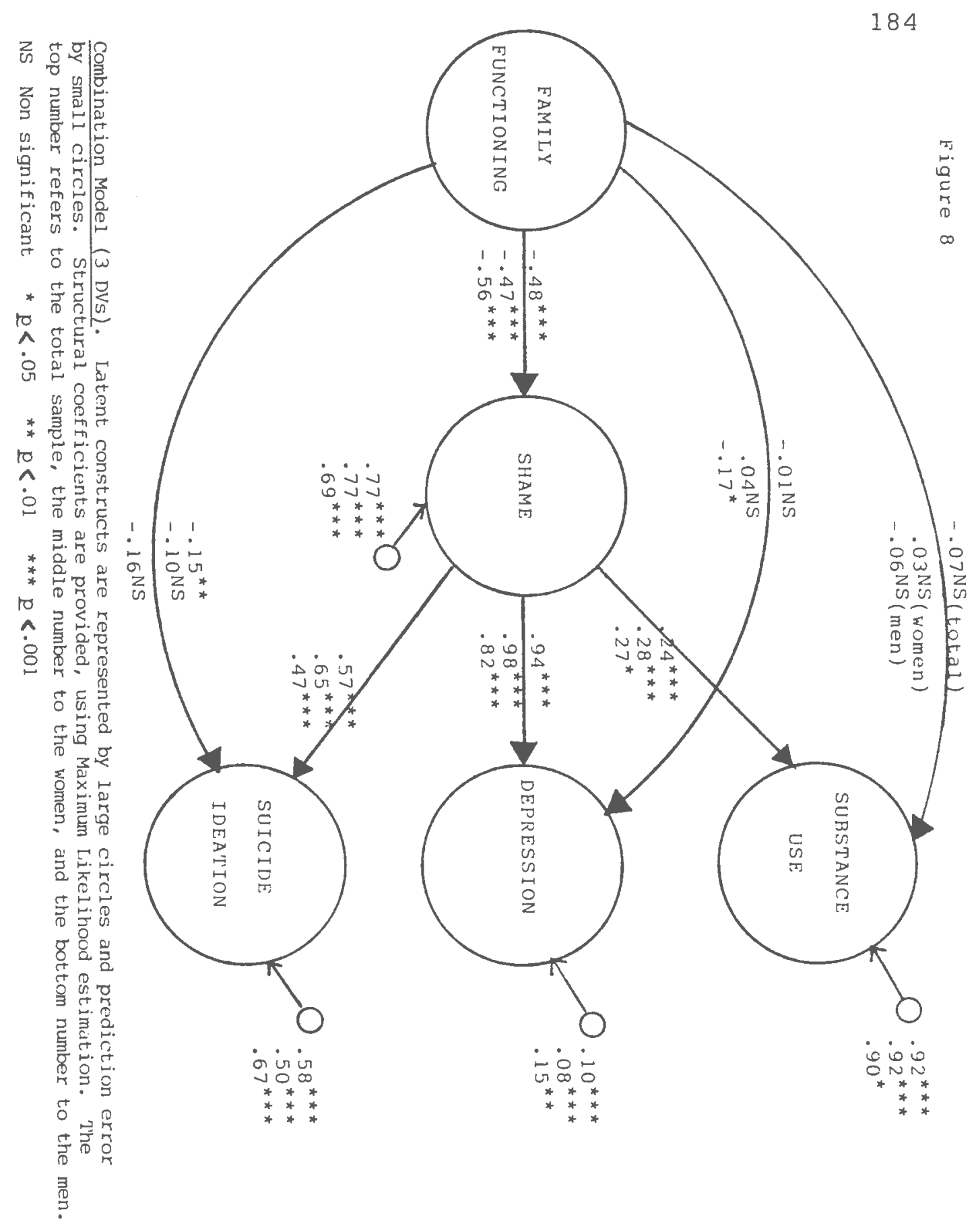


Bibliography

Ablamowics, H. (1985). An empirical phenomenological study of shame. Dissertation Abstracts International, 46 , $552-553 \mathrm{~B}$.

Albert, C. A. (1984). Shame and guilt as indicators of level of object relations: An attempt at psychoanalytic research. Dissertation Abstracts International, 45, $1002 \mathrm{~B}-1003 \mathrm{~B}$.

Alonso, A., \& Rutan, J. S. (1988a). Shame and guilt in psychotherapy supervision. Psychotherapy, 25, 576-581.

Alonso, A., \& Rutan, J. S. (1988b). The experience of shame and the restoration of self-respect in group therapy. International Journal of Group Psychotherapy, 38, 3-14.

Banmen, J. (1988). Guilt and shame: Theories and therapeutic possibilities. International Journal for the Advancement of counselling, 11, 79-91.

Bentler, P. M. (1985). Theory and implementation of EQS, a structural equations program. Los Angeles: BMDP Statistical Software.

Bentler, P. M. (1988). Comparative fit indexes in structural models. Psychological Bulletin, in press.

Bentler, P. M. (1989). EQS: Structural Equations Program Manual. Los Angeles: BMDP Statistical Software.

Bentler, P. M., \& Bonett, D. G. (1980). Significance tests and goodness of $\mathrm{fit}$ in the analysis of covariance structures. Psychological Bulletin, 88, 588-606.

Bessai, J. L. (1977). The Common Beliefs Survey: a factored measure of irrational beliefs. Paper presented at the 2nd National Conference on Rational Psychotherapy, Chicago.

Bilmes, M. (1967). Shame and delinquency. Contemporary Psychoanalysis, $\underline{3}, 113-133$.

Binder, J, L. (1971). The relative proneness to shame or guilt as a dimension of character style. Dissertation Abstracts International, $\underline{32}, 1833 \mathrm{~B}$. 
Boomsma, A. (1983). On the robustness of LISREL (maximum likelihood estimation) against small sample size and nonnormality. Unpublished doctoral dissertation, Rijksuniversiteit Groningen, 1983.

Bradlow, P. A. (1973). Depersonalization, ego splitting, non-human fantasy and shame. International Journal of Psycho-Analysis, 54, 487-492.

Bradshaw, J. (1988). Healing the shame that binds you. Deerfield Beach, FL: Health Communications.

Brennan, A. F., Walfish, S., \& AuBuchon, P. (1986). Alcohol use and abuse in college students. I. A review of individual and personality correlates, The International Journal of the Addictions, 21, 449-474.

Broday, S. F. (1988a). Perfectionism and Millon basic personality patterns. Psychological Reports, $\underline{63}$, 791-794.

Broday, S. F. (1988b). A shortened version of the Burns Perfectionism Scale. Psychological Reports, $62,70$.

Broucek, F. J. (1982). Shame and its relationship to early narcissistic developments. International Journal of Psycho-Analysis, 63, 369-378.

Broucek, F. J. (1991). Shame and the self. New York: Guilford Press.

Browne, M. W. (1982). Covariance structures. In D. W. Hawkins (Ed.), Topics in applied multivariate analysis. Cambridge: Cambridge University Press.

Brown, J. A. (1987). Shame, intimacy, and sexuality . Special Issue: Chemical dependency and intimacy dysfunction. Journal of Chemical Dependency Treatment, 1 , 61-74.

Browne, M. W. (1984). Asymptotically distribution-free methods for the analysis of covariance structures. British Journal of Mathematical and Statistical Psychology, 37, 62-83.

Bupp, C. S. (1984). An examination of shame and guilt among the American veterans of the Vietnam conflict. Dissertation Abstracts International, $\underline{45}, 663 \mathrm{~B}$. 
Burch, J. W., Pishkin, V. (1984). Family resemblance:

Category structure of joy and shame. Journal of Clinical Psychology, 40, 1136-1143.

Burggraf, S., \& Tangney, J. P. (1989, June). Proneness to shame, proneness to guilt, and self-concept. Paper presented at the meeting of the American Psychological Society, Alexandria, VA.

Burns, D. D. (1980). The perfectionist's script for self-defeat. Psychology Today, 14, 34-52.

Burns, D. D. (1983). The spouse who is a perfectionist. Medical Aspects of Human Sexuality, 17, 219-230.

Campbell, F. A. (1984). The concept of shame. Perspectives in Psychiatric Care, 22, 62-64.

Cassorla, A. A. (1986). A preliminary investigation of the experience of shame in psychiatrically hospitalized, conduct disordered adolescents. Dissertation Abstracts International, $47,1715 \mathrm{~B}$.

Chasseguet-Smirgel, J. (1985). The ego ideal. New York: Norton.

Clapper, R. L. (1990). Adult and adolescent arousal preferences: The revised reducer-augmenter scale. Personality and Individual Differences, 11, 1115-1122.

Cochran, C. D., \& Hale, W. D. (1985). College student norms on the Brief Symptom Inventory. Journal of Clinical Psychology, 41, 777-779.

Coleman, M. (1985). Shame: A powerful underlying factor in violence and war. Journal of Psychoanalytic Anthropology, 8, $67-79$.

Cook, D. R. (1987). Measuring shame: The Internalized Shame Scale. Alcoholism Treatment Quarterly, $\underline{4}, 197-215$.

Cook, D. R. (1988, August). The measurement of shame: The Internalized Shame Scale. Paper presented at the meeting of the American Psychological Association, Atlanta, GA.

Cook, D. R. (1989). Internalized Shame Scale, Revised edition.

Corcoran, K., \& Fischer, J. (1987). Measures for clinical practice: A sourcebook. New York: Free Press. 
Corulla, W. J. (1988). A further psychometric investigation of the Sensation Seeking Scale Form-V and its relationship to the EPQ-R and the I.7 Impulsiveness Questionnaire. Personality and Individual Differences, $\underline{9}$, 277-287.

Covington, M. V., \& Omelich, C. L. (1981). As failures mount: Affective and cognitive consequences of ability demotion in the classroom. Journal of Educational Psychology, 73, 796-808.

Covington, M. V., \& Omelich, C. L. (1984a). An empirical examination of Weiner's critique of attribution research. Journal of Educational Psychology, 76, 1214-1225.

Covington, M. V., \& Omelich, C. L. (1984b). The trouble with pitfalls: A reply to Weiner's critique of attribution research. Journal of Educational Psychology, 76, 1199-1213.

Covington, M. V., \& Omelich, C. L. (1985). Ability and effort valuation among failure-avoiding and failure-accepting students. Journal of Educational Psychology, 77, 446-459.

Crouppen, G. A. (1977). Field dependence-independence in depressed and normal males, as an indicator of relative proneness to shame or guilt and ego functioning. Dissertation Abstracts International, 37, 4669B-4670B.

Darwin, C. (1965). The expression of the emotions in man and animals. Chicago: University of Chicago Press. (Original work published 1872)

Davidowitz, J. J. (1976). Effects of causal ascriptions on pride and shame and the relationship of such ascriptions to need for achievement. Dissertation Abstracts International, $36,4224 \mathrm{~B}-4225 \mathrm{~B}$.

Deigh, J. G.(1980). Guilt and shame: Philosophical investigations in moral psychology. Dissertation Abstracts International, 40, 5469-5470A.

Derogatis, L. R. (1977). The SCL-90 Manual I: Scoring administration and procedures for the SCL-90. Baltimore: Johns Hopkins University School of Medicine, Clinical Psychometrics Unit. 
Derogatis, L. R., \& Melisaratos, N. (1983). The Brief Symptom Inventory: An introductory report. Psychological Medicine, 13, 595-605.

Derogatis, L. R., \& Spencer, M. S. (1982). The Brief Symptom Inventory (BSI) Administration, Scoring, and Procedures Manual-I. Baltimore: Johns Hopkins University School of Medicine, Clinical Psychometrics Research Unit.

Dixon, W. J. (Ed.) (1988). BMDP statistical stoftware manual. Los Angeles: University of California Press.

Dunn, J. E. Psychoanalysis, shame and the psychoanalytic psychotherapist. Dissertation Abstracts International, 47, $4646 \mathrm{~B}-4647 \mathrm{~B}$.

Emad, P. (1972). Max Scheler's phenomenology of shame. Philosophy \& Phenomenological Research, 32, 361-370.

Erikson, E. H. (1950), Childhood and society. New York: Norton.

Evans, S. (1987). Shame, boundaries and dissociation in chemically dependent, abusive and incestuous families. Alcoholism Treatment Quarterly, 4, 157-179.

Firestone, R. W. (1986). The "inner voice" and suicide. Psychotherapy, 23, 439-447.

Fischer, B. (1987). The process of healing shame. Alcoholism Treatment Quarterly, 4, 25-38.

Fischer, K. W., Carnochan, P., \& Shaver, P. R. (in press). How emotions develp and how they organize development. In Cognition and emotion.

Fischer, K. W., Shaver, P. R., \& Carnochan, P. (1989). A skill approach to emotional development: From basic- to subordinate-category emotions. In W. Damon (Ed.), Child development today and tomorrow (pp. 107-136). San Francisco: Jossey-Bass.

Fisher, R. A. (1971). The effects of guilt and shame on public and private helping. Dissertation Abstracts International, $\underline{31}, 6897 \mathrm{~B}-6898 \mathrm{~B}$.

Fisher, S. F. (1985). Identity of two: The phenomenology of shame in borderline development and treatment. Psychotherapy, 22, 101-109. 
Fitts, S. N. (1989). Relationships between measures of self-concept, existential variables, and maladaptive psychosocial outcomes in a college population. Unpublished master's thesis, University of Rhode Island, Kingston, RI.

Fitts, S. N., \& Harlow, L. L. (1989). Structural models of self-esteem, meaning in life, and maladaptive outcomes. Unpublished manuscript.

Flanigan, B. J. (1987). Shame and forgiving in alcoholism. Alcoholism Treatment Quarterly, $\underline{4}, 181-195$.

Fossum, M. A., \& Mason, M. J. (1986). Facing shame: Families in recovery. New York: W. W. Norton \& Co.

Friedman, B. G. (1980). Field dependence-independence as an indicator of relative proneness to shame and guilt in a nonclinical college population. Dissertation Abstracts International, $40,3889 \mathrm{~A}$.

Freud, S. (1961). Civilization and its discontents. In J. Strachey (Ed. \& Trans.), The standard edition of the complete psychological works of Sigmund Freud (Vol. 21, pp. 64-145). London: Hogarth Press. (Original work published 1930)

Freud, S. (1964). New introductory lectures on psychoanalysis. In J. Strachey (Ed. and Trans.), The standard edition of the complete psychological works of Sigmund Freud (Vol. 22, pp. 3-183). London: Hogarth Press. (Original work published 1933)

Geppert, U. (1986, July). A coding system for analyzing behavioral expressions of self-evaluative emotions (technical manual). Paper presented at the International Conference on Human Ethology, Tutzing, West Germany.

Geppert, U., \& Heckhausen, H. (1988, December). Self-related and self-evaluative emotions: Embarrassment, shame, guilt, and pride. Paper present at the Conference on the Development of Shame and Guilt, Pacific Grove, CA.

Gioiella, P. P. (1979). The relationship of relative shame/guilt proneness to the attribution of responsiblity under no shame and shame arousal. Dissertation Abstracts International, 40, $2432 \mathrm{~B}$. 
Glassman, D. J. (1975). An exploratory study of shame feeling states among shame-prone subjects. Dissertation Abstracts International, 35, 6093B-6094B.

Goldberg, C. (1991). Understanding shame. Northvale, NJ: Jason Aronson.

Gomberg, E. L. (1987). Shame and guilt issues among women alcoholics. Alcoholism treatment Quarterly, 4, 139-155.

Grabelsky, R. B. (1985). Shame and tact: An object relations view of intersubjectivity. Dissertation Abstracts International, $\underline{45}, 3618 \mathrm{~B}-3619 \mathrm{~B}$.

Harlow, L. L. (1985). Behavior of some elliptical estimators with nonnormal data in a covariance structures framework: A monte carlo study. Unpublished doctoral dissertation, University of California, Los Angeles.

Harlow, L. L. (1987). Unpublished questionnaire and raw data, University of Rhode Island.

Harlow, L. L. (1989). Unpublished questionnaire and raw data, University of Rhode Island.

Harlow, L. L., Newcomb, M. D., \& Bentler, P. M. (1986). Depression, self-derogation, substance use, and suicide ideation: lack of purpose in life as a mediational factor. Journal of Clinical Psychology, 42, 5-21.

Harlow, L. L., Newcomb, M. D., \& Bentler, P. M. (1987). Purpose in Life Test assessment using latent variable methods. British Journal of Clinical Psychology, 26, $235-236$.

Harlow, L. L., Quina, K., \& Morokoff, P. J. (1990, August) . Predicting AIDS-Risking behaviors in young adults. Paper accepted for presentation at the annual meeting of the American Psychological Association, Boston, MA.

Hawkins, J. D., \& Hederhood, B. (1987). Handbook for Evaluating Drug and Alcohol Prevention Programs; Staff/Team Evaluation of Prevention Programs (STEPP). U.S. Department of Health and Human Services; Public Health Service; Alcohol, Drug Abuse, and Mental Health Administration, Rockville, MD.

Hayduk, L. A. (1987). Structural equation modeling with LISREL: Essentials and advances. Baltimore, MD: Johns Hopkins University. 
Huba, G. J., \& Bentler, P. M. (1982). A developmental. theory of drug use: Derivation and assessment of a causal modeling approach. In P. B. Baltes \& O. G. Brim, Jr. (Eds.), Life-span development and behavior (Vol. 4, pp. 147-203). New York: Academic Press.

Hultberg, P. (1988). Shame: A hidden emotion. Journal of Analytical Psychology, 33, 109-126.

Jackson, D. N. (1984). Personality research from manual: Third edition. New York: Research Psychologists Press.

James, W. (1983). The principles of psychology. Cambridge, MA: Harvard University Press. (Original work published 1890)

James, L. R., Mulaik, S. A., \& Brett, J. M. (1982). Causal analysis: Assumptions, models, and data. Beverly Hills, CA: Sage Publications.

Jessor, R. (1969). General description of junior-senior high school questionnaire and its component measures. University of Colorado, Institute of Behavioral Science.

Johnson, R. C., Danko, G. P., Huang, Y., Park, J. Y., et al. (1987). Guilt, shame, and adjustment in three cultures. Personality \& Individual Differences, $\underline{8}$, 357-364.

Johnston, L. D., O'Malley, P. M., \& Bachman, J. G. (1986) . Drug use among American high school students, college students, and other young adults. Rockville, MD: National Institute on Drug Abuse.

Jones, D. D. (1982). Shame as a referent of nonverbal behavior in mothers' and daughters' interactions. Dissertation Abstracts International, 42, $5053 \mathrm{~A}$.

Jones, J. H. (1981). Shameproneness in mothers and their daughters and the dynamics of shame in mothers' and daughters' verbal interactions. Dissertation Abstracts International, 41, 4652A.

Joreskog, K., \& Sorbom, D. (1986). LISREL: Analysis of linear structural relationships by the method of maximum likelihood. Mooresville, Indiana, Scientific Software, Inc.

Kaplan, H. B. (1980). Deviant behavior in defense of self. New York: Academic Press. 
Kaplan, H. B., Martin, S. S., \& Johnson, R. J. (1986). Self-rejection and the explanation of deviance: Specification of the structure among latent constructs. American Journal of Sociology, 92, 384-411.

Kaplan, H. B., Martin, S. S., \& Robbins, C. (1984). Pathways to adolescent drug use: Self-derogation, peer influence, weakening of social controls, and early substance use. Journal of Health and Social Behavior, 25, 270-289.

Kaplan, H. B., Martin, S. S., \& Robbins, C. (1985). Toward an explanation of increased involvement in illicit drug use: Application of a general theory of deviant behavior. Research in Community and Mental Health, 5, 205-252.

Kaplan, H. B., Robbins, C., \& Martin, S. S. (1983a). Antecedents of psychological distress in young adults: Self-rejection, deprivation of social support, and life events. Journal of Health and Social Behavior, 24 , 230-244.

Kaplan, H. B., Robbins, C., \& Martin, S. S. (1983b). Toward the testing of a general theory of deviant behavior in longitudinal perspective: Patterns of psychopathology. Research in Community and Mental Health, $\underline{3}, 27-65$.

Katz, D. S. (1988). An analysis of defense mechanisms, moral reasoning, and shame-guilt proneness in pedophiles, rapists, and nonoffernders. Dissertation Abstracts Internaitonal, $49,544 \mathrm{~A}-545 \mathrm{~A}$.

Kaufman, G. (1974a, August). On shame, identity and the dynamics of change. In D. L. Grummon (Chair), Papers in memory of Bill Kell: Issues on therapy and the training of therapists. Symposium conducted at the meeting of the American Psychological Association, New Orleans.

Kaufman, G. (1974b). The meaning of shame: Toward a self-affirming identity. Journal of Counseling Psychology, 21, 568-574.

Kaufman, G. (1985). Shame: The power of caring. (2nd ed.). Cambridge, MA: Schenkman Books.

Kaufman, G. (1987). Disorders of self-esteem: Psychotherapy for shame-based syndromes. In P. A. Keller and S. R. Heyman (Eds.), Innovations in clinical practice: A source book (Vol. 6, pp. 53-62). Sarasota, FL: Professional Resource Exchange. 
Kaufman, G. (1989). The psychology of shame: Theory and treatment of shame-based syndromes. New York: Springer Publishing.

Kaufman, G., \& Raphael, L. (1984a). Relating to the self: changing inner dialogue. Psychological Reports, $\underline{54}$, $239-250$.

Kaufman, G., \& Raphael, L. (1984b). Shame as taboo in American culture. In R. Browne (Ed.), Forbidden fruits: Taboos and tabooism in culture. Bowling Green, $\mathrm{OH}$ : Popular Press.

Kaufman, G., \& Raphael, L. (1987). Shame: A perspective on Jewish identity. Journal of Psychology \& Judaism, 11, $30-40$.

Kinston, W. (1983). A theoretical context for shame. International Journal of Psycho-Analysis, 64, 213-226.

Kleeman, J.A. (1973). The Peek-A-Boo game: Its evoluation and associated behavior, expecially bye-bye and shame expression during the second year. Journal of the American Academy of Child Psychiatry, 12, 1-23.

Kohut, H. (1977). The restoration of the self. New York: International Universities Press.

Kolevson, M. S., \& Green, R. G. (1987). Family Awareness Scale. In K. Corcoran \& J. Fischer (Eds.), Measures for clinical practice: A sourcebook (pp. 436-439). New York: Free Press.

Korpi, D. R. (1977). Psychohistorical aspects of shame and guilt as functions of political ideology. Dissertation Abstracts International, $\underline{38}, 2866 \mathrm{~B}-2867 \mathrm{~B}$.

Kurtz, E. (1987). Shame in the eighties. Alcoholism Treatment Quarterly, $4,1-6$.

Lamb, R. E. (1983). Guilt, shame, and morality. Philosophy \& Phenomenological Research, $\underline{43}, 329-346$.

Lansky, M. R. (1981). Treatment of the narcissistically vulnerable marriage. In M. R. Lansky (Ed.), Family Therapy and Major Psychopathology (pp. 163-182). Grune \& Stratton. 
Lansky, M. R. (1982). Masks of the narcissistically vulnerable marriage. International Journal of Family Psychiatry, $\underline{3}, 439-449$.

Lansky, M. R. (1984). Violence, shame, and the family. International Journal of Family Psychiatry, ㅁ, 21-40.

Lansky, M. R. (1985). Preoccupation as a mode of pathologic distance regulation. International Journal of Psychoanalytic Psychotherapy, 11, 409-425.

Lansky, M. R. (in press). Murder of a spouse: A family systems viewpoint. International Journal of Family Psychiatry.

Lansky, M. R. (1987b). Shame and domestic violence. In D. L. Nathanson (Ed.), The many faces of shame (pp. 335-362). New York: Guilford Press.

Lansky, M. R. (1987c). Shame in the family relationships of borderline patients. In J. S. Grotstein, M. F. Solomon, \& J. A. Lang (Eds.), The borderline patient (pp. 187-199). Hillsdale, NJ: Analytic Press.

Laor, N. (1987). Psychoanalysis without shame. Israel Journal of Psychiatry \& Related Sciences, 24, 257-264.

Labouvie, E. W., \& McGee, C. R. (1986). Relation of personality to alcohol and drug use in adolescence. Journal of Consulting and Clinical Psychology, 54, 289-293.

Levin, S. Some metapsychological considerations on the differentiation between shame and guilt. International Journal of Psycho-Analysis, 48, 267-276.

Levin, S. (1971). The psychoanalysis of shame. International Journal of Psycho-Analysis, 52, 355-362.

Levy, R. I. (1983). Self and emotion. Ethos, 11, 128-134.

Lewis, H. B. (1971). Shame and guilt in neurosis. Psychoanalytic Review, 58, 419-438.

Lewis, H. B. (1974), Shame and guilt in neurosis. New York: International Universities Press.

Lewis, H. B. (1984). Freud and modern psychology: The social nature of humanity. Psychoanalytic Review, 71, $7-26$. 
Lewis, H. B. (1987). The role of shame in symptom formation. Hillsdale, NJ: The Analytic Press.

Lindsay-Hartz, J. (1980). Two studies of guilt and shame experiences. Dissertation Abstracts International, 41, $2331 \mathrm{~B}$.

Lindsay-Hartz, J. (1984). Contrasting experiences of shame and guilt. American Behavioral Scientist, 27, 689-704.

Linehan, M. M., Goldstein, J. L., Nielsen, S. L., \& Chiles, J. A. (1983). Reasons for staying alive when you are thinking of killing yourself: The Reasons for Living Inventory. Journal of Consulting and Clinical Psychology, 51, 276-286.

Lynd, H. M. (1958). On shame and the search for identity. New York: Harcourt, Brace \& Co.

Malatesta, C. Z., \& Dorval, B. (1989). Regulation of intimacy in families: Dynamics of contempt, shame, and affiliation. Unpublished manuscript. Long Island University.

Marsh, H. W., Balla, J. R., \& McDonald, R. P. (1988). Goodness-of-fit indexes in confirmatory factor analysis: The effect of sample size. Psychological Bulletin, 103, 391-410.

Miller, D. R. Shame/guilt proneness, symptoms and treatment satisfaction in Irish and Jewish families. Dissertation Abstracts International, 48, $1157 \mathrm{~B}$.

Miller, S. B. (1988). Humiliation and shame: Comparing two affect states as indicators of narcissistic stress. Bulletin of the Menninger Clinic, 52, 40-51.

Miller, S. J. (1981). Shame anxiety in the parent-son relationship and psychopathic tendencies: A perceptual study. Dissertation Abstracts International, 41, 4678B.

Mirman, M. C. (1985). Shame and guilt: Activators, associated unconscious dangers, and defenses. Dissertation Abstracts International, 45, 3625B-3626B.

Mollon, P. (1984). Shame in relation to narcissistic disturbance. British Journal of Medical Psychology, 57, 207-214. 
Morrison, A. P. (1983). Shame, ideal self, and narcissism. Contemporary Psychoanalysis, 19, 295-318.

Morrison, A. P. (1984). Working with shame in psychoanalytic treatment. Journal of the American Psychoanalytic Association, $\underline{32}, 479-505$.

Morrison, A. P. (1989). Shame: The underside of narcissism. Hillsdale, NJ: The Analytic Press.

Mosher, D. L., White, B. B. (1981). On differentiating shame and shyness. Motivation \& Emotion, $\underline{5}, 61-74$.

Mulaik, S. A., James, L. R., Van Alstine, J., Bennett, N., Lind, S., \& Stillwell, C. D. (in press). An evaluation of goodness of fit indices for structural equation models. Psychological Bulletin.

Naiditch, B. (1987). Rekindled spirit of a child: Intervention strategies for shame with eleemntary age children of alcoholics. Alcoholism Treatment Quarterly, 4, 57-69.

Nathanson, D. L. (Ed.). (1987). The many faces of shame. New York: Guilford Press.

Nathanson, D. L. (1992). Shame and pride: Affect, sex, and the birth of the self. New York: W. W. Norton.

Negri, T. F. (1979). Shame and guilt in relation to other aspects of personality. Dissertation Abstracts International, $\underline{39}, 5079 \mathrm{~B}-5080 \mathrm{~B}$.

Nergaard, M. O. (1986). The effects of shame, guilt and the negative reaction in brief dynamic psychotherapy. Dissertation Abstracts International, $\underline{46}, 2464 \mathrm{~B}$.

Neumann, S. (1974). The effects of experimentally induced guilt and shame on helping behavior. Dissertation Abstracts International, $\underline{35}, 485 \mathrm{~B}$.

Newcomb, M. D., \& Harlow, L. L. (1986). Life events and substance use among adolescents: Mediating effects of perceived loss of control and meaningless in life. Journal of Personality and Social Psychology, 51, 564-577.

Nielsen, L. A. (1987). Substance abuse, shame and professional boundaries and ethics: Disentangling the issues. Alcohoism Treatment Quarterly, 4, 109-137. 
Novak, W. G. The measurement and construct of shame. Dissertation Abstracts International, 47, 4691B-4692B.

Nuttin, J. (1950). Intimacy and shame in the dynamic structure of personality. In M. Reynert (Ed.), Feelings and emotions (PP. 342-352. New York: Mcgraw-Hill.

O'Leary, J., Wright, F. (1986). Shame and gender issues in pathological narcissism. Psychoanalytic Psychology, $\underline{3}$, $327-339$.

Penning, M., \& Barnes, G. E. (1982). Adolescent marijuana use: A review. The International Journal of the Addictions, 17, 749-791.

Peterson, C. A. (1987). Review of the Brief Symptom Inventory. In Ninth Mental Measurements Yearbook.

Petrie, A. (1967). Individuality in pain and suffering. Chicago: University of Chicago Press.

Petrie, K., \& Chamberlain, K. (1983). Hopelessness and social desirability as moderating variables in predicting suicide behavior. Journal of Consulting and Clinical Psychology, 51, 485-487.

Piers, G., \& Singer, M. B. (1971). Shame and guilt: A psychoanalytic and a cultural study. New York: W. W. Norton.

Pichert, J. W., Elam, P. (1986). Guilt and shame in therapeutic relationships. Patient Education \& Counseling, $8,359-365$.

Potter-Efron, P. S. (1987). Creative approaches to shame and guilt: Helping the adult child of an alcoholic. Alcoholism Treatment Quarterly, 4, 39-56.

Potter-Efron, R. T. (1987). Shame and guilt: Definitions, processes and treatment issues with AODA clients. Alcoholism Treatment Quarterly, 4, 7-24.

Presley, C., Harrold, R., Scouten, E., \& Lyerla, R. (1990). Core Pre/Post Evaluation Instrument User's Manual. Fund for the Improvement of Post-secondary Education (FIPSE).

Pruitt, C. D. (1987). But "thou shalt forget the shame of thy youth": A study of authoritarianism, religiosity and child sexual abuse. Dissertation Abstracts International, $\underline{48}, 959 \mathrm{~A}$. 
Radloff, L. S. (1977). The CES-D scale: A self-report depression scale for research in the general population. Applied Psychological Measurement, 1, 385-401.

Ratliff, K. G., \& Burkhart, B. R. (1984). Sex differences in motivations for and effects of drinking among college students. Journal of Studies on Alcohol, 45, 26-32.

Ramsey, E. (1987). From guilt through shame to AA: A self-reconciliation process. Alcoholism Treatment Quarterly, $\underline{4}, 87-107$.

Raymond, M. R., \& Roberts, D. M. (1987). A comparison of methods for treating incomplete data in selection research. Educational and Psychological Measurement, 47 , $13-26$.

Rawls, J. (1971). A theory of justice. Cambridge, MA: Belknap Press.

Retzinger, S. M. (1987). Resentment and laughter: Video studies of the shame-rage spiral. In H. B. Lewis (Ed.), The role of shame in symptom formation (pp. 151-181). Hillsdale, NJ: Lawrence Erlbaum Associates.

Retzinger, S. M. (1989a). A theory of mental illness: Integrating social and emotional aspects. Psychiatry, $\underline{52}$, 325-335.

Retzinger, S. M. (1989b, August). The role of shame in marital conflict. Paper presented at the meeting of the Society for the Study of Social Problems, Berkeley, CA.

Richards, P. S., \& Williams, R. C. (1989, August). The assessment of shame and guilt proneness in counseling. Paper presented at the meeting of the American Psychological Association, New Orleans, LA.

Saltzman, N. (1983). Paracatastasis and exorcism in bio psychotherapy: Treating shame, guilt and bad feelings about the Self. International Journal of Eclectic Psychotherapy, $\underline{2}, 14-30$.

Schecter, D. (1979). The loving and persecuting superego. Contemporary Psychoanalysis, 15, 361-379.

Scheff, T. J. (1984). The taboo on coarse emotions. Review of Personality and Social Psychology, $\underline{5}, 146-169$. 
Scheff, T. J. (1988). The deference-emotion system. American Sociological Review, 53, 395-406.

Schubert, C. M. (1976). Embedded figures performance as an indicator of relative proneness to shame and guilt. Dissertation Abstracts International, $\underline{36}, 5161 \mathrm{~A}$.

Serber, M. (1970). Shame aversion therapy. Journal of Behavior Therapy \& Experimental Psychiatry, 1, 213-215.

Serber, M. (1972). Shame aversion therapy with and without heterosexual retraining. In $R$. D. Rubin, H. Fensterheim, J. D. Henderson \& L. P. Ullman (Eds.), Advances in behavior therapy: Proceedings of the Fourth Conference of the Association for Advancement of Behavior Therapy. New York: Academic Press.

Severino, S. K., McNutt, E. R., \& Feder, S. L. (1987). Shame and the development of autonomy. Journal of the American Academy of Psychoanalysis, 15, 93-106.

Shane, P. (1980). Shame and learning. American Journal of Orthopsychiatry, $\underline{50}, 348-355$.

Shapiro, D. (1989). Psychotherapy of neurotic character. New York: Basic Books.

Shreve, B. W., \& Kunkel. M. A. (1989, August). The role of shame in adolescent suicide: A self-psychological perspective. Paper presented at the meeting of the American Psychological Association, New Orleans, LA.

Shreve, B. W., \& Patton, M. J. (1988, Atlanta).

Shame-proneness among suicidal persons: Psychometric properties of the shame-proneness scale. Paper presented at the meeting of the American Psychological Association, Atlanta, GA.

Silverman, M. (1980). An empirical test of a theory of personality differences in relation to shame and guilt. Dissertation Abstracts International, 41, $677 \mathrm{~B}$.

Smith, R. L. (1972). The relative proneness to shame or guilt as an indicator of defensive style. Dissertation Abstracts International, $33,2823 \mathrm{~B}-2824 \mathrm{~B}$.

Sorotzkin, B. (1985). The quest for perfection: Avoiding guilt or avoiding shame? Psychotherapy, 22, 564-571. 
Spero, M. H. (1984). Shame: An object-relational

formulation. Psychoanalytic study of the Child, 39 , 259-282.

Spiegel, L. A. (1966). Affects in relation to self and object: A model for the derivation of desire, longing, pain, anxiety, humiliation, and shame. Psychoanalytic Study of the Child, 21, 69-92.

Stevenson, J. F. (1989). Unpublished questionnaire, University of Rhode Island.

Stierlin, H. (1974). Shame and guilt in family relations. Archives of General Psychiatry, 30, 381-389.

Stipek, D. J. (1983). A developmental analysis of pride and shame. Human Development, 26, 42-54.

Strauss, J. S. (1989). Commentary on Retzinger. Psychiatry, 52, 336-338.

Tabachnick, B. G., \& Fidell, L. S. (1983). Using Multivariate Statistics. NY: Harper \& Row.

Tabachnick, B. G., \& Fidell, L. S. (1989). Using Multivariate Statistics (2nd ed.). New York: Harper \& Row.

Tanaka, J. S. (1982). The evaluation and selection of adequate causal models: A compensatory education example. Evaluation and Program Planning, $\underline{5}, 11-20$.

Tanaka, J. S. (1987). "How big is big enough?": Sample size and goodness of fit in strucutral equation models with latent variables. Child Development, $\underline{58}, 134-146$.

Tanaka, J. S., \& Huba, G. J. (1985). A fit index for covariance structure models under arbitrary GLS estimation. British Journal of Mathematical and Statistical Psychology, 38, 197-201.

Tangney, J. P. (1988a). Assessing individual differences in proneness to shame and guilt: Development of the self-conscious affect and attribution inventory. Paper presented at the meeting of the Eastern Psychological Association, Buffalo, NY. 
Tangney, J. P. (1988b, August). Proneness to shame, proneness to guilt, and empathic responsiveness. Paper presented at the meeting of the American Psychological Association, Atlanta, GA.

Tangney, J. P. (1989a, August). A quantitative assessment of phenomenological differences between shame and guilt. Paper presented at the meeting of the American Psychological Association, New Orleans, LA.

Tangney, J. P. (1989b, June). Shame and guilt in young adulthood: A qualitative analysis. Paper presented at the meeting of the American Psychological Society, Alexandria, VA.

Tangney, J. P. (1989c). Shame-Proneness, Guilt-Proneness, and Interpersonal Processes. In J. P. Tangney (Chair), Self-Conscious Emotions and Social Behavior. Symposium conducted at the meeting of the Society for Research in Child Development, Kansas City, KS.

Tangney, J. P., Burgraff, S. A., Hamme, H., \& Domingos, B. (1988). Assessing individual differences in proneness to shame and guilt: The Self-Conscious Affect and

Attribution Inventory. Poster presented at the meeting of the Eastern Psychological Association, Buffalo, NY.

Tangney, J. P., Wagner, P., \& Gramzow, R. (1989). The Self-Conscious Affect and Attribution Inventory Revised. George Mason University, Fairfax, VA.

Tavitian, M. L., Lubiner, J., Green, L., Grebstein, L. C. , \& Velicer, W. F. (1987). Dimensions of family functioning. Journal of Social Behavior and Personality, 2, 191-204.

Taylor, G. (1987). Pride, shame, and guilt: Emotions of self-assessment. Oxford: Clarendon Press.

Tomkins, S. S. (1963). Affect/imagery/consciousness: II. The negative affects. New York: Springer.

Tomkins, S. S. (1987). Shame. In D. L. Nathanson (Ed.), The many faces of shame (pp. 133-161). New York: Guilford.

Touoliatos, J., Perlmutter, B. F., \& Struas, M. A. (Eds.). (1990). Handbook of Family Measurement Techniques.

Newbury Park, CA: Sage Publications. 
Tucker, L. R., \& Lewis, C. (1973). The reliability coefficient for maximum likelihood factor analysis. Psychometrika, 38, 1-10.

Ursu, M. W. (1984). An investigation of the construct validity of several measures of proneness to shame. Dissertation Abstracts International, 45, $1001 \mathrm{~B}$.

Vallelonga, D. (1976). Straus on shame. Journal of Phenomenological Psychology, 7, 55-69.

Vance, T. R. (1987). Shame and the Minnesota Multiphasic Personality Inventroy: An exploratory study. Dissertation Abstracts International, 47, 5086-5087B.

Ward, H. P. (1972). Aspects of shame in analysis. American Journal of Psychoanalysis, $32,62-73$.

Weigel, D. E. (1975). The association of parent/child-rearing practices with children's reports of shame1Dissertation Abstracts International, 36, 462-463B.

Westerlundh, B. (1983). The motives of defence:

Perceptgenetic studies: I. Shame. Psychological Research Bulletin, $\underline{23}, 13$ p.

Wheaton, B., Muthen, B., Alwin, D., \& Summers, G. (1977). Assessing reliability and stability in panel models. IN D. Heise (Ed.), Sociological Methodology 1977 (pp. 84-136). San Francisco: Jossey-Bass.

Wicker, F. W., Payne, G. C., Morgan, R. D. (1983). Participant descriptions of guilt and shame. Motivation \& Emotion, $\underline{7}, 25-39$.

Wolf, E. S., Gedo, J. E., \& Terman, D. M. (1972). On the adolescent process as a transformation of the self. Journal of Youth and Adolescence, 1, 257-272.

Zahn-Waxler, C., \& Cole, P. (in press). Guilt and empathy: Sex differences and implications for the development of depression. In K. Dodge \& J. Garber (Eds.), Emotion Regulation and Dysregulation. Cambridge Press.

Zahn-Waxler, C., \& Kochanska, G. (1989). The origins of guilt. In R. Thompson (Ed.), Proceedings of the $36 \mathrm{th}$ Annual Nebraska Symposium on Motivation: Socioemotional Development. 
Zahn-Waxler, C., Kochanska, G., Krupnick, J., \& Mcknew, D. (1990, in press). Patterns of guilt in children of depressed and well mothers. Developmental Psychology.

Zander, A., Fuller, R., Armstrong, W. (1972). Attributed pride or shame in group and self. Journal of Personality \& Social Psychology, 23, 346-352.

Zuckerman, M. (1984). Experience and desire: A new format for sensation seeking scales. Journal of Behavioral Assessinent, $\underline{6}, 101-114$.

Zuckerman, M., Eysenck, S. B. G., \& Eysenck, H. J. (1978). Sensation seeking in England and America: cross-cultural, age and sex comparisons. Journal of Consulting and Clinical Psychology, $\underline{46}, 139-149$.

Zuckerman, M., Kolin, E. A., Price, L., \& Zoob, I. (1964). Development of a sensation-seeking scale. Journal of Consulting and Clinical Psychology, 28, 472-482.

Zung, W. W. K. (1974). Index of potential suicide. In A. T. Beck, H. L. P. Resnik, \& D. J. Lettieri (Eds.), The prediction of suicide. Bowie, MD: Charles Press. 